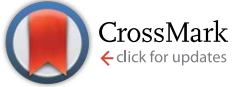

Cite this: RSC Adv., 2017, 7, 10021

Received 21st October 2016 Accepted 19th January 2017

DOI: $10.1039 / c 6 r a 25616 c$

www.rsc.org/advances

\title{
Promising advances of thiacalix[4]arene in crystal structures
}

\begin{abstract}
Mei Zhao, Jing Lv and Dian-Shun Guo*
Thiacalix[4]arenes are one kind of robust scaffolds and extensively applied in supramolecular chemistry and materials science owing to their novel features. This article reviews the research progress of thiacalix [4]arene derivatives in crystal and organic supramolecular structures. The actual morphological parameters of various conformers and their binding patterns as well as typical supramolecular assemblies are briefly summarized. Versatile interactions involving hydrogen bonds, $\mathrm{C}-\mathrm{H} \cdots \pi, \pi-\pi$, halogen $\cdots \pi$ and ancillary electrostatic contacts between heteroatoms were found to play an important role in governing the conformational and supramolecular structures of thiacalix[4]arenes in the solid state. In some cases, the solvent molecules also participate in regulating the conformer and the packing of thiacalix[4]arenes.
\end{abstract}

\section{Introduction}

Thiacalix[4]arenes, new members of the calixarene family, ${ }^{\mathbf{1 , 2}}$ have now become one kind of robust scaffolds and have attracted considerable attention in supramolecular chemistry and materials science. ${ }^{3-14}$ Compared with calix[4]arene, the four $S$ bridges replacing the $\mathrm{CH}_{2}$ linkers endow many novel features such as larger cavity, better flexibility, richer conformational behavior, and the possibility of multiple chemical modifications. ${ }^{5}$ Moreover, the introduction of $\mathrm{S}$ atoms makes thiacalix[4]arenes possess the additional affinity for binding desired substrates in their supramolecular systems.

College of Chemistry, Chemical Engineering and Materials Science, Collaborative Innovation Center of Functionalized Probes for Chemical Imaging in Universities of Shandong, Shandong Normal University, Jinan 250014, P. R. China. E-mail: chdsguo@sdnu.edu.cn; Fax: +8653186928773; Tel: +8653186180743
Thiacalix[4]arenes, as versatile building blocks for highly organized receptors, have attracted much interest for more than two decades largely because of their specific affinity and selectivity in molecular recognition, ${ }^{6-9}$ and supramolecular assembly. ${ }^{\mathbf{1 0 - 1 4}}$ Meanwhile, great advances have also been made to describe the precise morphology of various conformers and binding patterns of thiacalix[4]arene derivatives in the solid state, which are difficult to accurately deal with in solution owing to the flexibility of the thiacalix[4]arene platform. The crystal structures of thiacalix[4]arene derivatives as important ligands in coordination chemistry have been highlighted in recent reviews. ${ }^{11,12}$ However, as of now, the progress of thiacalix [4]arene derivatives in the crystal structures and organic supramolecular assemblies has not been reviewed. This article is intended to summarize the major advances in this field, according to cone, 1,3-alternate, 1,2-alternate and partial cone conformers (Fig. 1), respectively.

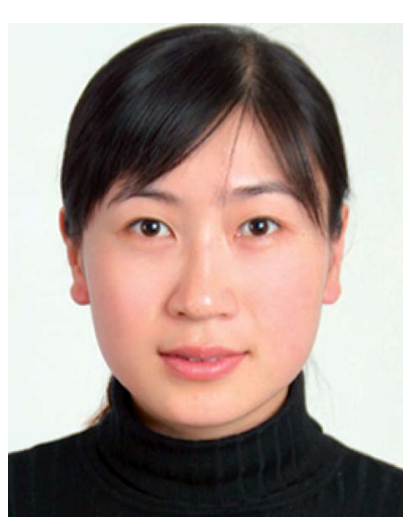

Mei Zhao received her $M S$ degree in organic chemistry from Shandong Normal University. She has been working in Shandong Analysis and Test Center since 2009. Currently, she is pursuing her PhD at Shandong Normal University under the supervision of Prof. Dian-Shun Guo. Her research interest is focused on the development of new optical- and redox-active sensors based on thiacalix[4] arenes and their applications.

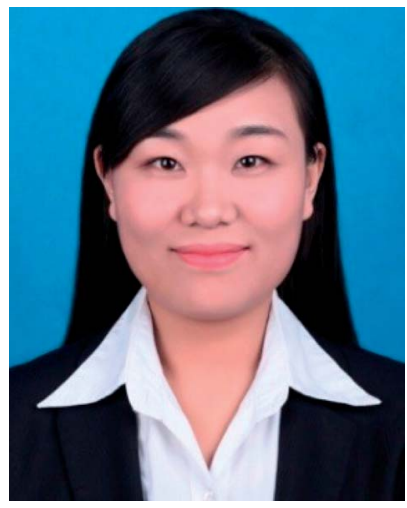

Jing Lv is working for her MS degree at Shandong Normal University under the supervision of Prof. Dian-Shun Guo. She completed her BSc degree in chemistry at Shandong Normal University in 2014. Her current research interest is concentrated on the development of novel optical and redox active multiple sensors. 


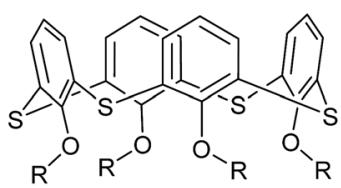

(a) cone

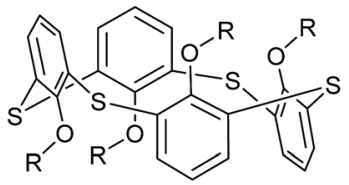

(c) 1,2-alternate

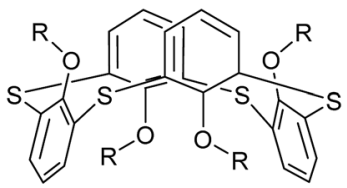

(b) 1,3-alternate

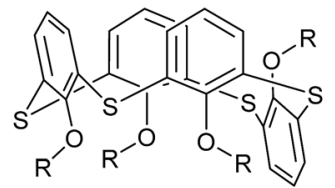

(d) partial cone
Fig. 1 Four main conformers of thiacalix[4]arene: (a) cone, (b) 1,3alternate, (c) 1,2-alternate, and (d) partial cone.

In this review, we will focus on the precise conformations, binding patterns, and some typical supramolecular assemblies of thiacalix[4]arene derivatives mainly found in the solid state. The exactly conformational shape of thiacalix[4]arene core is characterized with the dihedral angles (termed as $\theta$, interior angle) between the phenolic rings and the virtual plane $(R)$ defined by the four $\mathrm{S}$ bridges. The difference amongst $\theta$ angles is significant for the shape of the thiacalix[4] arene core, the bigger the $\theta$ range, the more distorted the conformation.

\section{Cone structures of thiacalix[4] arenes}

Thiacalix[4]arenes in a cone conformation are easily available, thus many crystal structures of such conformers are proved by $\mathrm{X}$-ray diffraction analysis. In this section, they will be discussed mainly according to the $O$-substituted extent at the lower rim.

\subsection{Parent thiacalix[4] arenes and their analogues}

As demonstrated by Miyano et al., ${ }^{3}$ the parent $p$-t-butylthiacalix [4] arene 1 (Fig. 2) shows very simple ${ }^{1} \mathrm{H}$ NMR spectra in solution. Although the ${ }^{1} \mathrm{H}$ NMR chemical shift for the $\mathrm{OH}$ groups of 1 suggested the formation of intramolecular $\mathrm{H}$-bonds, their

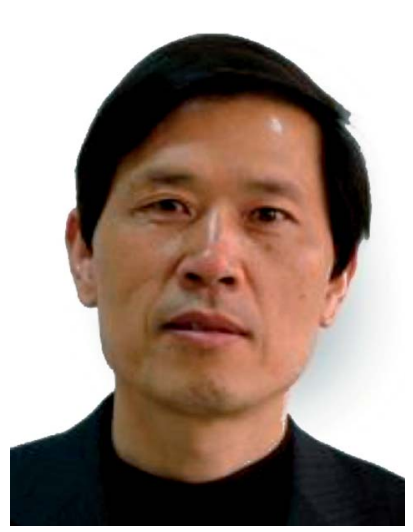

Dian-Shun Guo is currently a Professor of organic chemistry at Shandong Normal University. He obtained his PhD in 1999 at Nankai University and worked as a Postdoctoral Research Associate with Prof. Wei-Min Dai at Hong Kong University of Science \& Technology between 2000 and 2003. His current research is on the development of advanced materials involving thiacalix[4] arenes, optical probes and electrochemical sensors.

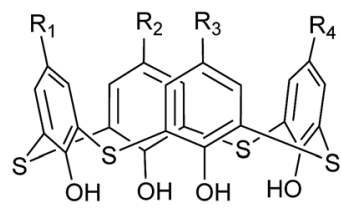

1, $\mathrm{R}_{1-4}=t-\mathrm{Bu}$

2, $\mathrm{R}_{1-4}=\mathrm{H}$

3, $\mathrm{R}_{1-3}=\mathrm{H}, \mathrm{R}_{4}=t-\mathrm{Bu}$

4, $\mathrm{R}_{1-2}=\mathrm{H}, \mathrm{R}_{3-4}=t-\mathrm{Bu}$

5, $\mathrm{R}_{1}=\mathrm{H}, \mathrm{R}_{2-4}=t-\mathrm{Bu}$

Fig. 2 Structures of compounds $1-5$.

actual morphology is difficult to give. Alternatively, in the solid state, the parameters of a conformer can be exactly described by the X-ray diffraction analysis. And the shape of the thiacalix[4] arene core can be characterized by the $\theta$ angles. ${ }^{15}$ The crystal structure of 1 (Fig. 3) shows a perfect $C_{4}$-symmetric cone conformation identified by the same $\theta$ value of $119.0^{\circ}$ (Table 1). ${ }^{\mathbf{1 6}}$ This may be ascribed to the formation of an intramolecular cyclic hydrogen bonding array involving four identical $\mathrm{O}-\mathrm{H} \cdots \mathrm{O}$ H-bonds between the phenolic $\mathrm{OH}$ groups. ${ }^{17}$

The skeleton of $\mathbf{1}$ is flexible enough to preorganize and include various small organic molecules into its cavity forming inclusion crystals. ${ }^{18-21}$ It was found that molecule 1 still retains a perfect $C_{4}$-symmetric structure when some small organic molecules incorporated into its cavity, while it will adopt a slightly distorted conformation upon inclusion of some bigger molecules. This tailors the need for producing stable crystals through conformational interchanges between host and guest molecules. For instance, the cone conformer of $\mathbf{1}$ in complex 1.DCE (DCE is 1,2-dichloroethane, a bigger molecule) is slightly distorted, with different $\theta$ values of 125.9, 118.7, 136.5 and $124.1^{\circ} \cdot{ }^{18}$ When MeCN (a smaller molecule) is included into the cavity of 1 , it still keeps the perfect $C_{4}$ symmetry (Fig. 3). ${ }^{20}$ The Me group of MeCN directs inside the cavity and its $\mathrm{C}-\mathrm{H}$ bonds are perpendicular to the aromatic rings, where $\mathrm{C}-\mathrm{H} \cdots \pi$ contacts exist to stabilize the complex $1 \cdot \mathrm{MeCN}$. Moreover, the $\mathrm{CN}$ lobe of MeCN connects to the lower rim of the vicinal molecule 1 by $\mathrm{O}-\mathrm{H} \cdots \mathrm{N}$ H-bonds. Thus a head-to-tail type of infinite columnar structure is created by these interactions.

Compounds 2-5 (Fig. 2), ${ }^{\mathbf{1 6 , 2 2}}$ various de-t-butylation derivatives of 1, all adopt a cone conformation (Fig. 4). However, they
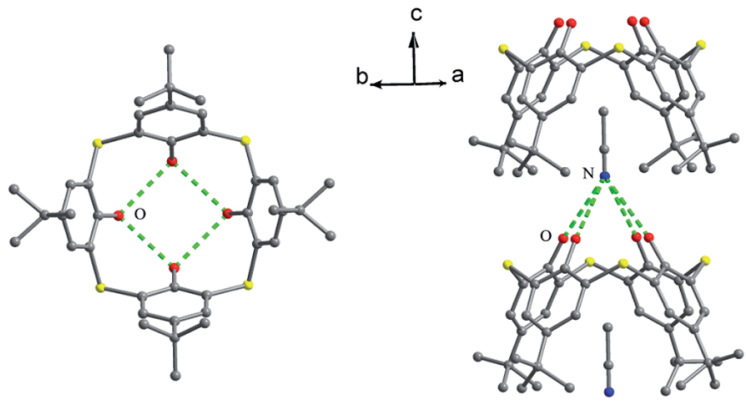

Fig. 3 Crystal structure (left) and partial packing structure (right) of 1 with $\mathrm{MeCN}$ in a head-to-tail manner. All protons of the $\mathrm{OH}$ groups were not found in its crystal. Note: all $\mathrm{H}$ atoms not involving weak interactions (mapped with various colour dashed lines) and minor disordered atoms (if any) are omitted for clarity in all crystal structures discussed in this review. 
Table 1 The $\theta$ angles of compounds $1-46^{a}$

\begin{tabular}{|c|c|c|c|c|}
\hline Compd. & $\theta\left(^{\circ}\right)$ & & & \\
\hline 1 & 119.0 & 119.0 & 119.0 & 119.0 \\
\hline 2 & 114.4 & 136.9 & 117.8 & 136.9 \\
\hline $3 \mathbf{A}$ & 108.2 & 142.9 & 111.4 & 143.2 \\
\hline 3B & 107.9 & 144.5 & 108.7 & 139.8 \\
\hline 4 & 100.0 & 141.4 & 112.1 & 146.3 \\
\hline 5 & 120.4 & 133.1 & 130.1 & 126.7 \\
\hline 6 & 115.7 & 126.2 & 121.1 & 126.0 \\
\hline 7 & 123.3 & 123.3 & 123.3 & 123.3 \\
\hline 8 & 108.1 & 142.2 & 120.3 & 132.6 \\
\hline 9 & 112.0 & 112.6 & 112.0 & 112.6 \\
\hline 10 & 115.7 & 115.7 & 115.7 & 115.7 \\
\hline 11 & 103.6 & 125.8 & 103.6 & 125.8 \\
\hline 12 & 60.0 & 139.3 & 120.5 & 139.5 \\
\hline 13 & 65.5 & 139.8 & 129.8 & 133.6 \\
\hline 14A & 66.2 & 148.1 & 116.4 & 139.3 \\
\hline 14B & 65.5 & 149.3 & 116.4 & 138.9 \\
\hline 15 & 108.2 & 128.3 & 112.2 & 122.0 \\
\hline 16 & 68.9 & 125.9 & 137.3 & 139.8 \\
\hline 17 & 104.7 & 147.0 & 106.3 & 146.4 \\
\hline 18 & 92.9 & 148.7 & 111.6 & 143.6 \\
\hline 20 & 86.5 & 147.9 & 62.2 & 154.2 \\
\hline 21 & 112.1 & 123.5 & 115.5 & 131.1 \\
\hline 22 & 71.2 & 146.2 & 102.4 & 147.3 \\
\hline 23 & 74.3 & 135.1 & 103.0 & 140.0 \\
\hline $24 \mathrm{~A}$ & 69.9 & 140.1 & 109.2 & 135.6 \\
\hline 24B & 71.3 & 138.4 & 115.2 & 134.7 \\
\hline 25 & 77.0 & 133.4 & 108.8 & 124.1 \\
\hline 26 & 68.3 & 139.5 & 108.2 & 138.1 \\
\hline $27 \mathrm{~A}$ & 93.0 & 136.4 & 96.6 & 138.6 \\
\hline 27B & 94.3 & 135.5 & 102.1 & 138.2 \\
\hline 28 & 71.0 & 157.4 & 109.2 & 143.1 \\
\hline 29 & 108.8 & 149.4 & 109.7 & 144.3 \\
\hline 30 & 106.5 & 142.1 & 108.9 & 146.5 \\
\hline 31 & 102.9 & 135.6 & 114.1 & 147.3 \\
\hline 32 & 111.3 & 136.0 & 111.3 & 136.0 \\
\hline 33 & 69.8 & 159.3 & 70.8 & 151.6 \\
\hline $34 \mathrm{~A}$ & 54.3 & 104.3 & 43.1 & 75.7 \\
\hline 34B & 41.5 & 94.0 & 51.9 & 87.5 \\
\hline 35 & 79.2 & 126.7 & 95.8 & 141.1 \\
\hline 36 & 78.7 & 121.3 & 91.5 & 123.8 \\
\hline 37 & 65.2 & 136.0 & 65.4 & 136.7 \\
\hline 38 & 106.0 & 108.2 & 115.0 & 116.9 \\
\hline $39^{b}$ & 67.5 & 146.5 & 69.2 & 146.0 \\
\hline 40 & 92.6 & 131.7 & 93.1 & 126.3 \\
\hline 41 & 90.2 & 128.8 & 91.5 & 132.8 \\
\hline 42 & 90.3 & 130.6 & 96.0 & 132.5 \\
\hline 43 & 87.4 & 142.8 & 91.2 & 140.8 \\
\hline 44 & 75.0 & 141.9 & 107.0 & 143.5 \\
\hline 45 & 65.6 & 139.7 & 81.2 & 153.9 \\
\hline 46 & 106.7 & 134.9 & 110.9 & 132.0 \\
\hline
\end{tabular}

exhibit two different modes: one has near $C_{2}$ symmetry $(2,3$ and 4), and the other shows near $C_{4}$ symmetry (5), with four varied $\theta$ angles (Table 1). In the conformers of $\mathbf{2 - 4}, \mathrm{O}$ atoms of the $\mathrm{OH}$ groups are not arranged on one plane but deviate up and down, which would obstruct the formation of the intramolecular cyclic H-bonded array. Especially in 4, such tendency appears clearly with disappearance of the circular $\mathrm{O}-\mathrm{H} \cdots \mathrm{O}$ H-bonds (Fig. 4c), due to the asymmetrical situations of the $p$-substituted groups.

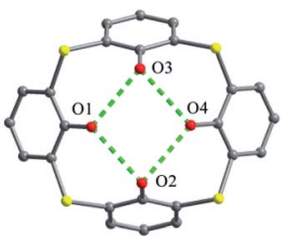

(a)

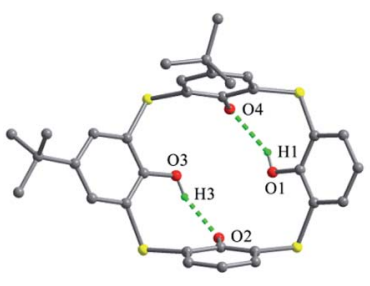

(c)

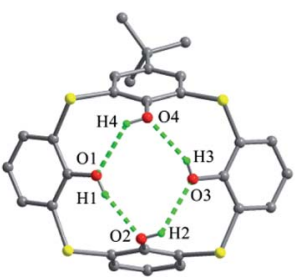

(b)

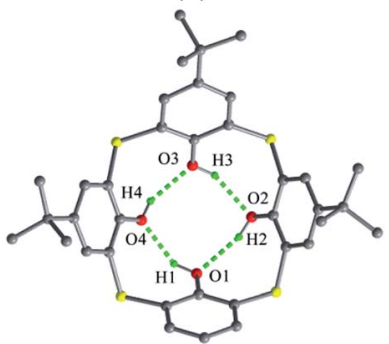

(d)
Fig. 4 Crystal structures of 2 (a), 3 (b), 4 (c) and 5 (d). All protons of the $\mathrm{OH}$ groups were not found in the crystal of 2 .

On the other hand, for $\mathbf{2 , 3}$ and $\mathbf{5}$, the cyclic $\mathrm{H}$-bonded array is remained (Fig. 4).

In the packing, a self-inclusion trimer of 2 is formed by $\mathrm{C}-$ $\mathrm{H} \cdots \pi$ interactions, owing to removal of all four $t$-butyl groups (Fig. 5a). In the cases of 3-5, all give self-inclusion dimers in such a manner that the phenolic moiety of one molecule is inserted into the cavity of the other one. In 3 (Fig. 5b) and 4 (Fig. $5 \mathrm{c}$ ), the phenolic rings with $t$-butyl-free are inserted into each other with face-to-face $\pi-\pi$ interactions. In 5 (Fig. $5 \mathrm{~d}$ ), a $t$ butyl group enters into the cavity, accompanied by some $\mathrm{C}-\mathrm{H} \cdots$ $\pi$ interactions. Moreover, these dimers in 3-5 further associate each other by the face-to-face overlap between the $t$-butyl-free phenol rings.

Thiacalix[4]arene 6 (Fig. 6) ${ }^{23}$ with four phenyl groups at the upper rim, adopts a cone conformation with four different $\theta$ values (Table 1). This conformer is also governed by the intramolecular cyclic H-bonding array at the lower rim, creating

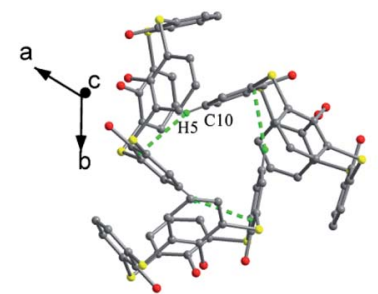

(a)

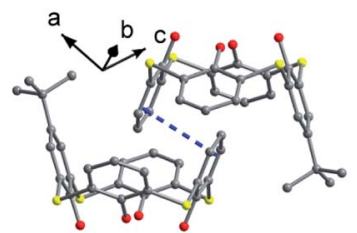

(b)

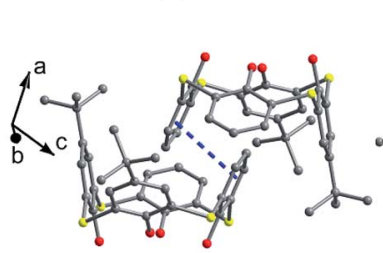

(c)

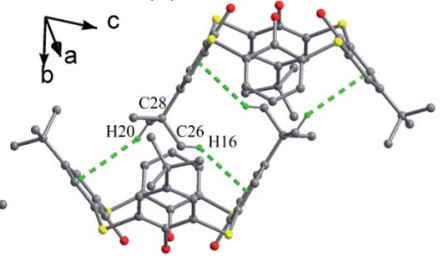

(d)
Fig. 5 Partial packing structures of 2 (a), 3 (b), 4 (c) and 5 (d). 

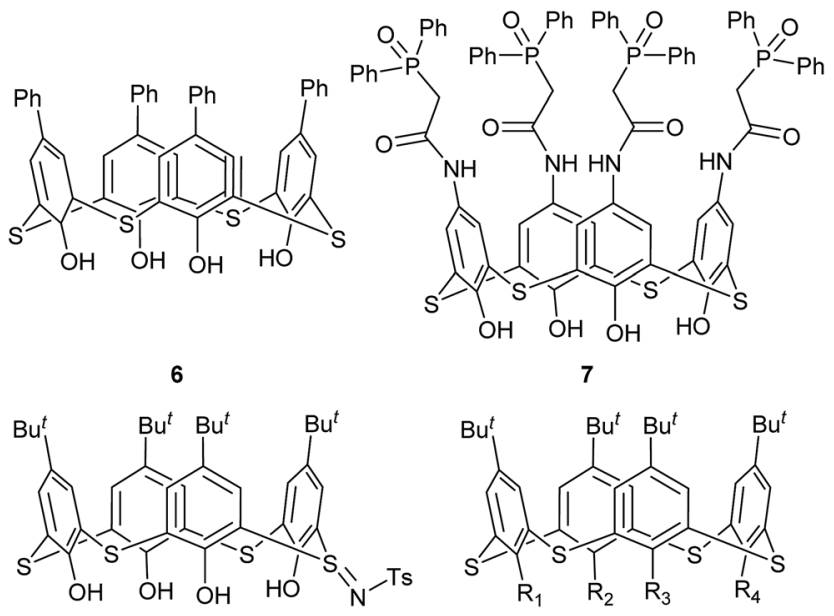

9, $\mathrm{R}_{1}=\mathrm{R}_{4}=\mathrm{OH}, \mathrm{R}_{2}=\mathrm{R}_{3}=\mathrm{NH}_{2}$ 8

10, $\mathrm{R}_{1-2}=\mathrm{OH}, \mathrm{R}_{3-4}=\mathrm{NH}_{2}$

11, $\mathrm{R}_{1-4}=\mathrm{NH}_{2}$

Fig. 6 Structures of compounds 6-11.

a deeper cavity (Fig. 7a). Such a deep-cavity thiacalix[4]arene possesses an extended $\pi$-aromatic system, and is potentially useful for solid state inclusion of suitable molecules.

Thiacalix[4]arene 7 (Fig. 6), ${ }^{24}$ with four CMPO (carbamoylmethylphosphineoxide) units at the upper rim, shows a perfect cone conformation with the same $\theta$ value of $123.3^{\circ}$. In its crystal structure (Fig. 7b), the typical circular hydrogen bonding array is also found, indicating that the CMPO units are large but cannot disrupt the $\mathrm{H}$-bonded array formation. In the stacking (Fig. 8), the CMPO moieties of two molecules are interlocked to create a capsule-like dimer with $S_{8}$ symmetry by intermolecular $\mathrm{N}-\mathrm{H} \cdots \mathrm{O} \mathrm{H}$-bonds between the $\mathrm{CONH}$ and $\mathrm{P}=\mathrm{O}$ groups. This capsule-like dimmer can exist in apolar solvents and be applied for inclusion of some guests in solution.
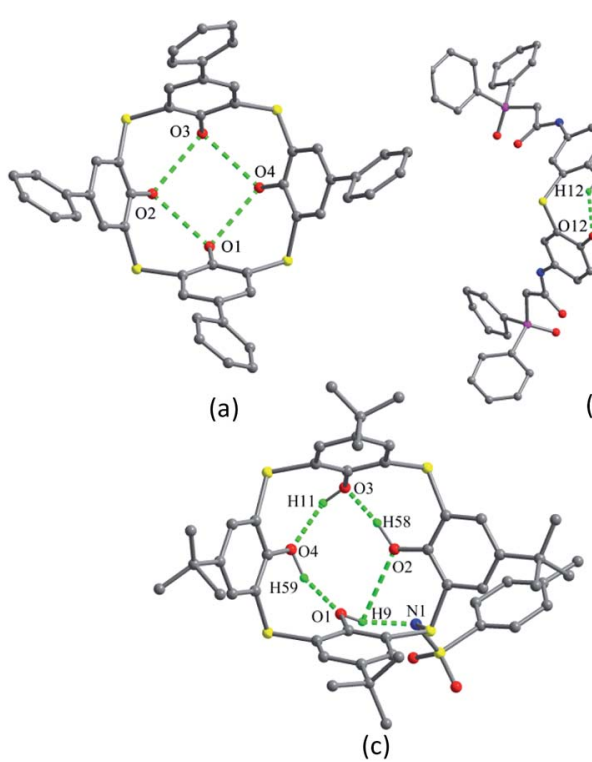

Fig. 7 Crystal structures of 6 (a), 7 (b) and 8 (c), showing the circular $\mathrm{H}$ bonding array.

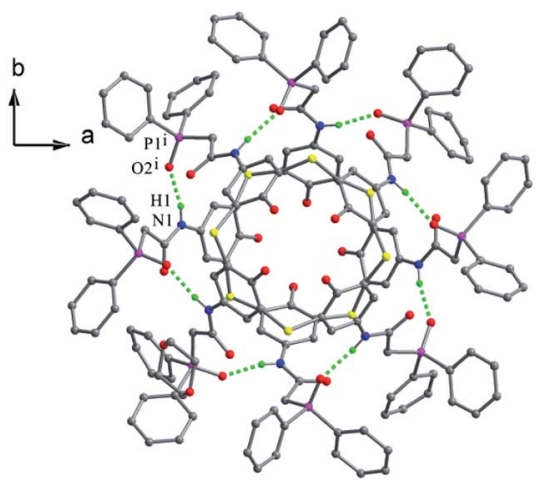

Fig. 8 A dimeric capsule of 7, showing intermolecular $\mathrm{H}$-bonds.

Compound 8 (ref. 25) (Fig. 6) is a derivative of 1 with a S bridge modified by sulfilimine moiety, and takes a distorted cone conformation with four different $\theta$ values (Table 1), in which the sulfilimine group directs toward the axial orientation (Fig. 7c). This conformer is stabilized by an intramolecular cyclic $\mathrm{H}$-bonded array and an $\mathrm{O} 1-\mathrm{H} 9 \cdots \mathrm{N} 1 \mathrm{H}$-bond between one $\mathrm{OH}$ group and $\mathrm{N}$ atom of the sulfilimine unit.

Thiacalix[4]arene analogues 9 and 10 (Fig. 6), ${ }^{26}$ with two amino groups at the lower rim, are also in a cone conformation with a circular H-bonded array in their crystals (Fig. 9a and b). However, the averaged distance between adjacent $\mathrm{N}, \mathrm{O}$ atoms of $\mathbf{9}$ and 10 falls in the order of $\mathrm{O} \cdots \mathrm{O}<\mathrm{O} \cdots \mathrm{N}<\mathrm{N} \cdots \mathrm{N}$, revealing that the strength of intramolecular $\mathrm{H}$-bonds is weaker than those of 1. For this reason, thiacalix[4]arene analogue 11 (Fig. 6), with four $\mathrm{NH}_{2}$ groups, takes in either a cone or a 1,3alternative conformation based on inclusion with different solvent molecules. ${ }^{27,28}$ It adopts a $C_{2}$ cone conformation when a MeCN molecule is included into its cavity with two pairing $\theta$ angles of 103.6 and $125.8^{\circ}$, resulting from the co-operation of intramolecular $\mathrm{N}-\mathrm{H} \cdots \mathrm{N}$ and $\mathrm{N}-\mathrm{H} \cdots \mathrm{S}$ H-bonds (Fig. 9c), as well as intermolecular $\mathrm{N}-\mathrm{H} \cdots \mathrm{N}$ H-bonds with MeCN molecule (Fig. 9d). Whereas, it takes a 1,3-alternate conformation when a $\mathrm{CH}_{2} \mathrm{Cl}_{2}$ molecule occupies its cavity with two pairs of $\theta$ values $\left(100.2\right.$ and $112.4^{\circ}$ ) as they only form weak $\mathrm{C}-\mathrm{H} \cdots \pi$ contacts (Fig. 9e). In the case of guest-free, 11 shows a typical 1,3-alternate conformer with the same $\theta$ value of $95.3^{\circ}$, creating eight intramolecular $\mathrm{N}-\mathrm{H} \cdots \mathrm{S}$ H-bonds (Fig. 9f).

\section{$2.2 O$-Monosubstituted thiacalix[4]arenes}

The chemical modification of the $\mathrm{OH}$ groups at the lower rim of thiacalix[4]arenes by selective etherification or esterification could provide mono- to tetra- $O$-substituted thiacalix[4]arene derivatives with some novel features.

Compounds 12-14 (Fig. 10), mono ethereal derivatives of 1, all display a pinched cone conformation typically with four different $\theta$ angles (Table 1). The substituted phenolic ring is almost parallel to its opposite one and forms the smallest $\theta$ angle with the $R$ plane. In 12 (Fig. 11a), ${ }^{29}$ such a conformer is fixed by intramolecular sequential $\mathrm{O}-\mathrm{H} \cdots \mathrm{O} \mathrm{H}$-bonds between $\mathrm{OH}$ groups. Additionally, an intramolecular $\mathrm{C}-\mathrm{H} \cdots \mathrm{O} \mathrm{H}$-bond between the $\mathrm{P}(\mathrm{O}) \mathrm{CH}_{2} \mathrm{O}$ moiety and one neighboring $\mathrm{OH}$ group 


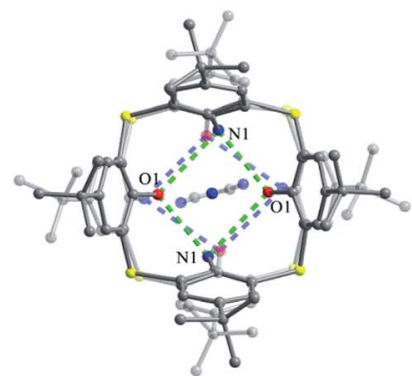

(a)

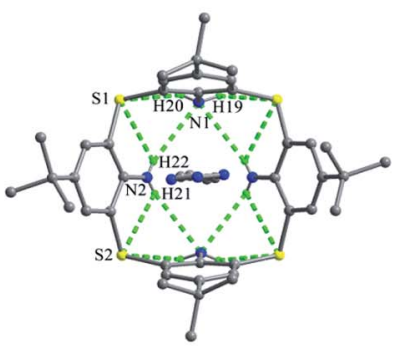

(c)

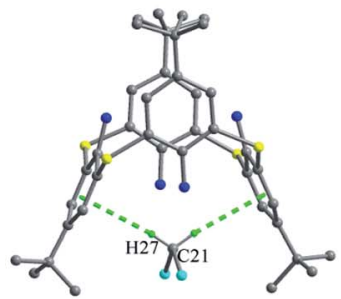

(e)

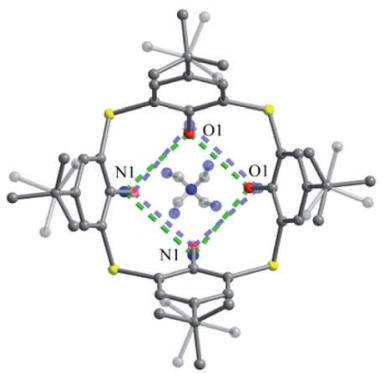

(b)

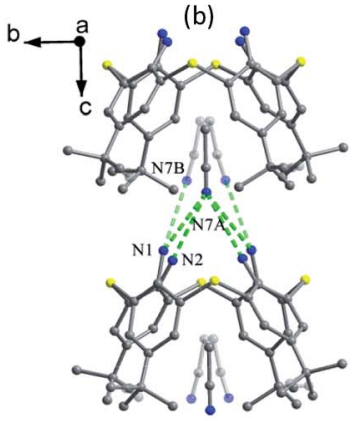

(d)

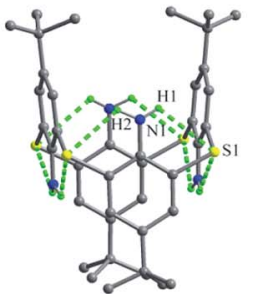

(f)

Fig. 9 Crystal structures of 9 with $\mathrm{MeCN}$ (in disorder) (a), 10 with $\mathrm{MeCN}$ (in disorder) (b), 11 with $\mathrm{MeCN}$ (c), and partial packing structures of 11 with $\mathrm{MeCN}(\mathrm{d})$ and $\mathrm{CH}_{2} \mathrm{Cl}_{2}(\mathrm{e})$, as well as crystal structure of 11 (f), showing different $\mathrm{H}$-bonds, respectively. All protons of $\mathrm{OH}$ and $\mathrm{NH}_{2}$ groups in 9 and 10 were not found in their crystals.
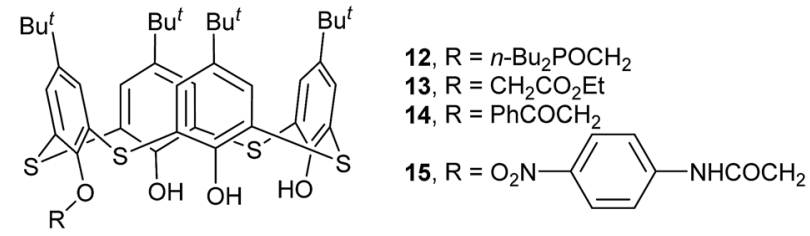

Fig. 10 Structures of compounds 12-15.

results in the $\mathrm{CH}_{2}$ unit orienting inside the cavity. In the packing, a centrosymmetric dimer is produced by two intermolecular $\mathrm{O} 4-\mathrm{H} 4 \cdots \mathrm{O} 5$ bonds between the remained $\mathrm{OH}$ group and the $\mathrm{P}=\mathrm{O}$ unit.

Molecule $13,{ }^{30}$ bearing an ester unit at the lower rim, crystallizes in the form of its tetrabutylammonium salt. One interesting feature of the crystal is $\mathrm{O} 4$ with a negative charge, which is stabilized by two strong $\mathrm{H}$-bonds from the two adjacent phenolic groups (Fig. 11b).

In the asymmetric unit of $\mathbf{1 4},{ }^{\mathbf{3 1}}$ there are two independent thiacalix[4] arene molecules $\mathbf{A}$ and $\mathbf{B}$, with two $\mathrm{Et}_{4} \mathrm{~N}^{+}$and two $\mathrm{Cl}^{-}$ ions. Both molecules give the same type of intramolecular $\mathrm{O}-\mathrm{H} \cdots \mathrm{O} \mathrm{H}$-bonds as in $\mathbf{1 3}$. This may be ascribed to the $\mathrm{H}$ atom

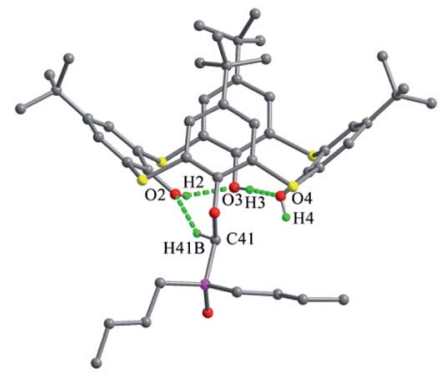

(a)

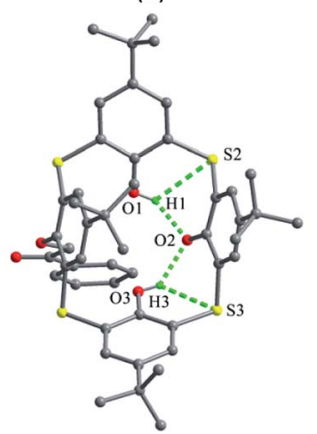

(c)

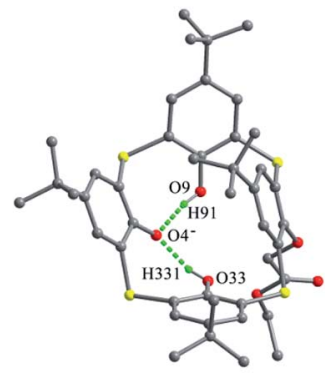

(b)

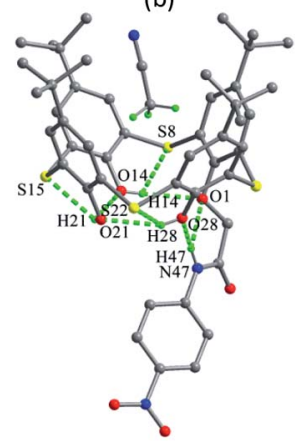

(d)

Fig. 11 Crystal structures of 12 (a), 13 (b), 14 (c) and 15 (d), showing intramolecular $\mathrm{H}$-bonds.

of the middle $\mathrm{OH}$ group creating an intermolecular $\mathrm{O}-\mathrm{H} \cdots \mathrm{Cl} \mathrm{H}$ bond with $\mathrm{Cl}^{-}$ion. Dissimilar to 12 and 13, the conformers of $\mathbf{A}$ and $\mathbf{B}$ are further fixed by intramolecular $\mathrm{O}-\mathrm{H} \cdots \mathrm{S} \mathrm{H}$-bonds (Fig. 11c).

Monosubstituted thiacalix[4]arene 15 (ref. 32) (Fig. 10) exhibits a different cone conformation with a $\theta$ angle of $108.2^{\circ}$ between the substituted phenolic ring and the $R$ plane, much larger than those in 12-14. This can be rationalized by the formation of a cyclic $\mathrm{H}$-bonding array involving $\mathrm{N}-\mathrm{H} \cdots \mathrm{O}$ and $\mathrm{O}-\mathrm{H} \cdots \mathrm{O} \mathrm{H}$-bonds (Fig. 11d). The MeCN molecule was found in the calix cavity, with the Me group directing inside the cavity and its $\mathrm{C}-\mathrm{H}$ bonds being perpendicular to the aromatic rings, yielding $\mathrm{C}-\mathrm{H} \cdots \pi$ contacts.

Molecule 16 (ref. 33) (Fig. 12) is a derivative of thiacalix[4] arene containing two imidazole rings linked by a methylene bridge. It shows a pinched cone conformation with 1- charge at $\mathrm{O} 3$ and $1+$ charge at N2. Two opposite phenolic rings are splayed

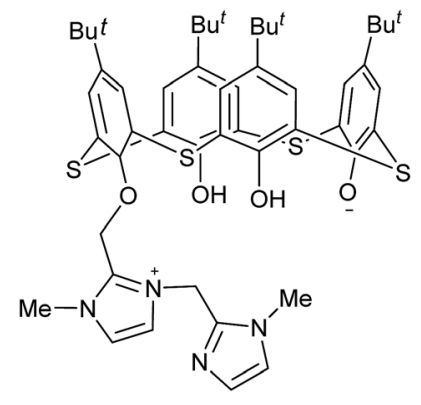

16

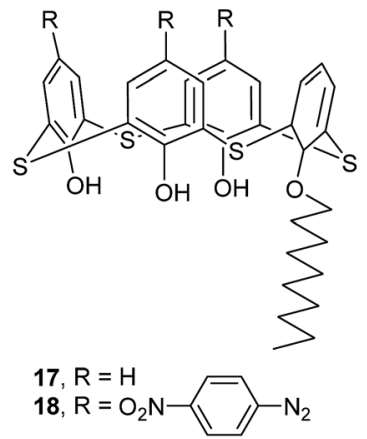

Fig. 12 Structures of compounds 16-18 
out with $\theta$ values of 139.8 and $125.9^{\circ}$, while the other benzene rings are pinched with $\theta$ values of 68.9 and $137.3^{\circ}$. Similar to 13, the thiacalix[4]arene core is very distorted with the middle phenolic ring bent outwards the cavity, resulting from $\mathrm{H}$-bonds between $\mathrm{O}^{-}$and two adjacent $\mathrm{OH}$ groups (Fig. 13a). In addition, the asymmetric unit comprises one thiacalix[4]arene molecule, one methanol and two waters of crystallization, in which $\mathrm{H}$ bonds between them are further to stabilize the conformer.

Thiacalix[4] arene derivatives 17 and 18 (Fig. 12), ${ }^{34,35}$ with one decyloxy group at the lower rim, give a similarly flattened cone conformation with $\theta$ ranges of 104.7-147.0 $0^{\circ}$ and 92.9-148.7 (Table 1), respectively. Although either conformer is governed by three intramolecular $\mathrm{H}$-bonds, the $\mathrm{H}$-bonding patterns are different: the former created in a sequential way from one $\mathrm{OH}$ group to the ether $\mathrm{O}$ atom (Fig. 13b), while the latter yielded in such a way that one ether $\mathrm{O}$ atom forms two $\mathrm{H}$-bonds with its vicinal $\mathrm{OH}$ groups (Fig. 13c).

Lhoták et al. synthesized a phenoxanthiin-containing thiacalix[4]arene 19 (Fig. 14). ${ }^{36}$ It takes a cone conformer, where the $\mathrm{S}$ atom of phenoxanthiin ring makes a radical departure from the other S bridges. Such a structure is supported by an intramolecular circular array of $\mathrm{H}$-bonds between the three $\mathrm{OH}$ groups. This bonding array is further strengthened by $\mathrm{H}$-bonds between the $\mathrm{S}$ bridges and the adjacent $\mathrm{OH}$ groups. In addition, it crystallizes with two $\mathrm{CH}_{2} \mathrm{Cl}_{2}$ molecules, one of which is situated directly inside the calix cavity, with $\mathrm{Cl}$ atom located above the centre of one phenolic ring with a distance of $3.31 \AA$, indicating the presence of $\mathrm{Cl} \cdots \pi$ interaction.

\subsection{O-Disubstituted thiacalix[4]arenes}

Most disubstituted derivatives of thiacalix[4]arene could be easily obtained in their 1,3-diethers with two free $\mathrm{OH}$ groups. Usually, they show a pinched cone conformation with a couple of opposite benzene rings tilting to the same orientation.

Compounds 20 and 21 (Fig. 15), ${ }^{37}$ diacetate derivatives of thiacalix[4]arene and calix[4]arene respectively, have distinct

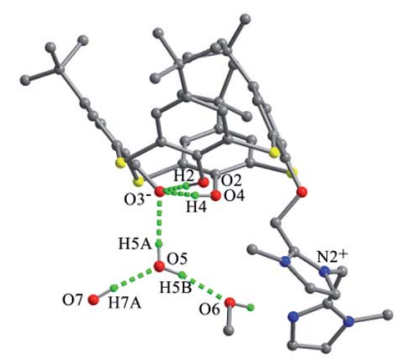

(a)

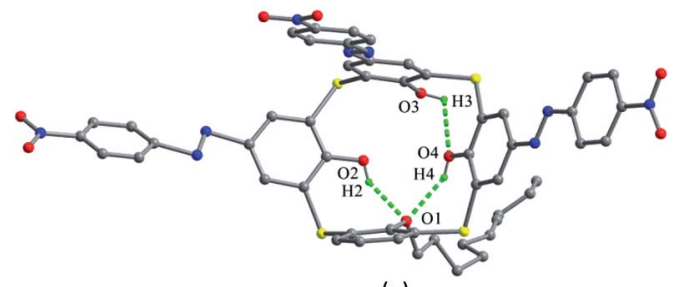

(c)

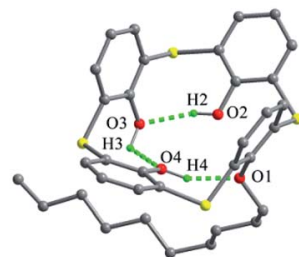

(b)

Fig. 13 Crystal structures of 16 (a), 17 (b) and 18 (c), showing different $\mathrm{H}$-bonds.
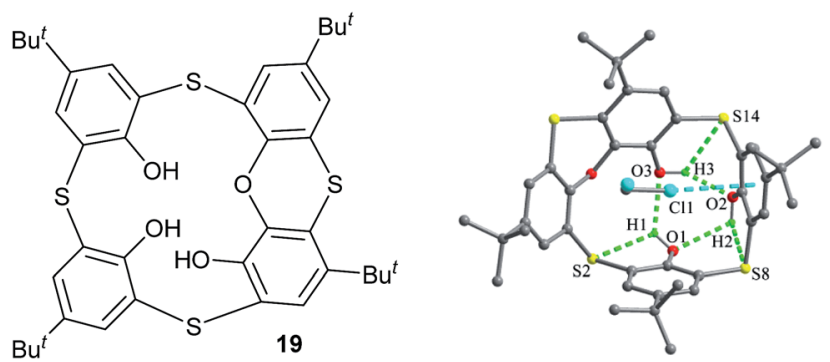

Fig. 14 Chemical and crystal structures of compound 19, showing intramolecular $\mathrm{H}$-bonding array and intermolecular $\mathrm{Cl} \cdots \pi$ interaction.

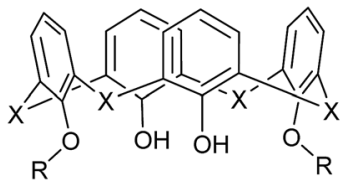

20, $\mathrm{X}=\mathrm{S}, \mathrm{R}=\mathrm{CH}_{2} \mathrm{CO}_{2} \mathrm{Et}$ 21, $\mathrm{X}=\mathrm{CH}_{2}, \mathrm{R}=\mathrm{CH}_{2} \mathrm{CO}_{2} \mathrm{Et}$ 22, $\mathrm{X}=\mathrm{S}, \mathrm{R}=\mathrm{CH}_{2} \mathrm{CH}=\mathrm{CH}_{2}$

Fig. 15 Structures of compounds 20-22

conformational behavior owing to the different H-bonding patterns. In the crystal structure of 20 (Fig. 16a), the distorted cone conformer, with different $\theta$ values of 86.5, 147.9, 62.2 and $154.2^{\circ}$, is governed by two intramolecular H-bonds from both $\mathrm{OH}$ groups to the same ether $\mathrm{O}$ atom. This asymmetrical arrangement of $\mathrm{H}$-bonds decreases the overall symmetry. However, in the case of 21 (Fig. 16b), two free $\mathrm{OH}$ groups interact with the different ether $\mathrm{O}$ atoms, producing almost symmetrical intramolecular $\mathrm{H}$-bonds and giving a nearly $C_{2}$ symmetric cone conformation with $\theta$ values of $112.1,123.5$, 115.5 and $131.1^{\circ}$. This difference could be ascribed to the size of the thiacalix[4]arene cavity larger (15\%) than that of the calix[4] arene. ${ }^{16}$

Thiacalix[4]arene diallylether 22 (ref. 38) (Fig. 15) adopts a pinched cone conformation with $\theta$ values of $71.2,146.2,102.4$ and $147.3^{\circ}$, in which one ether chain is bent towards the cavity. This conformer is fixed by the same intramolecular $\mathrm{H}$-bonds as in 20 (Fig. 16c). In the packing, an infinite chain of 22 with alternating orientations is formed by the $\pi-\pi$ stacking between phenolic rings (Fig. 17).

Thiacalix[4]arene derivatives 23-26 (Fig. 18) all take a pinched cone conformation with similar $\theta$ values from 68.3 to $140.1^{\circ}$ (Table 1$)$. The two opposing aromatic rings attaching

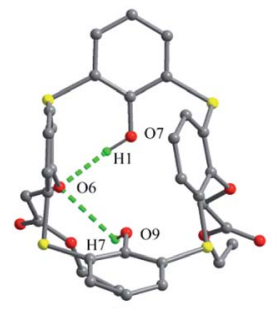

(a)

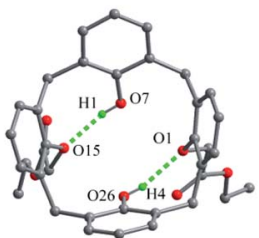

(b)

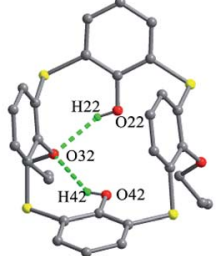

(c)
Fig. 16 Crystal structures of 20 (a), 21 (b) and 22 (c), showing intramolecular $\mathrm{H}$-bonds. 


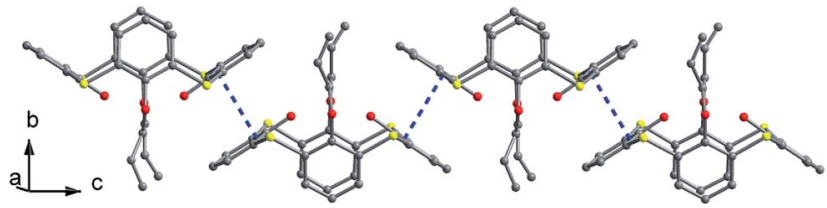

Fig. 17 An infinite chain of 22 built by $\pi-\pi$ stacking.

ether arm are almost parallel to each other, while two phenolic rings are tilted outwards and nearly perpendicular. The conformer of $\mathbf{2 3}$ (ref. 39) is fixed by the H-bonds as mentioned above, in which two opposite aromatic rings with $\mathrm{OCH}_{2} \mathrm{CN}$ moiety tilt parallel to the same direction (Fig. 19a). Moreover, intramolecular $\mathrm{O}-\mathrm{H} \cdots \mathrm{S}$ H-bonds yielded between the $\mathrm{OH}$ groups and $\mathrm{S}$ bridges are the factor for stabilizing the conformation.

Thiacalix[4]arene diisocyanide derivative $\mathbf{2 4}$ (ref. 40) exists two molecules $\mathbf{A}$ and $\mathbf{B}$ in its crystal structure. In A (Fig. 19b), both $\mathrm{OCH}_{2} \mathrm{CH}_{2} \mathrm{~N} \equiv \mathrm{C}$ arms point vertically to two sides, while in B (Fig. 19c), both $\mathrm{OCH}_{2} \mathrm{CH}_{2} \mathrm{~N} \equiv \mathrm{C}$ arms point parallel to one side owing to the formation of an intramolecular $\mathrm{C}-\mathrm{H} \cdots \mathrm{C}$ H-bond between the two arms. Similarly, intramolecular $\mathrm{O}-\mathrm{H}^{\cdots} \mathrm{O} \mathrm{H}^{-}$ bonds were also found between the $\mathrm{OH}$ groups and ether $\mathrm{O}$ atoms. In the packing (Fig. 20), an asymmetric dimer of molecule 24 is formed by an intermolecular $\mathrm{C} 90-\mathrm{H} 90 \cdots \mathrm{C} 46$ interaction between vicinal molecules $\mathbf{A}$ and $\mathbf{B}$. Then, each dimer is connected in turn to produce a 1-D ABAB type of chain by C22$\mathrm{H} 22 \cdots \mathrm{O} 8 \mathrm{H}$-bonds. Moreover, this chain is further fixed by intermolecular $\mathrm{O} 4 \cdots \mathrm{S} 5$ and $\mathrm{C} 21-\mathrm{H} 21 \cdots \pi$ contacts.

The conformer of 25 (Fig. 21a), ${ }^{40}$ with two $\mathrm{OCH}_{2} \mathrm{CH}_{2} \mathrm{NH}_{2}$ arms, is also fixed by the intramolecular $\mathrm{O}-\mathrm{H} \cdots \mathrm{O}$ H-bonds from both $\mathrm{OH}$ groups to the same ether $\mathrm{O}$ atom. Interestingly, one aminoethyl group was disordered over two orientations, where

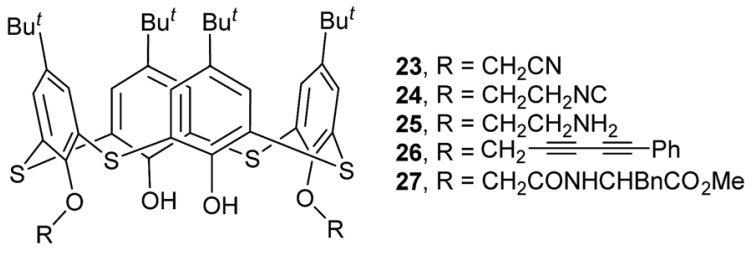

Fig. 18 Structures of compounds 23-27.

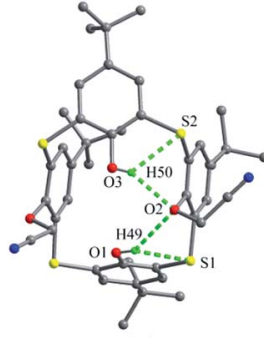

(a)

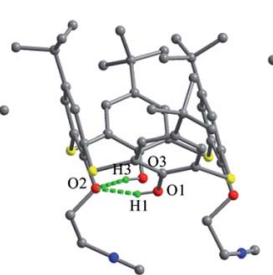

(b)

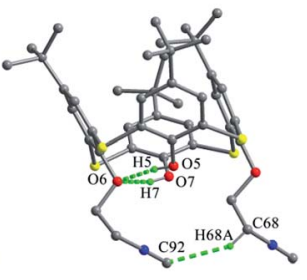

(c)
Fig. 19 Crystal structures of 23 (a), 24A (b) and 24B (c), showing intramolecular $\mathrm{H}$-bonds.

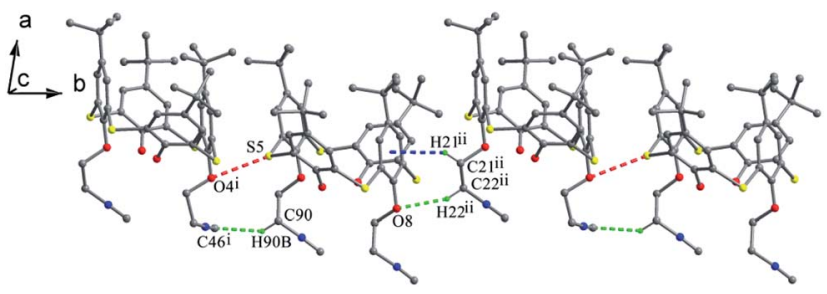

Fig. 20 A 1-D chain of 24 , showing the $\mathrm{C}-\mathrm{H} \cdots \mathrm{C}$ (green), $\mathrm{C}-\mathrm{H} \cdots \mathrm{O}$ (green), $\mathrm{C}-\mathrm{H} \cdots \pi$ (blue) and $\mathrm{O} \cdots \mathrm{S}$ (red) interactions.

three fifths of an intramolecular $\mathrm{N} 2-\mathrm{H} 2 \cdots \mathrm{O} 3 \mathrm{H}$-bond further governs the pinched cone conformation, while two fifths of an intermolecular $\mathrm{O} 1 \mathrm{~W}-\mathrm{H} 1 \mathrm{D} \cdots \mathrm{O} 3 \mathrm{H}$-bond occupies the site of $\mathrm{N} 2-$ $\mathrm{H} 2 \cdots \mathrm{O} 3$ when the aminoethyl unit is disordered over the other position. In the packing, six molecules of 25 combine in a sequential manner to construct a circular hexamer by cooperative intermolecular $\mathrm{C} 43-\mathrm{H} 43 \cdots \pi$ and $\mathrm{S} \cdots \mathrm{S}$ contacts (Fig. 22). Although compound 26 (ref. 41) possesses two longer chains, it still displays the similar conformational behavior (Fig. 21b), where two $\mathrm{OH}$ groups take part in H-bonds with the same ether $\mathrm{O}$ atom.

Thiacalix[4]arene derivative 27 (ref. 42) (Fig. 18) contains two ether arms with amide and ester groups at 1,3-position and can be applied for selective binding $\mathrm{Hg}^{2+}$ ion in acetonitrile solution. In the solid state, there are two molecules $\mathbf{A}$ and B in the asymmetric unit, both showing a cone conformation with near $C_{2}$ symmetry (Table 1). Differently, two $\mathrm{OH}$ groups as a donor form $\mathrm{O}-\mathrm{H} \cdots \mathrm{O} \mathrm{H}$-bonds not with the same ether $\mathrm{O}$ atom but with two $\mathrm{O}$ atoms (Fig. 21c). Moreover, each $\mathrm{OH}$ group also creates $\mathrm{O}-\mathrm{H} \cdots \mathrm{O}$ and $\mathrm{N}-\mathrm{H} \cdots \mathrm{O}$ H-bonds with the ester carbonyl $\mathrm{O}$ and $\mathrm{NH}$ atoms of the other ether strand, as well as $\mathrm{O}-\mathrm{H} \cdots \mathrm{S}$ H-bond with the $\mathrm{S}$ bridge. The donor and acceptor capability of the $\mathrm{OH}$ groups with the ester carbonyl $\mathrm{O}$ and amide $\mathrm{H}$ formulates the orientation of the flexible arms upwards to the calix core direction. In addition, the terminal

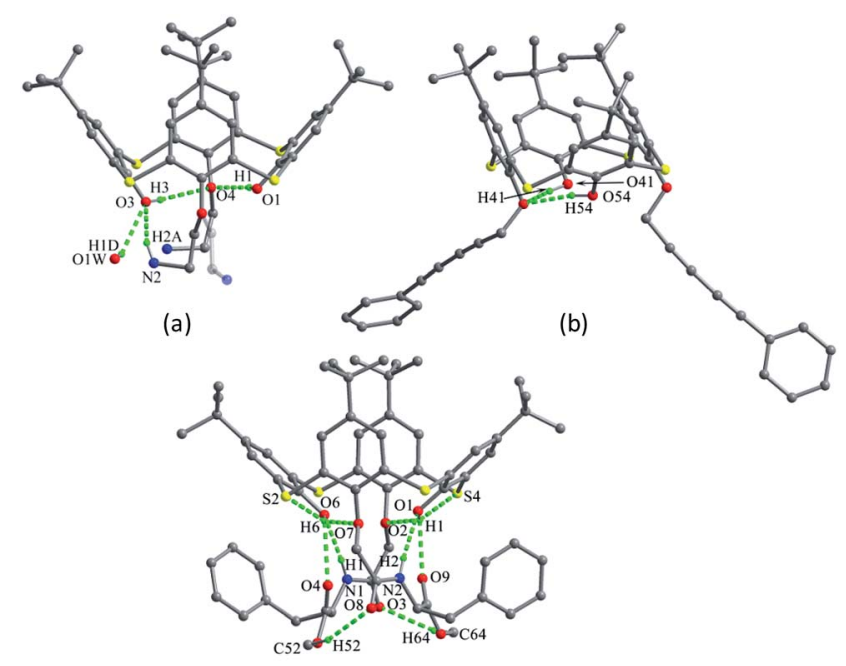

(c)

Fig. 21 Crystal structures of 25 (a), 26 (a) and 27 (c), showing H-bonds. 


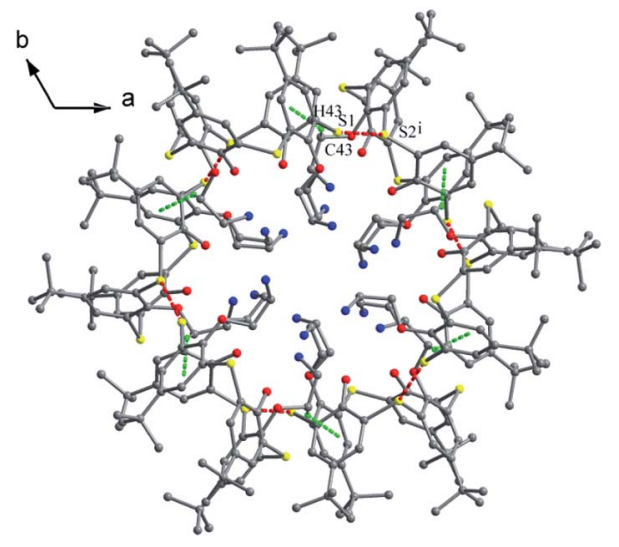

Fig. 22 An annular hexamer of 25 assembled by $\mathrm{C}-\mathrm{H} \cdots \pi$ (green) and S $\cdots$ S (red) interactions.

methyl $\mathrm{H}$ of the ester group is involved in $\mathrm{C}-\mathrm{H} \cdots \mathrm{O}$ interaction with the amide $\mathrm{O}$ of the opposite arm to orient the phenyl rings outwards from the calix unit. Thus the two tethered arms undergo an unusual crossover based on these unique interactions in the crystal structure.

Kumar et al. reported thiacalix[4]tube 28 (Fig. 23), ${ }^{43}$ which is composed of two thiacalix[4] arene units and two diimine linkages. In the crystal structure, both thiacalix[4]arene cores adopt the same pinched cone conformation and no difference in their $\theta$ values (Table 1). In either thiacalix[4]arene core, both $\mathrm{OH}$ groups are titled into the cavity and create two $\mathrm{O}-\mathrm{H} \cdots \mathrm{O} \mathrm{H}$-bonds with the same ether $\mathrm{O}$ atom. In addition, other three $\mathrm{H}$-bonds were found between the $\mathrm{OH}$ groups and the imine $\mathrm{N}$ atom, as well as two $\mathrm{S}$ atoms. This thiacalix[4]tube receptor can quantitatively extract $\mathrm{Ag}^{+}$ion from aqueous into organic phase under neutral conditions.

Compounds 29-33 (Fig. 24), ${ }^{44,45}$ a family of thiacalix[4]arene derivatives modified at its lower and upper rims, all give a cone conformation with similar $\theta$ ranges except for 33 (Table 1). These molecules show the same type of intramolecular $\mathrm{O}-\mathrm{H} \cdots \mathrm{O}$ and $\mathrm{O}-\mathrm{H} \cdots \mathrm{S} \mathrm{H}$-bonds as in $\mathbf{2 3}$ discussed above, but they

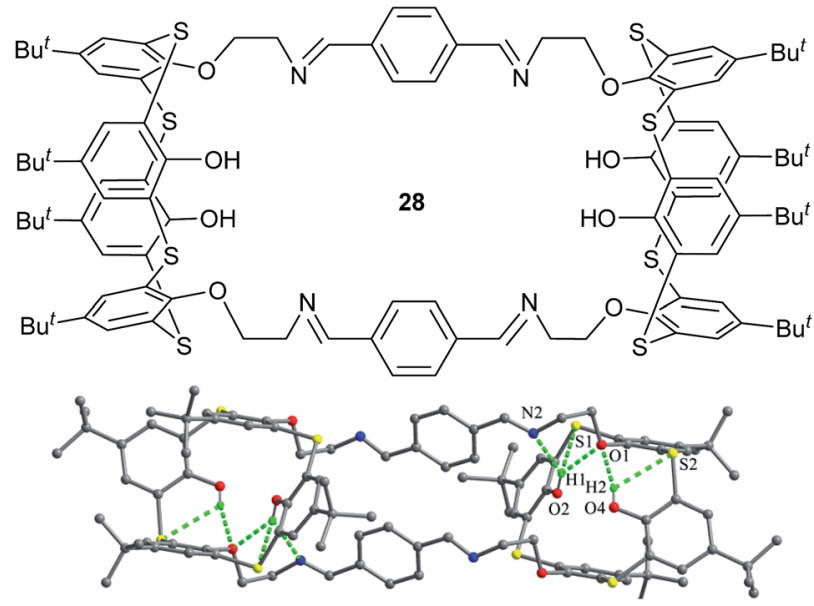

Fig. 23 Chemical and crystal structures of compound 28, showing intramolecular $\mathrm{H}$-bonds.

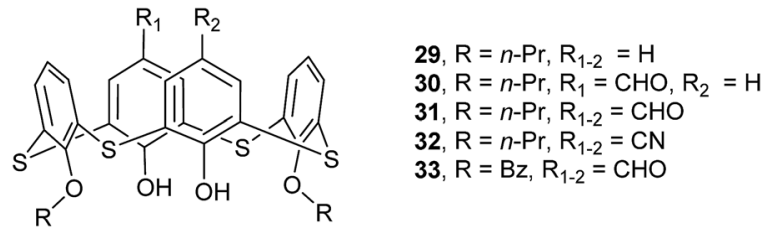

Fig. 24 Structures of compounds 29-33.

demonstrate diverse assemblies in the solid state. Both 29 and 30 (with one CHO group) (Fig. 25a) are assembled into a kind of head-to-head dimers via interdigitation of aromatic rings with $\pi-\pi$ and $\mathrm{C}-\mathrm{H} \cdots \pi$ contacts, while 31 (with two CHO groups) is associated into a different head-to-head dimer through $\pi-\pi$ contact and weak $\mathrm{C} 6-\mathrm{H} 6 \cdots \mathrm{O} 5$ and $\mathrm{C} 7-\mathrm{H} 7 \cdots \mathrm{O} 5 \mathrm{H}$-bonds (Fig. 25b). This could be ascribed to the introduction of the second CHO group. In comparison, molecule 32 (with two CN groups) displays a remarkable difference in the assemblies (Fig. 25c). A unique off-set kind of dimer is formed via $\mathrm{Cl} \cdots \mathrm{Cl}$ and $\mathrm{Cl} \cdots \pi$ contacts. In such a dimer, two $\mathrm{CHCl}_{3}$ molecules linked by $\mathrm{Cl} \cdots \mathrm{Cl}$ contact, serve as a bridge to join two vicinal thiacalix[4]arene molecules by $\mathrm{Cl} \cdots \pi$ contacts, with one $\mathrm{Cl}$ atom of the $\mathrm{CHCl}_{3}$ molecule lodged into the $\pi$-basic host cavity.

Amongst these compounds, 33 gives the biggest $\theta$ range (Table 1) owing to the replacement of $n$-propyl moiety with bigger benzoyl group. In the packing, it does not generate a head-to-head dimer but yield a tail-to-tail one by interaction between benzoyl groups with $\pi-\pi$ stacking (Fig. 25d).

In addition, they all produce a similar type of honeycomb channel architectures. For instance, six molecules of $\mathbf{3 0}$ are packed in a back-to-back fashion, creating a disc-like hexamer

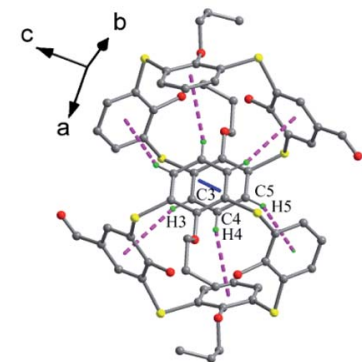

(a)

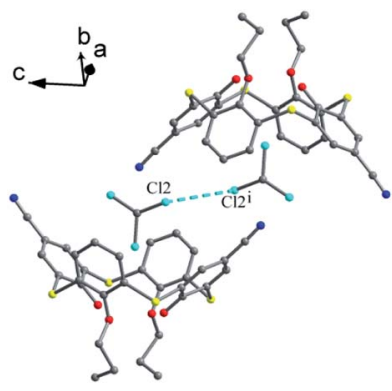

(c)
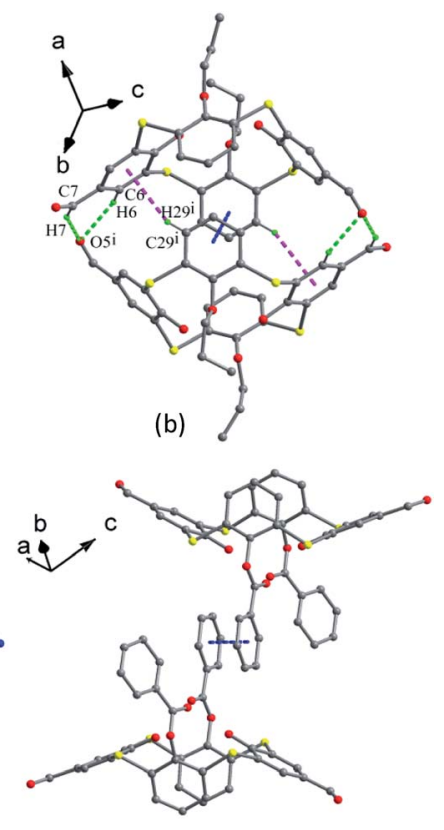

(d)
Fig. 25 Dimers of 30 (a), 31 (b), 32 (c) and 33 (d), showing diverse intermolecular interactions involving $\pi-\pi$ (blue), $\mathrm{C}-\mathrm{H} \cdots \pi$ (pink), $\mathrm{C}-\mathrm{H} \cdots \mathrm{O}$ (green) and $\mathrm{Cl} \cdots \mathrm{Cl}$ (cyan) contacts. 


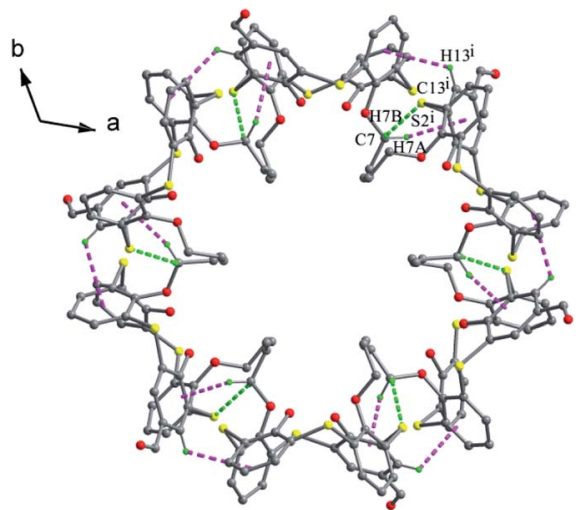

Fig. 26 A disc-like hexamer of 30, showing intermolecular $\mathrm{C}-\mathrm{H} \cdots \mathrm{S}$ (green) and $\mathrm{C}-\mathrm{H} \cdots \pi$ (pink) interactions.

via weak $\mathrm{C} 7-\mathrm{H} 7 \mathrm{~B} \cdots \mathrm{S} 2, \mathrm{C} 13-\mathrm{H} 13 \cdots \pi$ and $\mathrm{C} 7-\mathrm{H} 7 \mathrm{~A} \cdots \pi$ contacts (Fig. 26), while a disordered $\mathrm{CHCl}_{3}$ molecule locates in the centre of such a hexamer with $\mathrm{C}-\mathrm{H} \cdots \mathrm{Cl}$ contacts. Then, these hexamers aggregate into a channel through $\mathrm{C}-\mathrm{H} \cdots \mathrm{S}$ and $\mathrm{S} \cdots \pi$ interactions. And neighbouring channels connect to form a honeycomb architecture by inter-channel $\pi-\pi$ and $\mathrm{C}-\mathrm{H} \cdots \pi$ contacts.

In contrast, few of 1,2-disubstituted thiacalix[4]arenes have been obtained in a cone conformation up to now, thus their crystal structures are rarely reported. An only known example is 1,2-bistriflate thiacalix[4]arene derivative 34 (ref. 46) (Fig. 27). In the crystal structure, there exist two molecules $\mathbf{A}$ and $\mathbf{B}$ in its unit cell. Both molecules adopt a pinched cone conformation and show different $\theta$ values (Table 1). As shown in Fig. 27, such a pinched cone conformer is stabilized by an intramolecular $\mathrm{O}-\mathrm{H} \cdots \mathrm{O} \mathrm{H}$-bond between the two $\mathrm{OH}$ groups and $\mathrm{O} \cdots \mathrm{S}$ contacts between the triflate groups and $\mathrm{S}$ bridges. Additionally, in the packing, intermolecular $\mathrm{F} \cdots \mathrm{F}$ and $\mathrm{O} \cdots \mathrm{S}$ contacts are generated and further fix its crystal structure.

\section{$2.4 O$-Tri/tetrasubstituted thiacalix[4] arenes}

Thiacalix[4]arene tridiethylthiophosphate 35 (ref. 47) (Fig. 28) is a sulphur-enriched compound and can efficiently extract $\mathrm{Ag}^{+}$ ion from water into dichloromethane. In the solid state, it shows a markedly distorted cone conformation with four $\theta$ angles in great difference (Table 1). In such a conformer, the sole $\mathrm{OH}$ group takes part in the formation of $\mathrm{H}$-bonds with $\mathrm{O} 8$ and S4 atoms (Fig. 29a).
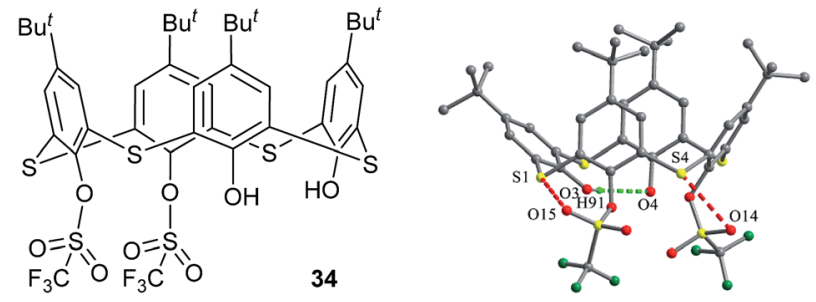

Fig. 27 Chemical and crystal structures of compound 34, showing intramolecular $\mathrm{H}$-bond and $\mathrm{O} \cdots \mathrm{S}$ contacts.
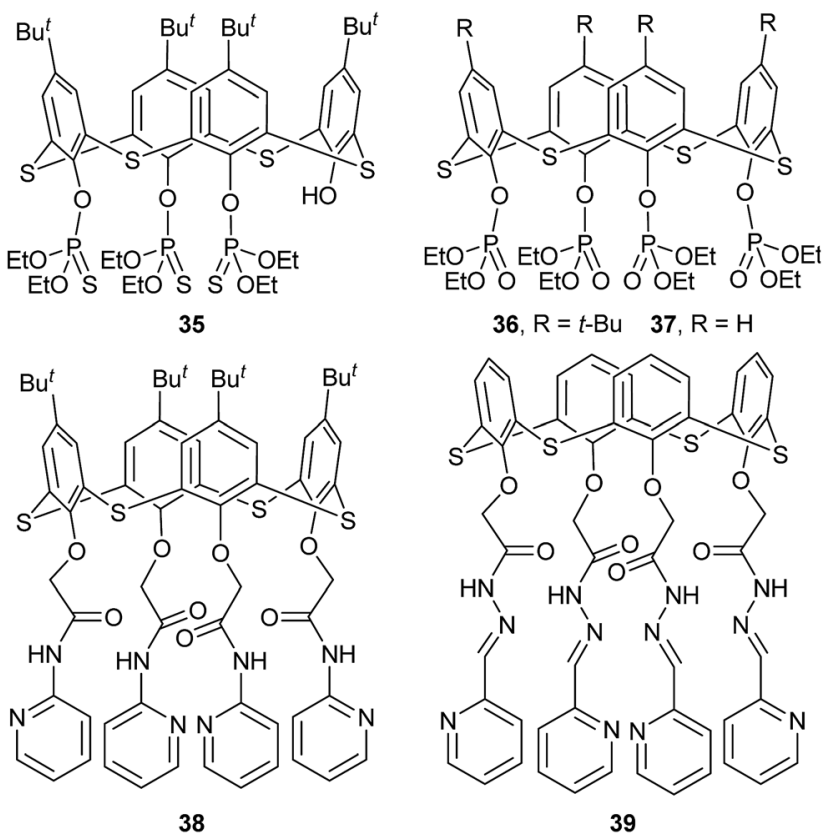

Fig. 28 Structures of compounds 35-39

Tetraphosphorylated thiacalix[4]arenes 36 and 37 (ref. 48) (Fig. 28) are good ligands that can selectively extract $\mathrm{Pd}^{2+}$ ion from automotive catalyst residue solution. In the solid state, they adopt a cone conformation with $\theta$ ranges of 78.7-123.8 and $65.2-136.7^{\circ}$ (Table 1 ), respectively. Intramolecular $\mathrm{S} \cdots \mathrm{O}$ interactions between $\mathrm{S}$ bridges and $\mathrm{P}=\mathrm{O}$ units were found to stabilize the conformers of either molecule (Fig. 29b and c). In addition, for 37 , its conformer is further governed by intramolecular $\mathrm{C}-\mathrm{H} \cdots \pi$ interactions. In the packing (Fig. 30), 1-D chains of them are formed with $\mathrm{C}-\mathrm{H} \cdots \pi$ interactions between aromatic rings and ethyl $\mathrm{H}$ atoms of vicinal molecules. In addition, their $\mathrm{P}=\mathrm{O}$ groups also participate in making their three-dimensional supramolecular assemblies via $\mathrm{H}$-bonds.

Thiacalix[4]arene derivative 38 (ref. 49) (Fig. 28) possesses four amide-bridged pyridine arms and takes a cone conformation with a small $\theta$ range of $106.0-116.9^{\circ}$ (Table 1 ). All amide $O$ atoms cannot act as an acceptor to form intramolecular $\mathrm{N}-\mathrm{H} \cdots \mathrm{O}$ H-bonds as they orient outwards the cavity due to their electron repulsion. However, all $\mathrm{NH}$ groups can serve as a donor to create $\mathrm{N}-\mathrm{H} \cdots \mathrm{O} \mathrm{H}$-bonds with the phenolic $\mathrm{O}$ atom of the same arm, and generate three $\mathrm{N}-\mathrm{H} \cdots \mathrm{S} \mathrm{H}$-bonds with the $\mathrm{S}$ bridges (Fig. 29d). The O atoms of some amide groups play an important role in the formation of intermolecular $\mathrm{H}$-bonds with $\mathrm{H}_{2} \mathrm{O}$ molecules in the packing. This molecule shows high affinity towards $\mathrm{Ag}^{+}$ion in solution owing to the introduction of pyridine function.

Podyachev et al. reported thiacalix[4] arene derivative 39 (Fig. 28), ${ }^{50}$ having four identical hydrazone-bridged pyridine arms at the lower rim. The thiacalix[4] arene core displays a cone conformation with a large $\theta$ range of $67.5-146.5^{\circ}$ (Table 1), where two opposite phenolic rings inclined towards the cavity, and the other two point outwards. Compared with 38, only two $\mathrm{NH}$ groups can yield similar $\mathrm{N}-\mathrm{H} \cdots \mathrm{O}$ bonds with the ether $\mathrm{O}$ 

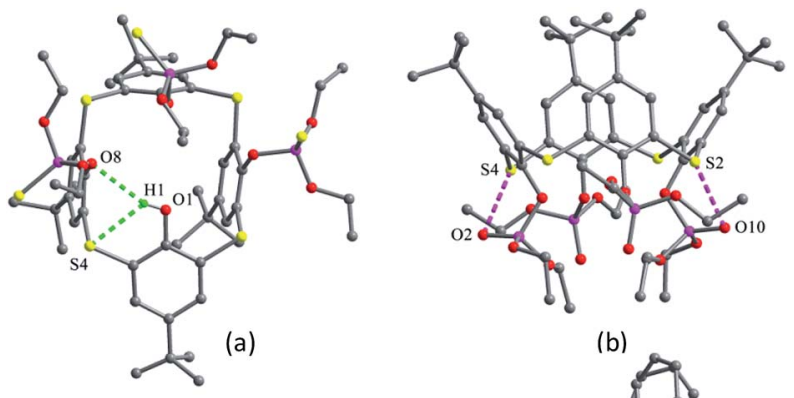

(b)

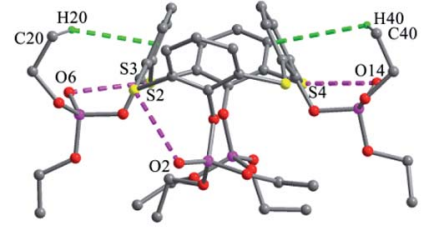

(c)

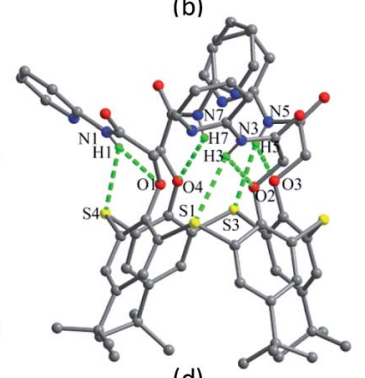

(d)
Fig. 29 Crystal structures of 35 (a), 36 (b), 37 (c), and 38 (d) showing intramolecular $\mathrm{H}$-bonds.

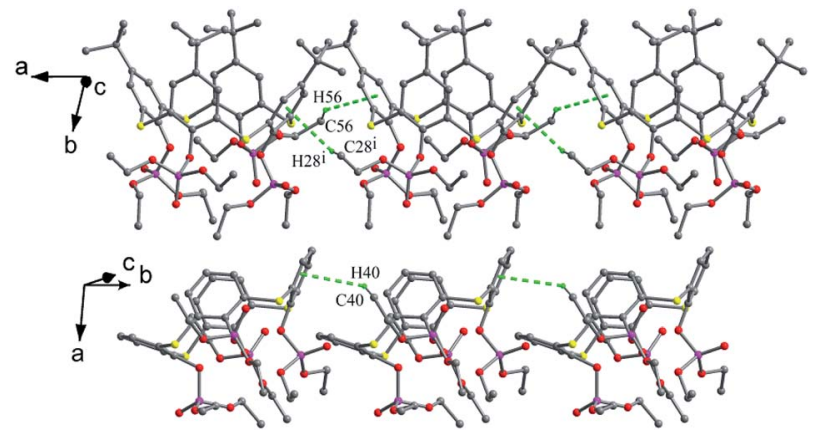

Fig. 30 1-D chains of 36 (top) and 37 (bottom) showing $\mathrm{C}-\mathrm{H} \cdots \pi$ interactions.

atom of the same arm (Fig. 31). The other two NH groups can produce the intermolecular $\mathrm{N}-\mathrm{H} \cdots \mathrm{O}$ bonds with adjacent host and guest molecules, respectively. In addition, there is an intramolecular $\mathrm{N} 46-\mathrm{H} 46 \cdots \mathrm{O} 38 \mathrm{H}$-bond between two amide groups of the vicinal arms. In the packing, a centrosymmetric

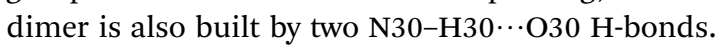

Doubly bridged thiacalix[4]arenes 40-42 (Fig. 32), ${ }^{51}$ obtained by the aminolysis of thiacalix[4]arene tetraacetate with various

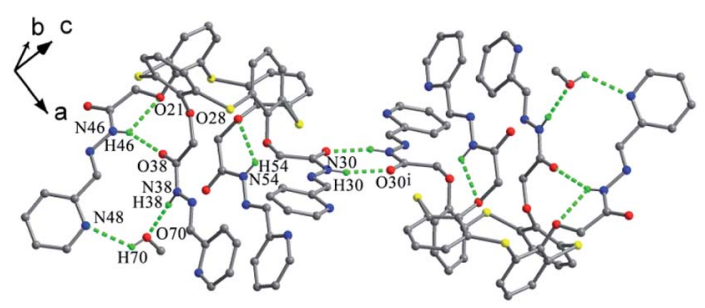

Fig. 31 Crystal structure of 39 , showing a dimer with intra- and intermolecular $\mathrm{H}$-bonds.

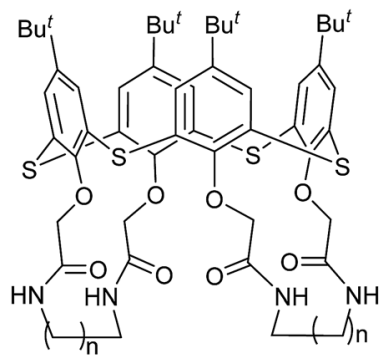

40, $n=1 \quad 41, n=2 \quad 42, n=3$

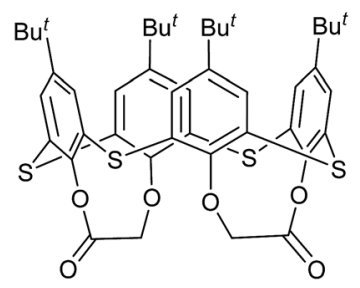

43

Fig. 32 Structures of compounds 40-43.

$\alpha, \omega$-diamines, generate cage-like structures possessing well preorganised array of - $\mathrm{NH}-\mathrm{CO}-$ binding sites in the lower rim. $\mathrm{X}$-ray analysis indicates that they all take a cone conformation and possess a very similar configuration with $\theta$ ranges of 92.6$131.7^{\circ}, 90.2-132.8^{\circ}$ and $90.3-132.5^{\circ}$ (Table 1), respectively. One pair of opposing aromatic rings points outwards the cavity, while the other pair tilts inwards. For three molecules, there is one strong intramolecular $\mathrm{N}-\mathrm{H} \cdots \mathrm{O}$ H-bond existed between two crown moieties, resulting in one amide $\mathrm{C}=\mathrm{O}$ group distorting into the cavity. Moreover, there is one intra-crown $\mathrm{H}$-bond formed between two amide groups in $\mathbf{4 0}$ (Fig. 33a) and $\mathbf{4 1}$ (Fig. 33b), but between one amide group and one ether $\mathrm{O}$ atom in 42 (Fig. 33c). Additionally, an intramolecular $\mathrm{N}-\mathrm{H} \cdots \mathrm{S}$ H-bond was found in the crystal structures of $\mathbf{4 0}$ and $\mathbf{4 2}$. All these $\mathrm{H}^{-}$ bonds together govern the cone conformers.

In the crystal structure of 43 (Fig. $33 \mathrm{~d}$ ),${ }^{52}$ a dilactone derivative of $\mathbf{1}$, although the presence of two lactone bridges induces the cone conformer distorted, the whole structure still has approximate $C_{2}$ symmetry with $\theta$ values of 87.4, 140.8, 91.2 and $142.8^{\circ}$. So two opposing aromatic rings are almost coplanar, while the other two are tilted outwards making lactone bridges bent towards the cavity. In such a conformation, two kinds of

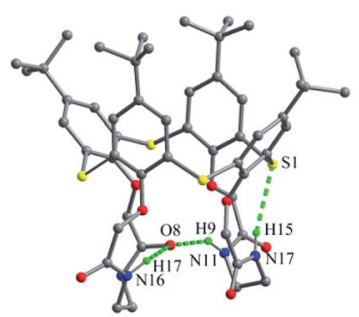

(a)

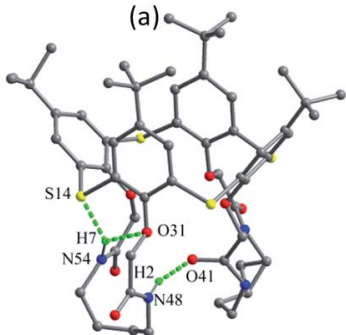

(c)

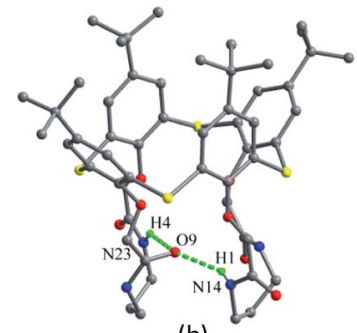

(b)

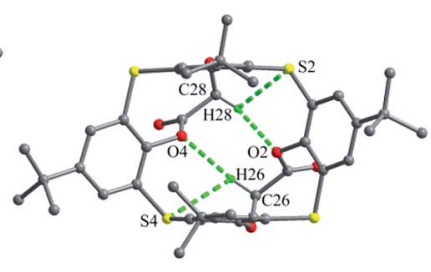

(d)

Fig. 33 Crystal structures of 40 (a), 41 (b), 42 (c) and 43 (d), showing intramolecular $\mathrm{H}$-bonds. 


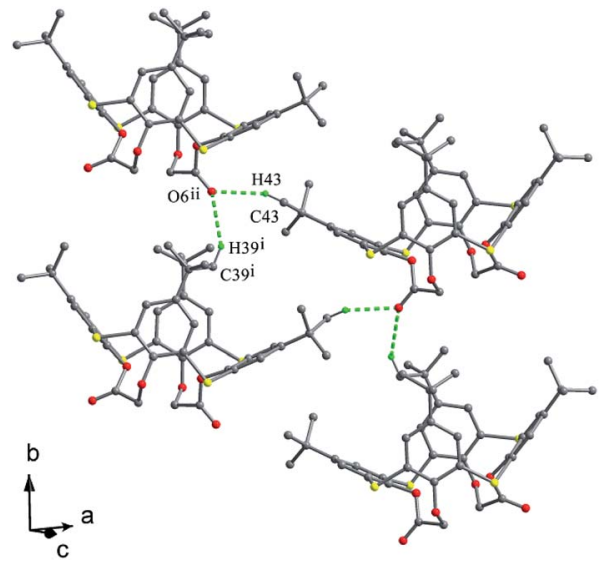

Fig. 34 Partial packing structure of 43 , showing $\mathrm{H}$-bonds.

intramolecular $\mathrm{H}$-bonds exist between lactone methylene $\mathrm{H} 28$, $\mathrm{H} 26$ atoms and vicinal $\mathrm{O} 2, \mathrm{O} 4$ atoms with contribution of bridging $\mathrm{S}$ atoms. In the packing (Fig. 34), only carbonyl O6 participates in the soft intermolecular $\mathrm{H}$-bonds with two $\mathrm{H}$ atoms of $t$-butyl groups from two molecules, creating an infinite network of molecules.

In the crystal structures of dibromothiacalix[4]arenes $\mathbf{4 4}$ and 45 (Fig. 35), ${ }^{53,54}$ the thiacalix[4] arene units give different pinched cone conformations with large $\theta$ ranges of $75.0-143.5^{\circ}$ and 65.6$153.9^{\circ}$ (Table 1), respectively. For 44 (Fig. 36a), two brominated benzene rings are bent outwards the cavity with a long $\mathrm{Br} \cdots \mathrm{Br}$ distance of $13.17 \AA$ A. However, the other two benzene rings, one of which is bent towards the cavity, are almost parallel to each other with a dihedral angle of $2.99^{\circ}$. One of the ether $\mathrm{O}$ atoms makes two H-bonds with both $\mathrm{OH}$ groups. Whereas, for 45 (Fig. 36b), two brominated aromatic rings also incline outwards the cavity with a slight longer $\mathrm{Br} \cdots \mathrm{Br}$ distance of $13.82 \AA$. Remarkably, the other two aromatic rings are not parallel and both tilt inwards with a large dihedral angle of $33.4^{\circ}$. This may be ascribed to the destruction of the two H-bonds and the influence of the bulky $\mathrm{CH}_{2} \mathrm{CO}_{2}$ Me moieties.

In the packing of $\mathbf{4 4}$, two different molecular chains, one with alternating (Fig. 37a) and the other with tail-to-tail orientations (Fig. 37b), are formed by intermolecular offset-face-toface $\pi-\pi$ stackings of the aromatic rings. However, in the case of 45 (Fig. 37c), an infinite zigzag 1-D chain is formed by intermolecular $\mathrm{C}-\mathrm{H} \cdots \mathrm{S}$ H-bonds and $\mathrm{S} \cdots \mathrm{S}$ contacts between the adjacent molecules. Finally, such chains are associated into bilayers by a combination of interchain $\mathrm{C}-\mathrm{H} \cdots \mathrm{O} \mathrm{H}$-bonds.

Lhoták et al. reported that tetrasulfinyl thiacalix[4]arene 46 (Fig. 35), ${ }^{55}$ synthesized by selective oxidation of tetramethoxy

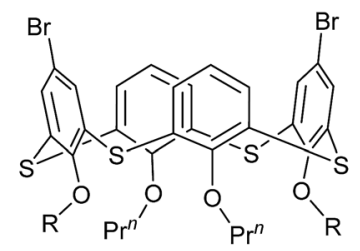

44, $\mathrm{R}=\mathrm{H} \quad 45, \mathrm{R}=\mathrm{CH}_{2} \mathrm{CO}_{2} \mathrm{Me}$

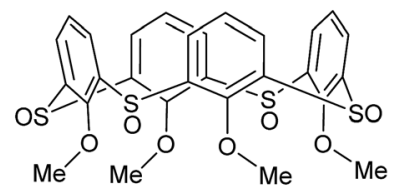

46
Fig. 35 Structures of compounds 44-46.

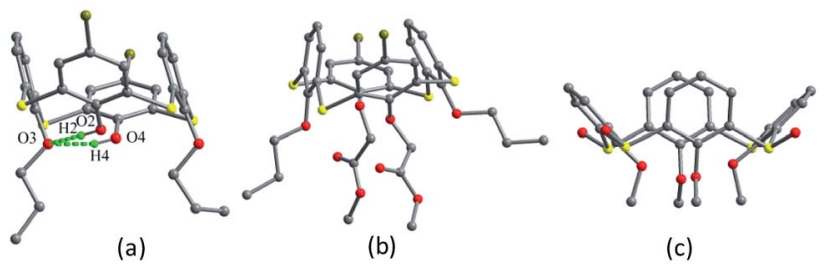

Fig. 36 Crystal structures of 44 (a), 45 (b) and 46 (c).

thiacalix[4]arene, adopts a nearly $C_{2}$ symmetric cone conformation with $\theta$ values of $106.7,134.9,110.9$ and $132.0^{\circ}$. Such structure is influenced by intermolecular C35-H35 $\cdots \pi$ contacts between the OMe group and its linked aromatic ring of vicinal molecules (Fig. 38). Therefore, an infinite chain is produced and the OMe unit of one molecule is immersed in the cavity of the other one in the packing.

Briefly, only few of thiacalix[4]arenes show a perfect cone conformation possessing the same $\theta$ values, while the majority of them give a pinched or distorted cone conformation having different angles. In general, thiacalix[4]arene molecules with four $\mathrm{OH}$ or/and $\mathrm{NH}_{2}$ groups at the lower rim exhibit $C_{4}$ or near $C_{2}$-symmetry and form an intramolecular annular $\mathrm{H}$-bonding array. For most $O$-mono- and di-substituted thiacalix[4]arenes, they are favored to take a pinched cone conformation as their free $\mathrm{OH}$ groups create asymmetrically intramolecular $\mathrm{H}$-bonds in a sequential pattern from one $\mathrm{OH}$ group to the ether $\mathrm{O}$ atom or in such a way that one ether $\mathrm{O}$ atom forms two $\mathrm{H}$-bonds with its vicinal $\mathrm{OH}$ groups. However, for $\mathrm{O}$-tetrasubstituted thiacalix[4]arenes, they usually exhibit different cone conformers as their substitutes are changed. In the assemble, versatile interactions involving $\mathrm{H}$-bonds, $\mathrm{C}-\mathrm{H} \cdots \pi, \pi-\pi$ and hetero atom contacts play a key role in constructing the supramolecular assemblies and fixing the conformations.

\section{1,3-Alternate structures of thiacalix [4]arenes}

Thiacalix[4]arenes with various functional groups are very popular because of their highly binding affinity. Especially,

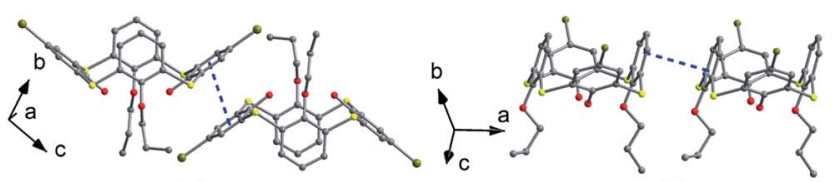

(a)

(b)

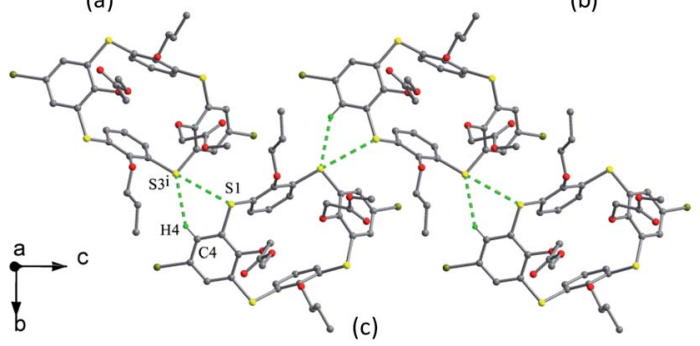

Fig. 37 Partial packing structures of 44 in alternating orientations between the phenolic rings (a) and in tail-to-tail orientations between the ether-substituted rings (b), and a 1-D zigzag chain of 45 (c). 


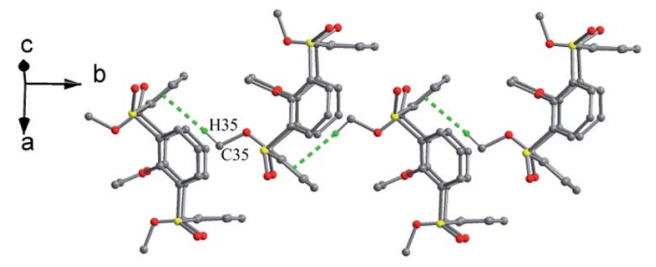

Fig. 38 A 1-D chain of 46 with $\mathrm{C}-\mathrm{H} \cdots \pi$ interactions.

these groups in 1,3-alternate orientations markedly enhance their binding properties. Thiacalix[4]arene derivatives are in a 1,3-alternate conformation rather than a cone one based on the chemical modification conditions and the substituents attached. The most such compounds are homo- or heterotetrasubstituted thiacalix[4]arene derivatives at the lower rim, and some S-oxidized derivatives.

\subsection{S-Oxydic thiacalix[4]arenes}

The conformation of some thiacalix[4]arenes may be changed upon oxidation of their S bridges. Tetrasulfinyl thiacalix[4]arenes 47 and 48 (Fig. 39) could be obtained via selective oxidization of the four $\mathrm{S}$ bridges. ${ }^{56,57}$ In the solid state, both compounds display a similar 1,3-alternate conformation with a narrow $\theta$ range of $79.5-94.8^{\circ}$ and the same $\theta$ value of $73.5^{\circ}$ (Table 2), respectively. All $\mathrm{O}$ atoms of their $\mathrm{S}=\mathrm{O}$ units are alternately oriented above and below the $R$ plane. This kind of conformers is governed by four alternate $\mathrm{O}-\mathrm{H} \cdots \mathrm{O} \mathrm{H}$-bonds between the $\mathrm{OH}$ groups and the $\mathrm{S}=\mathrm{O}$ units, with average bond distances of $2.67 \AA$ for 47 (Fig. 40a) and $2.65 \AA$ for 48 (Fig. 40b). Interestingly, a 3-D network is formed by intermolecular $\pi-\pi$ stacking between all four aromatic rings of $\mathbf{4 8}$ (Fig. 41). However, such a network was not observed in the crystal structure of 47 , owing to the presence of bulky $t$-butyl groups.

Using the similar strategy, the corresponding tetrasulfonyl derivative 49 (ref. 58) (Fig. 39) could be prepared and shows a typical 1,3-alternate conformation with the same $\theta$ value of $89.5^{\circ}$. Dissimilar to 47 and 48 , all sulfonyl $\mathrm{O}$ atoms of 49 point outwards the cavity. This conformer can be rationalized by the formation of $\mathrm{H}$-bonds between the $\mathrm{OH}$ groups and the $\mathrm{SO}_{2}$ units (Fig. 40c). In the packing, a 3-D network is built by intermolecular $\mathrm{H}$-bonds between the $\mathrm{OH}$ and $\mathrm{SO}_{2}$ moieties belonging to adjacent molecules (Fig. 42).
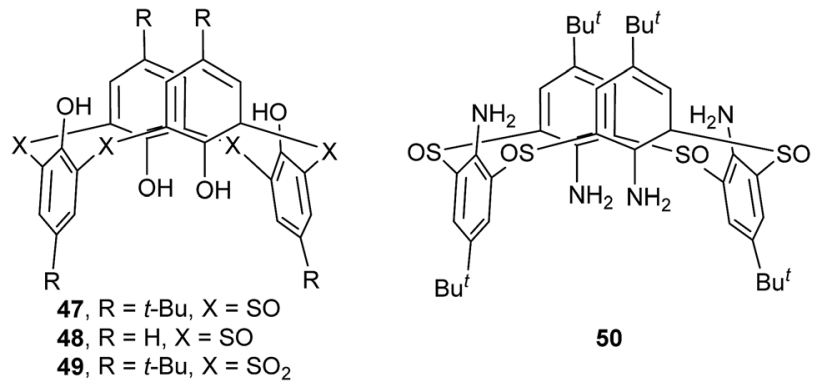

Fig. 39 Structures of compounds 47-50.
Table 2 The $\theta$ angles of compounds 47-93

\begin{tabular}{|c|c|c|c|c|}
\hline Compd. & $\theta\left(^{\circ}\right)$ & & & \\
\hline 47 & 79.5 & 86.6 & 94.8 & 87.6 \\
\hline 48 & 73.5 & 73.5 & 73.5 & 73.5 \\
\hline 49 & 89.5 & 89.5 & 89.5 & 89.5 \\
\hline 50 & 95.5 & 95.5 & 95.5 & 95.5 \\
\hline 51 & 107.1 & 105.4 & 107.1 & 105.4 \\
\hline 52 & 102.1 & 106.6 & 102.1 & 106.6 \\
\hline 53 & 93.6 & 94.9 & 93.6 & 94.9 \\
\hline 54 & 110.1 & 113.1 & 122.9 & 116.9 \\
\hline 55 & 108.3 & 117.8 & 124.7 & 110.1 \\
\hline $56^{b}$ & 92.2 & 97.7 & 98.7 & 93.9 \\
\hline 57 & 101.9 & 107.4 & 118.4 & 110.1 \\
\hline 58 & 98.2 & 110.9 & 112.9 & 109.6 \\
\hline 59 & 116.1 & 117.8 & 116.1 & 117.8 \\
\hline 60 & 109.2 & 112.9 & 125.7 & 115.5 \\
\hline 61 & 111.6 & 115.3 & 112.1 & 115.0 \\
\hline 62 & 91.2 & 92.2 & 91.2 & 92.2 \\
\hline 63 & 103.9 & 104.6 & 103.9 & 104.6 \\
\hline 64 & 83.5 & 88.8 & 86.4 & 87.8 \\
\hline 65 & 97.1 & 103.0 & 98.3 & 114.7 \\
\hline 66 & 100.3 & 102.4 & 103.9 & 102.6 \\
\hline 67 & 104.3 & 112.5 & 121.6 & 107.9 \\
\hline 68 & 104.2 & 116.5 & 104.2 & 116.5 \\
\hline 69 & 102.4 & 116.8 & 108.4 & 115.2 \\
\hline 70 & 109.2 & 112.9 & 110.6 & 119.5 \\
\hline 71 & 86.3 & 88.2 & 86.3 & 88.2 \\
\hline 72 & 106.0 & 113.8 & 118.4 & 108.3 \\
\hline 73 & 92.5 & 103.5 & 107.4 & 100.8 \\
\hline $74 \mathrm{~A}$ & 108.1 & 121.1 & 121.6 & 118.1 \\
\hline $74 \mathrm{~B}$ & 113.9 & 119.1 & 118.0 & 120.0 \\
\hline 75 & 109.8 & 112.4 & 122.0 & 118.2 \\
\hline 76 & 110.7 & 113.3 & 125.4 & 113.5 \\
\hline 77 & 100.9 & 102.9 & 100.9 & 102.9 \\
\hline 78 & 107.2 & 108.6 & 107.2 & 108.6 \\
\hline 80 & 103.7 & 107.5 & 103.7 & 107.5 \\
\hline 81 & 103.1 & 107.2 & 123.0 & 113.6 \\
\hline 82 & 101.5 & 112.1 & 107.6 & 111.4 \\
\hline 83 & 89.5 & 95.8 & 101.9 & 102.8 \\
\hline 84 & 103.1 & 110.5 & 107.3 & 105.9 \\
\hline 85 & 103.9 & 107.2 & 111.4 & 104.8 \\
\hline 86 & 101.0 & 106.7 & 110.6 & 117.9 \\
\hline 87 & 102.1 & 106.1 & 108.4 & 113.8 \\
\hline 88 & 101.4 & 102.2 & 112.6 & 104.9 \\
\hline 89 & 106.4 & 111.5 & 107.4 & 114.2 \\
\hline $90 \mathrm{~A}$ & 109.2 & 116.3 & 116.9 & 111.8 \\
\hline 90B & 111.3 & 114.4 & 114.9 & 114.7 \\
\hline 91 & 103.6 & 118.7 & 117.9 & 111.4 \\
\hline 92A & 66.1 & 147.7 & 74.2 & 154.6 \\
\hline 92B & 72.8 & 141.8 & 73.7 & 155.9 \\
\hline 93 & 111.4 & 114.0 & 115.9 & 114.3 \\
\hline
\end{tabular}

Tetrasulfinyl thiacalix[4]arene analogue 50 (ref. 27) (Fig. 39) also gives a typical 1,3-alternate conformation with the same $\theta$ value of $95.5^{\circ}$. Four intramolecular $\mathrm{N}-\mathrm{H} \cdots \mathrm{O}$ H-bonds are yielded between the $\mathrm{NH}_{2}$ groups and the sulfinyl $\mathrm{O}$ atoms (Fig. 40d). Moreover, a 2-D network is made by intermolecular H-bonds produced in the same way (Fig. 43). It should note that although 48, 49 and 50 all possess four identical $\theta$ angles, they increase in order, which may be attributed to the influence of de-t-butyl and the kinds of H-bonds. 


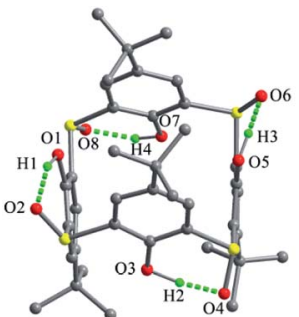

(a)

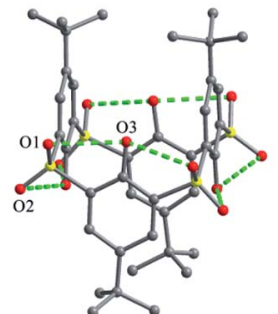

(c)

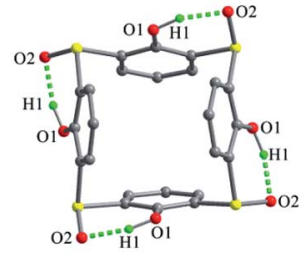

(b)

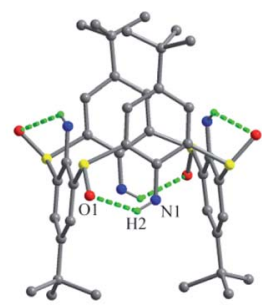

(d)
Fig. 40 Crystal structures of 47 (a), 48 (b), 49 (c) and 50 (d), showing intramolecular $\mathrm{H}$-bonds. All protons of the $\mathrm{OH}$ groups were not found in the crystal of 49

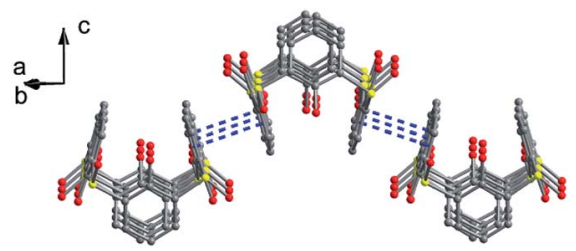

Fig. 41 A 3-D network of 48 through stacking of the aromatic groups.

Thiacalix[4]arene 51 (Fig. 44), ${ }^{59}$ a derivative of 49 with four ether chains ended with $\mathrm{Cl}$ atom, also takes a 1,3-alternate conformation and all sulfonyl $\mathrm{O}$ atoms point outwards the cavity. In the solid state, although no hard $\mathrm{H}$-bonds are found owing to the etherification of all $\mathrm{OH}$ groups, various soft $\mathrm{H}$-bonds involving intra- and intermolecular $\mathrm{C}-\mathrm{H} \cdots \mathrm{O}$ govern the conformation. Interestingly, an unusual 24-membered ring is created by a similar $\mathrm{H}$-bonding array consisting of $\mathrm{C}-\mathrm{H} \cdots \mathrm{O} \mathrm{H}$-bonds rather than $\mathrm{O}-\mathrm{H} \cdots \mathrm{O}$ H-bonds in 49. In this macrocycle, both $\mathrm{O}$ atoms of each sulfonyl unit act as $\mathrm{H}$-bond acceptor to $\mathrm{H}$ atoms of the two vicinal methylene groups closer phenolic rings. Thus it gives two pairing $\theta$ values of 107.1 and $105.4^{\circ}$, larger than that found in 49 . In the packing, an infinite zigzag 1-D chain is formed by four intermolecular $\mathrm{C}-\mathrm{H} \cdots \mathrm{O}$ H-bonds (Fig. 45).

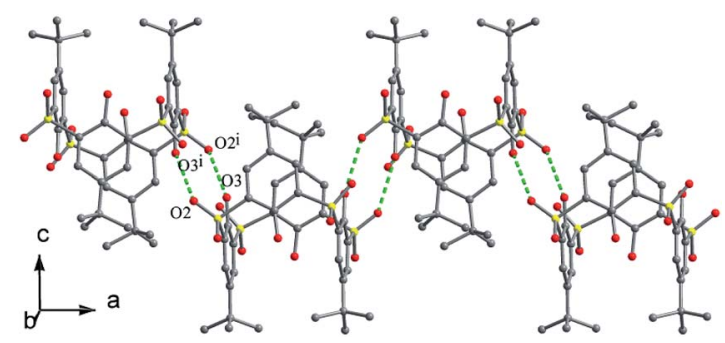

Fig. 42 A 1-D chain of 49 with intermolecular $\mathrm{H}$-bonds.

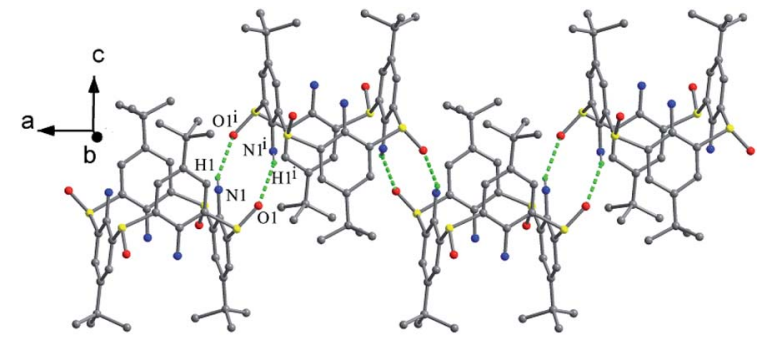

Fig. 43 A 2-D network of 50 built by intermolecular $\mathrm{N}-\mathrm{H} \cdots \mathrm{O} \mathrm{H}-$ bonds.

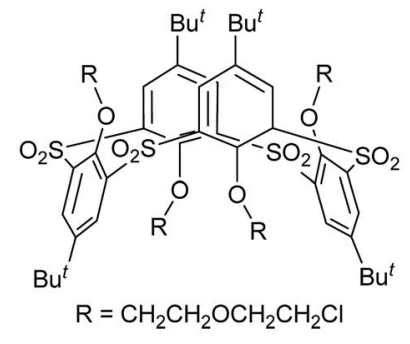

51

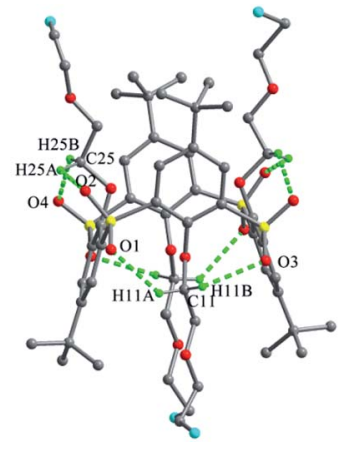

Fig. 44 Chemical and crystal structures of compound 51 with intramolecular $\mathrm{H}$-bonding array.

\section{2 $O$-Homosubstituted thiacalix[4]arenes}

$O$-Homosubstituted thiacalix[4]arenes can be facilely made via incorporating four identical substituents at the lower rim under the controlled reaction conditions..$^{6-9}$ Compounds 52 and 53 (Fig. 46), ${ }^{60}$ methyl ether derivatives of thiacalix[4]arenes, show different conformational behaviour in the solid state. Molecule 52 adopts a 1,3-alternate conformer with two pairs of $\theta$ angles (Table 2) upon crystallization from $\mathrm{CH}_{2} \mathrm{Cl}_{2}$ solvent (Fig. 47a). Square box-shaped cavities of thiacalix[4]arenes are packed parallel to each other and create infinite channels (Fig. 48), of which the inner and outer are filled with $\mathrm{H}_{2} \mathrm{O}$ and $\mathrm{CH}_{2} \mathrm{Cl}_{2}$ molecules, respectively. Whereas, 52 can also take a 1,2-alternate conformation with two pairing $\theta$ angles of 96.3 and $112.5^{\circ}$

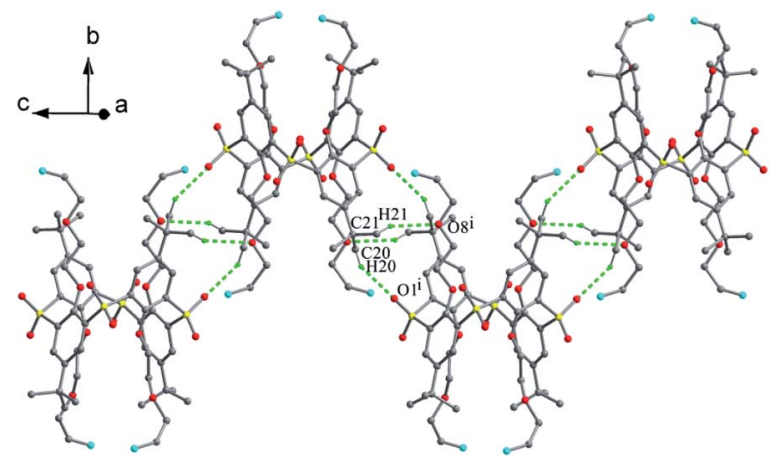

Fig. 45 A 1-D chain of 51 formed by intermolecular $\mathrm{C}-\mathrm{H} \cdots \mathrm{O} \mathrm{H}-$ bonds. 


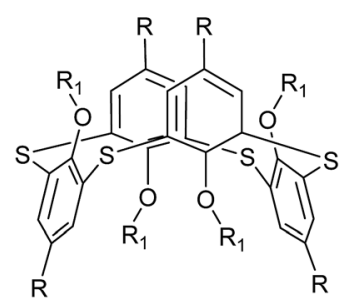

$$
\begin{aligned}
& \text { 52, } \mathrm{R}=t-\mathrm{Bu}, \mathrm{R}_{1}=\mathrm{Me} \\
& \text { 53, } \mathrm{R}=\mathrm{H}, \mathrm{R}_{1}=\mathrm{Me} \\
& \text { 54, } \mathrm{R}=t-\mathrm{Bu}, \mathrm{R}_{1}=\left(\mathrm{CH}_{2}\right)_{3} \mathrm{CN}
\end{aligned}
$$

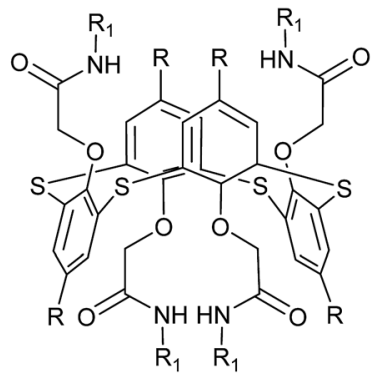

55, $\mathrm{R}=t-\mathrm{Bu}, \mathrm{R}_{1}=\mathrm{NH}_{2}$ 56, $\mathrm{R}=\mathrm{H}, \mathrm{R}_{1}=\mathrm{PhCH}=\mathrm{N}$ $57, \mathrm{R}=t-\mathrm{Bu}, \mathrm{R}_{1}=3$-pyridyl 58, $\mathrm{R}=t-\mathrm{Bu}, \mathrm{R}_{1}=4$-pyridyl
Fig. 46 Structures of compounds 52-58.

when crystallization from bulky solvents such as $\mathrm{Me}_{2} \mathrm{CHOH}$ or $p$-xylene as they cannot accommodate within the channels (Fig. 47b). However, upon crystallization from different solvents, molecule 53 gives a mixture of cone and 1,3-alternate conformers $(3: 1)$ rather than a single one (Fig. 47c). This difference can be ascribed to the loss of $t$-butyl groups. In the packing (Fig. 48), an infinite channel is constructed with regularly alternating cone and 1,3-alternate conformers via a combination of $\mathrm{C}-\mathrm{H} \cdots \pi$ and $\pi-\pi$ contacts. It should be noted that the methoxy groups are too small to block the conformational interconversion because of the absence of any $\mathrm{H}$-bonds and efficient sterical hindrance.

Molecule 54 (Fig. 46), ${ }^{61}$ a thiacalix[4] arene derivative functionalized with four cyanopropyl groups, adopts a 1,3-alternate conformation with four $\theta$ angles ranging from 110.1 to $122.9^{\circ}$ (Table 2). An intramolecular $\mathrm{C}-\mathrm{H} \cdots \mathrm{N}$ H-bond is yielded between $\mathrm{CN}$ and $\mathrm{OCH}_{2}$ units in the same arm (Fig. 49a). In the packing, a 2-D network is produced by the combination of intermolecular $\mathrm{C}-\mathrm{H} \cdots \mathrm{N}$ and $\mathrm{C}-\mathrm{H} \cdots \mathrm{S}$ H-bonds between vicinal molecules (Fig. 50). In addition, the $\mathrm{CHCl}_{3}$ molecules are packed in the crystal by $\mathrm{C}-\mathrm{H} \cdots \mathrm{N}$ H-bonds.

Thiacalix[4] arene 55 (Fig. 46), ${ }^{62}$ bearing four hydrazide arms, gives a 1,3-alternate conformation with four $\theta$ values from 108.3 to $124.7^{\circ}$ (Table 2). One of the hydrazide arms on each side directs into the cavity and creates an intramolecular $\mathrm{N}-\mathrm{H} \cdots \mathrm{O} \mathrm{H}-$ bond with the adjacent ether $\mathrm{O}$ atom (Fig. 49b). Thus, the $\mathrm{H}_{2} \mathrm{O}$ molecule locates outside the cavity. In the packing, a centrosymmetric dimer is produced by cooperative N45- $\mathrm{H} 45 \cdots \mathrm{O} 30 \mathrm{H}-$

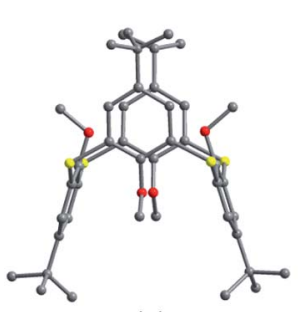

(a)

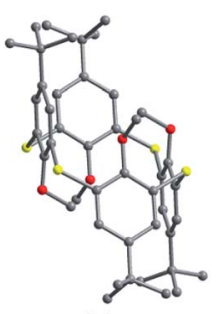

(b)

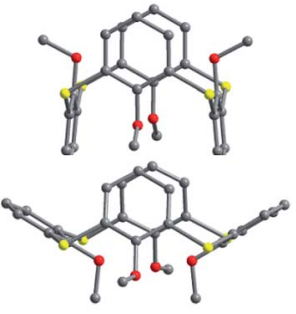

(c)
Fig. 47 Crystal structures of 52 (a) in 1,3-alternate, (b) in 1,2-alternate, and 53 (c) in cone and 1,3-alternate.

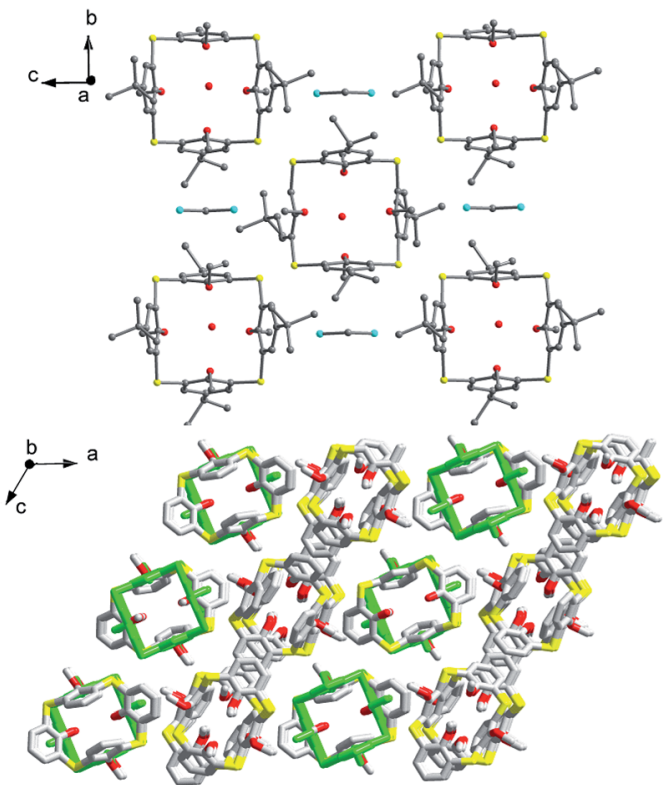

Fig. 48 Partial packing structures of 52 (top) with $\mathrm{CH}_{2} \mathrm{Cl}_{2}$ and $\mathrm{H}_{2} \mathrm{O}$, and 53 (bottom) with cone and 1,3-alternate (green) conformers (3:1).

bonds (Fig. 51). Then such dimers associate into molecular layers with $\mathrm{H}_{2} \mathrm{O}$ bridges linked by $\mathrm{O}-\mathrm{H} \cdots \mathrm{O}$ H-bonds.

Compound 56 (Fig. 46), ${ }^{50}$ a derivative by replacing four pyridyl units of 39 (Fig. 28) with phenyl groups, adopts a 1,3alternate conformation with four similar $\theta$ values (Table 2) rather than a pinched cone conformation in 39. Although both compounds could interchange their conformations owing to removal of $t$-butyl groups, only 39 keeps a pinched cone conformer due to the hindrance of intermolecular $\mathrm{N}-\mathrm{H} \cdots \mathrm{O}$ and $\mathrm{O}-\mathrm{H} \cdots \mathrm{N} \mathrm{H}$-bonds between two vicinal arms with a $\mathrm{MeOH}-$

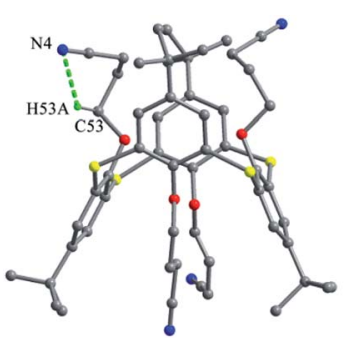

(a)

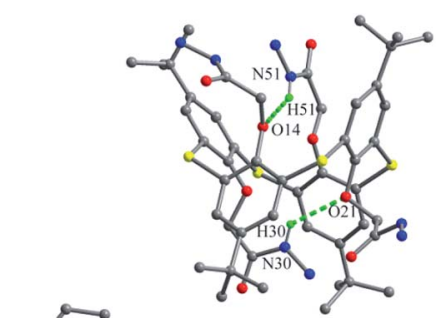

(b)

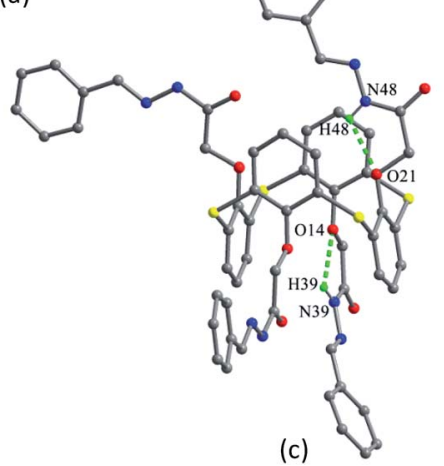

Fig. 49 Crystal structures of 54 (a), 55 (b) and 56 (c) showing intramolecular $\mathrm{H}$-bonds. 


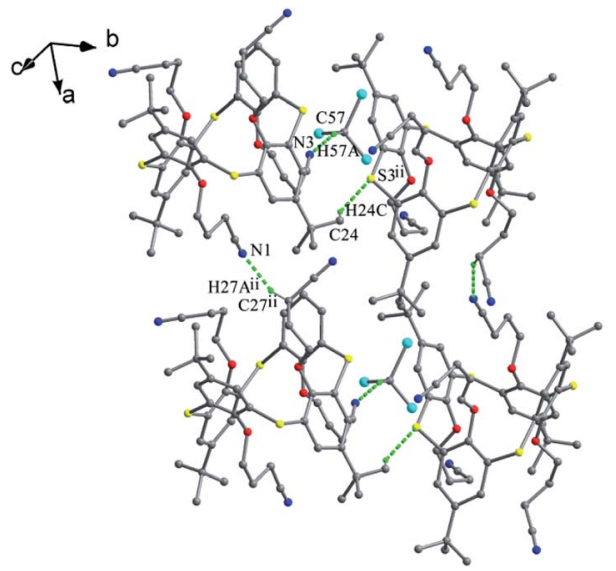

Fig. 50 Partial packing structure of 54 , showing intermolecular $\mathrm{H}$ bonds.

bridge. For 56 (Fig. 49c), only two intramolecular $\mathrm{N}-\mathrm{H} \cdots \mathrm{O} \mathrm{H}-$ bonds are formed in the same arm. In the packing (Fig. 52), an infinite molecular chain is produced by intermolecular N58$\mathrm{H} 58 \cdots \mathrm{O} 48 \mathrm{H}$-bonds between the $\mathrm{NH}$ and $\mathrm{C}=\mathrm{O}$ groups. These chains are associated in parallel way into a 3-D network bridged by $\mathrm{H}_{2} \mathrm{O}$ molecules, where four vicinal thiacalix[4]arene molecules are interlinked via hard $\mathrm{H}$-bonds involving two $\mathrm{NH}$ and two $\mathrm{C}=\mathrm{O}$ groups, as well as a pair of $\mathrm{H}_{2} \mathrm{O}$ molecules.

In some 1,3-alternate thiacalix[4]arenes bearing heterocyclic rings, the hetero atoms can play an additional acceptor to yield H-bonds and complex metal ions. Thiacalix[4] arenes 57 and $\mathbf{5 8}$ (Fig. 46), ${ }^{63}$ anchoring isomeric pyridine rings by amide linkage, display a 1,3-alternate conformation. Both molecules can bind $\mathrm{Ag}^{+}$ion selectively in solution, while the binding efficiency is influenced by the structures of aminopyridyl pendent arms, the former shows a better extraction capacity. In the solid state, it was found that they give the similar thiacalix[4] arene shape with four $\theta$ values from 101.9 to 118.4 , and 98.2 to $112.9^{\circ}$ (Table 2), respectively. However, their whole molecular structures are much more asymmetrical because of the spatial different outspread of the flexible side chains. And the most significant

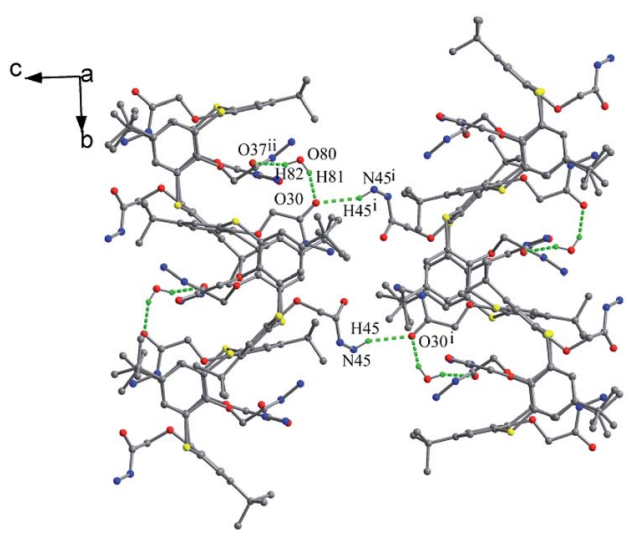

Fig. 51 Partial packing structure of 55, showing a centrosymmetric dimer and molecular layers.
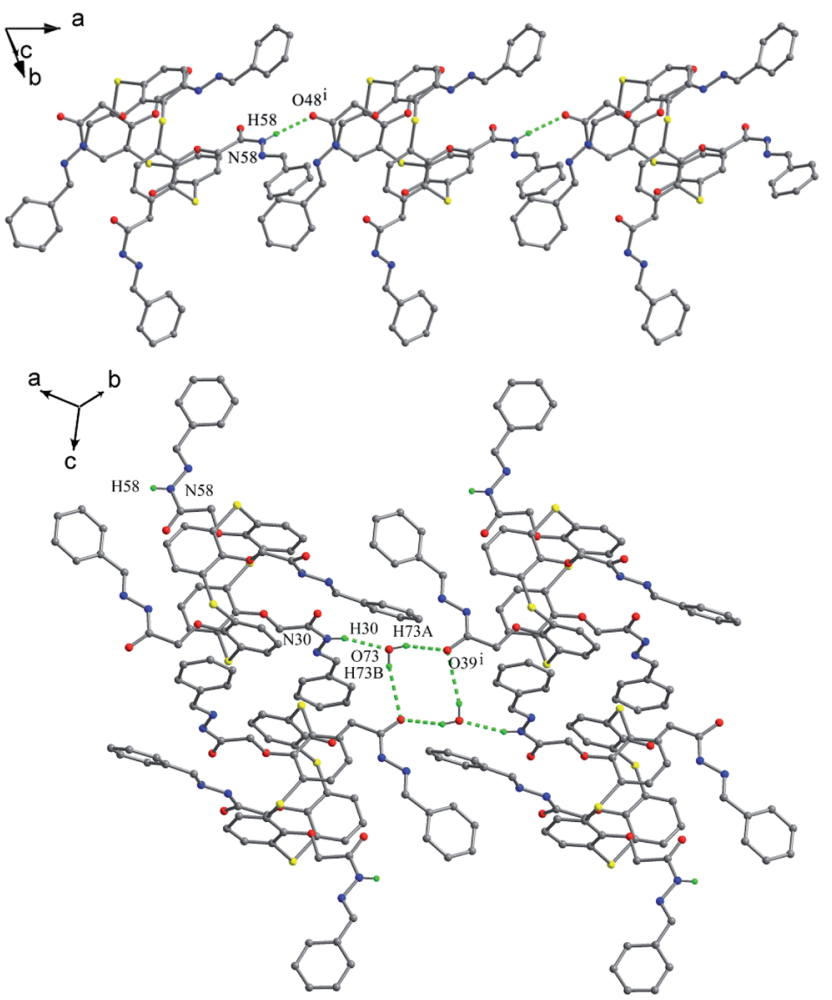

Fig. 52 Partial packing structure of 56 , showing an infinite molecular chain (top), and a tetramer linked with two water molecules (bottom).

difference between them is the orientation of aminopyridyl side chains, ascribed to the differing position of pyridyl moiety connecting to the $\mathrm{NH}$ moiety.

For 57 (Fig. 53), it's favored to form intramolecular hard $\mathrm{H}$ bonds between the $\mathrm{N}$ atoms of $m$-pyridyl rings and the facing $\mathrm{NH}$ units of amide groups, while no such hard intermolecular $\mathrm{H}$-bonds were found between the vicinal molecules as all the amide $\mathrm{NH}$ groups bury in the cavity of thiacalix[4] arene. Only intermolecular $\mathrm{C}-\mathrm{H} \cdots \pi$ and $\mathrm{C}-\mathrm{H} \cdots \mathrm{O}$ contacts were observed, creating a 1-D chain in a side-by-side mode (Fig. 54). Then a double stranded chain is yielded by inter-chain C62-H62 $\cdots \mathrm{O} 6$ $\mathrm{H}$-bonds between $\mathrm{OCH}_{2}$ units of one strand and carbonyl $\mathrm{O}$ atoms of the other strand. Eventually, these double stranded chains are linked by $\mathrm{MeOH}$ solvent molecules in the crystal lattice.

In comparison, there is no corresponding intramolecular $\mathrm{H}$ bond existed in $\mathbf{5 8}$ because of the pyridyl $\mathrm{N}$ atom at the $p$ position rather than the $m$-position, orienting outwards the cavity (Fig. 53). As a result, the amide $\mathrm{N}$ atoms are available for contacts with the pyridyl $\mathrm{N}$ atoms of adjacent molecules. As shown in Fig. 55, individual molecules of $\mathbf{5 8}$ are in a side-by-side orientation, yielding a $1-\mathrm{D}$ chain by intermolecular $\mathrm{N} 7-\mathrm{H} 7 \cdots \mathrm{N} 4$ $\mathrm{H}$-bonds. With the help of $\mathrm{H}_{2} \mathrm{O}$ molecules, two strips of the resulting 1-D chains are further augmented to a water-bridged double strand.

Thiacalix[4]bis-crown analogue 59 (ref. 64) (Fig. 56) takes a 1,3-alternate conformation with four quite similar $\theta$ angles (Table 2) and shows two fold rotation symmetry with an cagelike cavity. All four $\mathrm{N}-\mathrm{H}$ bonds of both amide bridges are 

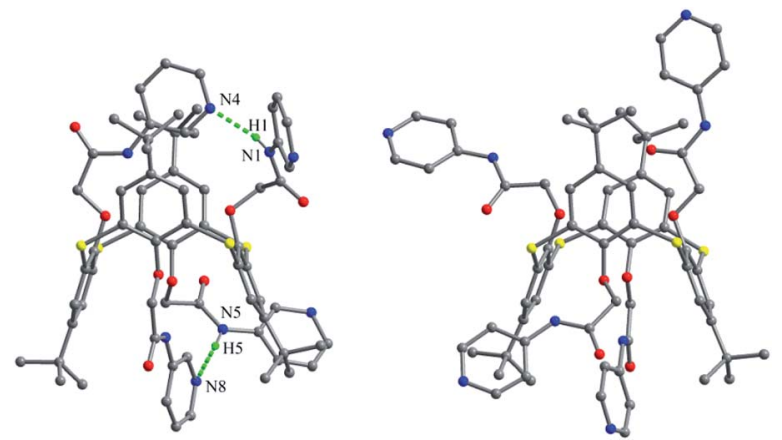

Fig. 53 Crystal structures of 57 (left) and 58 (right).
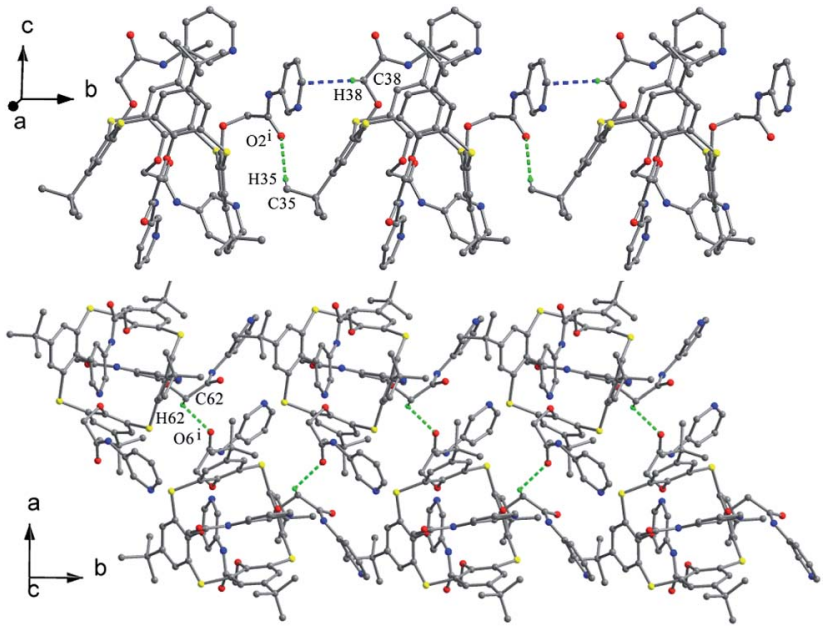

Fig. 54 Partial packing structures of 57 showing a 1-D chain (top), and a double stranded chain (bottom).

oriented into the calix cavity and generate intramolecular $\mathrm{H}^{-}$ bonds to all ether $\mathrm{O}$ atoms.

Thiacalix[4]arenes 60 and 61 (Fig. 57), ${ }^{65}$ with four thiadiazole termini, both give a 1,3-alternate conformation with similar $\theta$

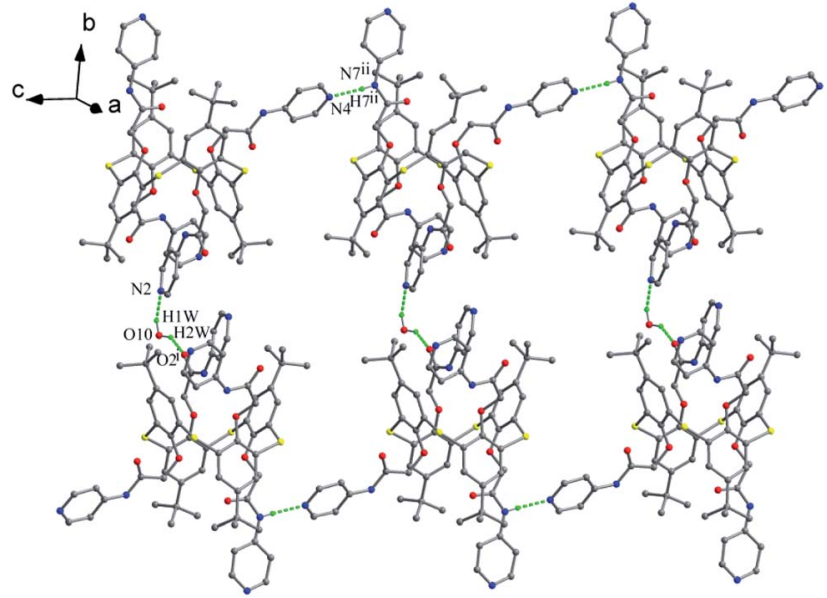

Fig. 55 Partial packing structure of 58, showing water-bridged double strand.
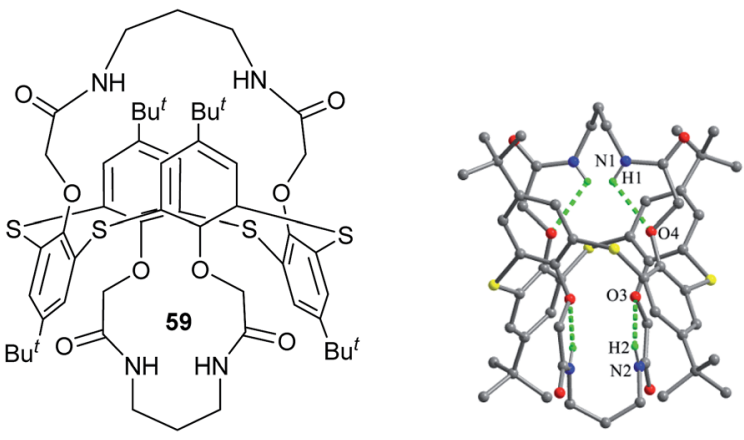

Fig. 56 Chemical and crystal structures of compound 59, showing $\mathrm{H}$ bonds.

angles (Table 2). In the solid state, a couple of opposite thiadiazole rings is nearly parallel to each other, while the other couple is perpendicular mutually (Fig. 58), forming dihedral angles of $10.9,77.3^{\circ}$ for 60 and $25.0,82.0^{\circ}$ for 61 . In the packing, molecule 60 creates a 1-D chain by weak $\mathrm{C} 50-\mathrm{H} 50 \cdots \mathrm{N} 4$ and C60-H60 $\cdots \mathrm{N} 5$ interactions between two thiadiazole rings of adjacent molecules (Fig. 59). These chains are further extended into a 2-D network by inter-chain $\mathrm{S} \cdots \mathrm{S}$ contacts between $\mathrm{S}$ atoms in the thiadiazole rings and 2-positional mercapto $\mathrm{S}$ atoms. Eventually, the 2-D networks are assembled into a 3-D supramolecular structure with the lattice water dimers through $\mathrm{O}-\mathrm{H} \cdots \mathrm{S}$ H-bonds. In the packing of 61 (Fig. 59), two molecules are connected into a dimer by two intermolecular $\mathrm{C}-\mathrm{H} \cdots \mathrm{S}$ contacts between the methylene $\mathrm{H}$ atom and the $\mathrm{S}$ atom in the thiacalix[4]arene unit. These dimers are further linked into a 1$\mathrm{D}$ chain by $\mathrm{S} \cdots \mathrm{S}$ contacts between the same $\mathrm{S}$ atoms linked to the thiadiazole rings of vicinal molecules. Afterwards, these 1-D chains are assembled into a 2-D network with the methanol dimers via $\mathrm{C}-\mathrm{H} \cdots \mathrm{N}$ and $\mathrm{C}-\mathrm{H} \cdots \mathrm{O}$ H-bonds.

Compound 62 (Fig. 57), ${ }^{66}$ possessing four polyether arms ended with the $4-\mathrm{NO}_{2} \mathrm{C}_{6} \mathrm{H}_{4}$ unit, crystallizes in a typical 1,3-

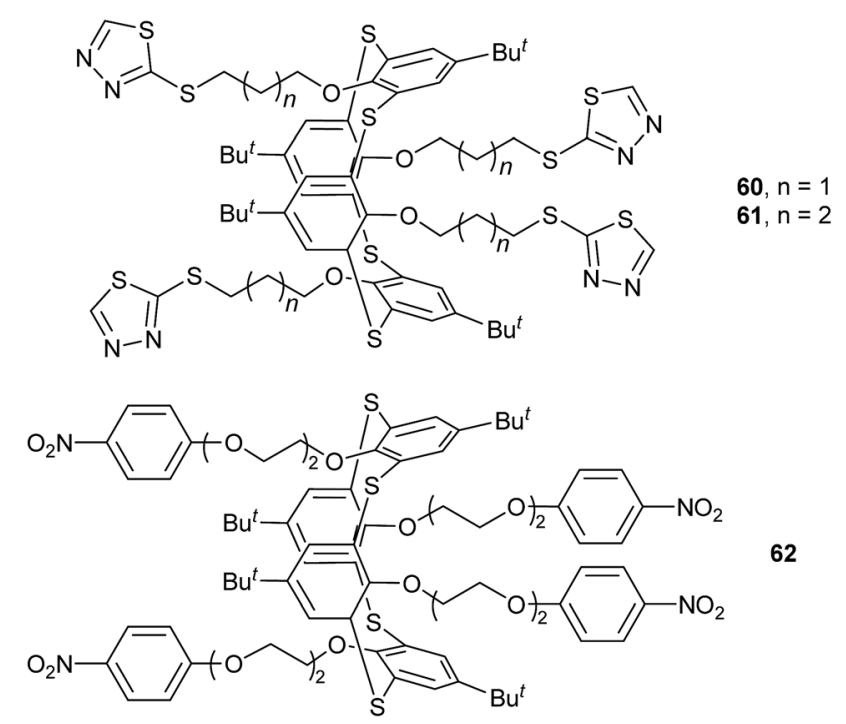

Fig. 57 Structures of compounds 60-62. 

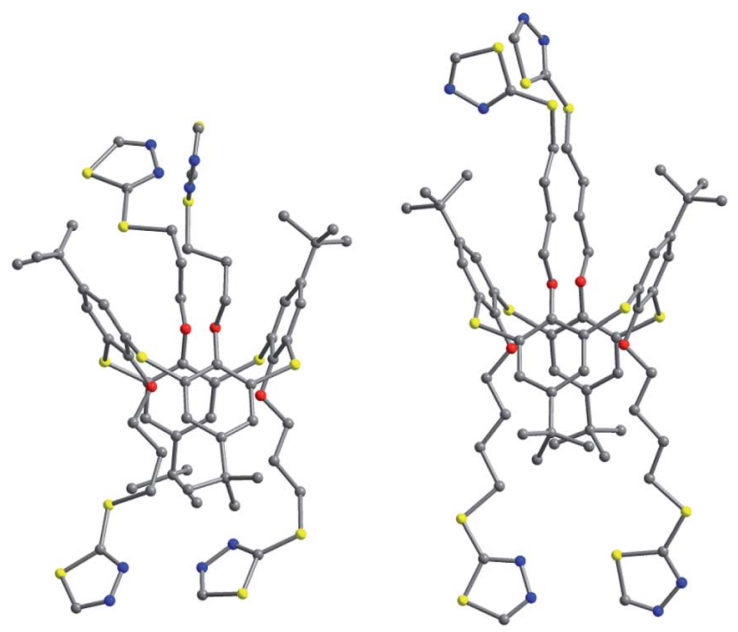

Fig. 58 Crystal structures of 60 (left) and 61 (right).

alternate conformation with two pairing $\theta$ angles of 91.2 and $92.2^{\circ}$, where the four polyether arms are distorted outboard of the cavity. The terminal benzene rings are nearly parallel to the $R$ plane, with interplanar angles of 14.09 and 9.05. In the packing, a 2-D array composed of the rare cyclic thiacalix[4] arene tetramers with an eighty-membered ring motif (Fig. 60) is formed by a combination of intermolecular $\mathrm{C}-\mathrm{H} \cdots \mathrm{O}$ H-bonds. These arrays are further linked into a complex 3-D framework through interlayer $\mathrm{C}-\mathrm{H} \cdots \mathrm{S} \quad \mathrm{H}$-bonds and aromatic $\pi-\pi$ interactions.
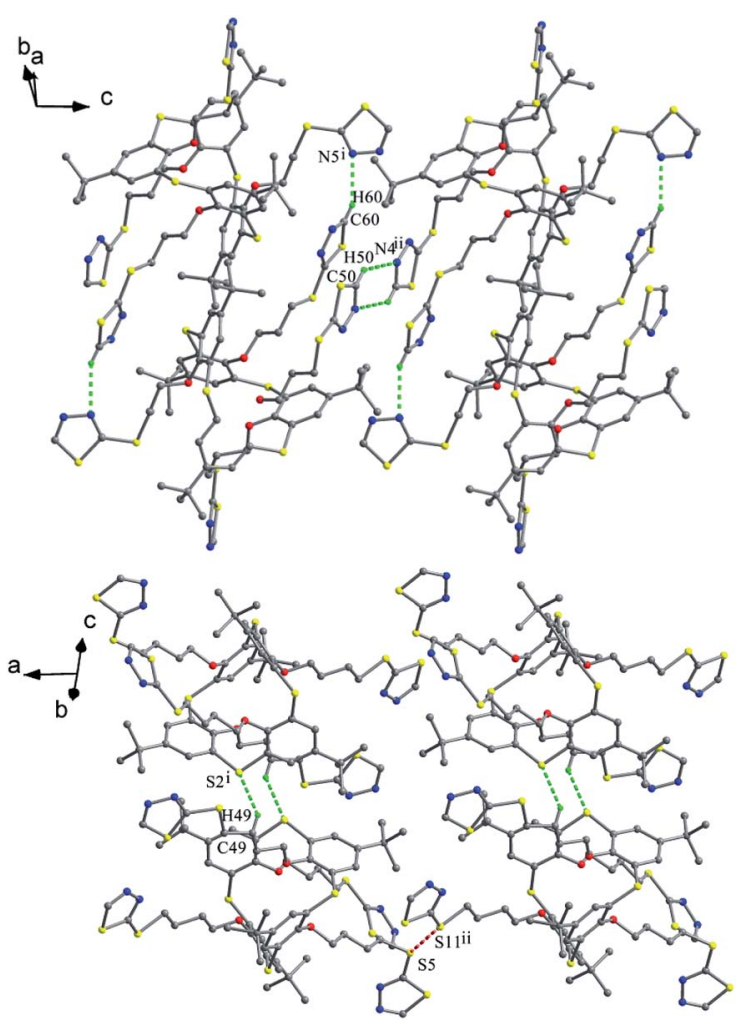

Fig. 59 Partial packing structures of 60 (top) and 61 (bottom), both showing a 1-D chain.

\section{3 $O$-Heterosubstituted thiacalix[4]arenes}

$O$-Heterosubstituted thiacalix[4]arenes are usually obtained by appending four different substituents at the lower rim via multiple steps. Compounds 63 and 64 (Fig. 61), ${ }^{67}$ synthesized by selective hydrolysis of tetraester thiacalix[4]arene derivatives, possess both $\mathrm{CO}_{2} \mathrm{H}$ and $\mathrm{CO}_{2}$ Et groups and take a 1,3-alternate conformation with two pairing $\theta$ angles of 103.9 and $104.6^{\circ}$, and four similar ones from 83.5 to $88.8^{\circ}$, respectively (Table 2 ). In the crystal structure of $\mathbf{6 3}$ (Fig. 62), one molecule $\mathrm{H}_{2} \mathrm{O}$ lies in the calix cavity and forms two $\mathrm{H}$-bonds with two $\mathrm{CO}_{2} \mathrm{H}$ groups. In the packing, a zigzag chain of $\mathbf{6 3}$ is apparent by intermolecular $\mathrm{O}-\mathrm{H} \cdots \mathrm{O}$ H-bonds, locally creating a four-membered ring motif between the carboxyl OH groups (Fig. 63). However, for 64, a dimeric structure is generated via four intermolecular $\mathrm{O}-\mathrm{H} \cdots \mathrm{O} \mathrm{H}$-bonds between $\mathrm{CO}_{2} \mathrm{H}$ groups, locally yielding two eight-membered ring motifs (Fig. 63).

Thiacalix[4]arene derivative 65 (ref. 68) (Fig. 61) contains both amide and ester groups. It has a 1,3-alternate conformation with four $\theta$ angles from 97.1 to $114.7^{\circ}$ (Table 2). In the solid state, it is clear that the orientations of the carbonyl $\mathrm{O}$ atoms of esters are outwardly orientated with respect to the cavity because of the electronic repulsion between $\mathrm{O}$ atoms. Interestingly, two intramolecular $\mathrm{N}-\mathrm{H} \cdots \mathrm{O} \quad \mathrm{H}$-bonds are formed (Fig. 64a): one is intra-arm type between the $\mathrm{NH}$ and ethereal $\mathrm{O}$ atom, and the other is inter-arm one between the $\mathrm{NH}$ and amide $\mathrm{O}$ atom. In solution, 65 can bind $\mathrm{K}^{+}$ion, while its structural symmetry has not been changed after complexation.

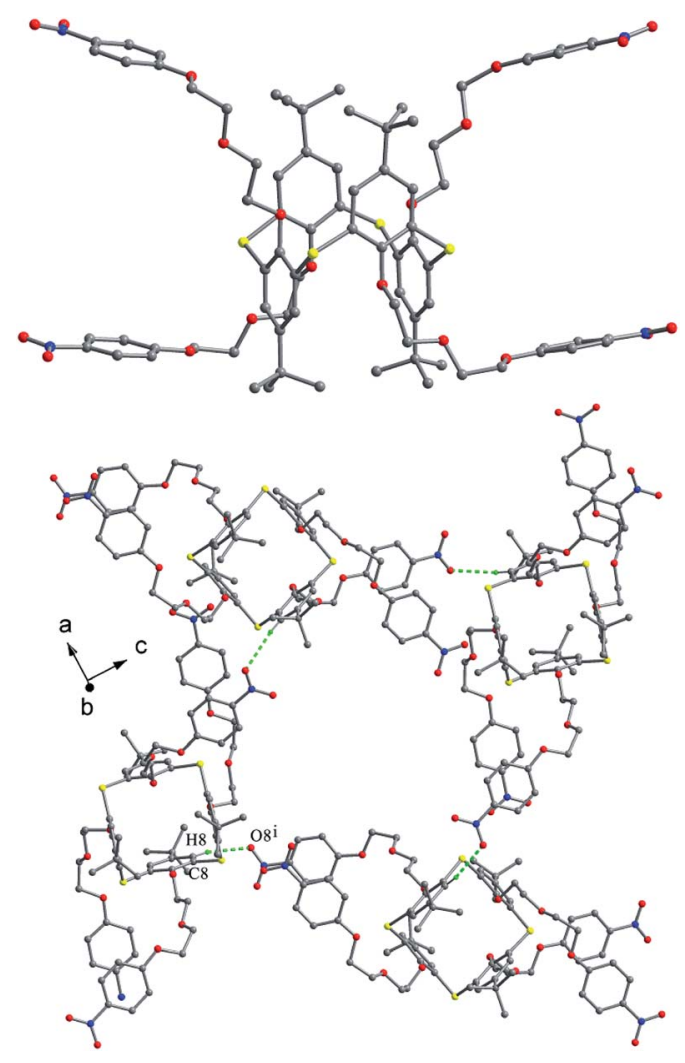

Fig. 60 Crystal structure of 62 (top) and its tetramer (bottom). 


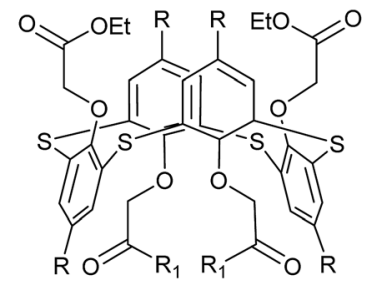

63, $\mathrm{R}=t-\mathrm{Bu}, \mathrm{R}_{1}=\mathrm{OH}$

64, $\mathrm{R}=\mathrm{H}, \mathrm{R}_{1}=\mathrm{OH}$

65, $\mathrm{R}=t-\mathrm{Bu}, \mathrm{R}_{1}=p-\mathrm{MeC}_{6} \mathrm{H}_{4} \mathrm{CH}_{2} \mathrm{NH}$

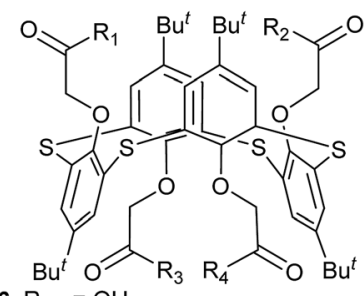

66, $\mathrm{R}_{1-4}=\mathrm{OH}$

67, $\mathrm{R}_{1-2}=\mathrm{NHCONH}_{2}, \mathrm{R}_{3-4}=\mathrm{OH}$

69, $\mathrm{R}_{1-3}=\mathrm{NHCONH}_{2}, \mathrm{R}_{4}=\mathrm{OH}$

70, $\mathrm{R}_{1-4}=\mathrm{NHCONH}_{2}$
68, $\mathrm{R}_{1}=\mathrm{R}_{3}=\mathrm{NHCONH}_{2}, \mathrm{R}_{2}=\mathrm{R}_{4}=\mathrm{OH}$

Fig. 61 Structures of compounds 63-70.

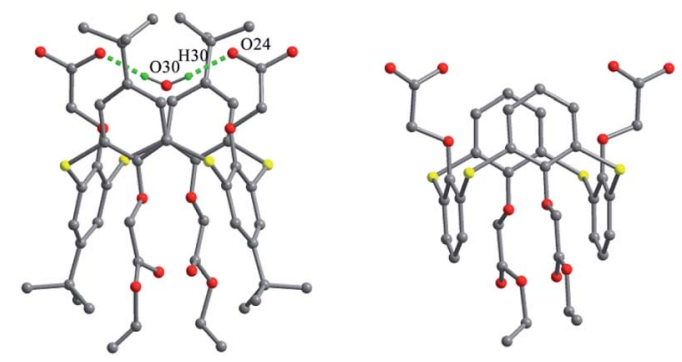

Fig. 62 Crystal structures of 63 (left) and 64 (right).

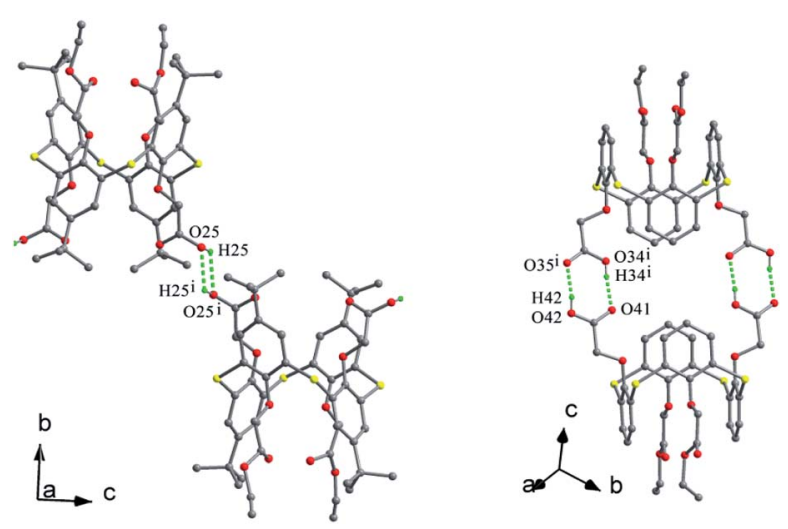

Fig. 63 Partial packing structures of 63 (left) and 64 (right), showing different $\mathrm{H}$-bonded ring motifs.

Thiacalix[4]arene derivatives 66-70 (Fig. 61), ${ }^{15}$ functionalized with $\mathrm{CO}_{2} \mathrm{H}$ and/or $\mathrm{CONHCONH}_{2}$ groups, are all in a 1,3-alternate conformation with four similar $\theta$ values except for $\mathbf{6 8}$ with two pairing $\theta$ angles of 104.2 and $116.5^{\circ}$ (Table 2). For 66 (Fig. 64b), there is no intramolecular $\mathrm{H}$-bond between the two opposing arms, but two $\mathrm{H}_{2} \mathrm{O}$ molecules occupy the cavities made by two pairs of facing aromatic rings and create intermolecular $\mathrm{H}$-bonds with the $\mathrm{CO}_{2} \mathrm{H}$ groups. For the other molecules, there are various intra- and inter-arm hard H-bonds owing to the presence of urea units. In the structures of $\mathbf{6 8}$ (Fig. 64c) and 70 (Fig. 64d), for instance, each urea group yields two different intra-arm $\mathrm{N}-\mathrm{H} \cdots \mathrm{O}$ H-bonds with $\mathrm{O}$ atoms of $\mathrm{CH}_{2} \mathrm{CO}$ and ether moieties, respectively. Moreover, there are inter-arm $\mathrm{O}-\mathrm{H} \cdots \mathrm{O}$ and $\mathrm{N}-\mathrm{H} \cdots \mathrm{O}$ H-bonds between two opposing

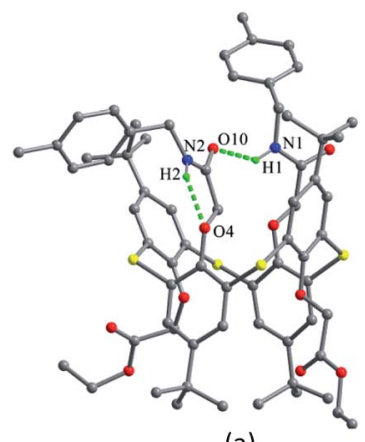

(a)

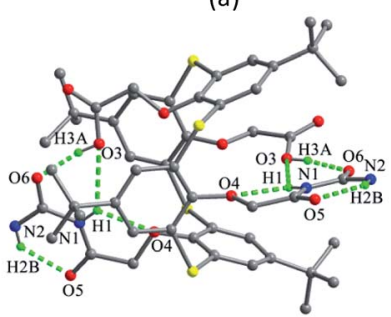

(c)

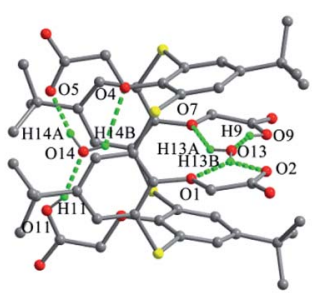

(b)

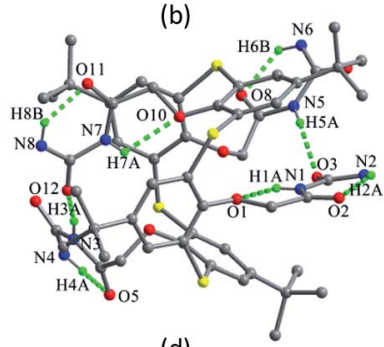

(d)
Fig. 64 Crystal structures of 65 (a), 66 (b), 68 (c) and 70 (d), showing the intra- and inter-arm $\mathrm{H}$-bonds.

arms. For these molecules, the main difference is the spatial orientations of their arms. When two urea arms locate on the same side, they direct outwards due to the steric repulsion, while there are one urea arm and one $\mathrm{CO}_{2} \mathrm{H}$ group on the same side, they orientate inwards because of their inter-arm $\mathrm{H}$-bonds.

In the packing of these compounds, the types of H-bonds between vicinal arms play an important role in the assemblies. For instance, two molecules of 67 create a dimer by N4$\mathrm{H} 4 \mathrm{~A} \cdots \mathrm{O} 3$ and $\mathrm{N} 4-\mathrm{H} 4 \mathrm{~B} \cdots \mathrm{O} 8 \mathrm{H}$-bonds. These dimers are interlinked to produce a 1-D double-stranded linear chain by the combination of $\mathrm{N} 3-\mathrm{H} 3 \cdots \mathrm{O} 12$ and $\mathrm{O} 11-\mathrm{H} 11 \cdots \mathrm{O} 9 \mathrm{H}$-bonds (Fig. 65). While in the case of 68, a 1-D single-stranded linear chain is formed via $\mathrm{N} 2-\mathrm{H} 2 \cdots \mathrm{O} 2 \mathrm{H}$-bonds (Fig. 65). Moreover, self-assemble also depends on the spatial orientation of pendant arms. Through the cavity stacking fashion, only $\mathbf{6 6}$ can give nanotubes, in which the four pendant arms orient along the basic axis of the molecule. For the others, the inwardly orientated pendant arms obstruct the channel formation owing to protruding into the calix cavity.

Thiacalix[4] arenes 71 and 72 (Fig. 66), ${ }^{69}$ modified with thiourea or urea groups, both adopt a 1,3-alternate conformation but have different symmetry. Molecule 71 shows crystallographic $C_{2}$-symmetry with two pairing $\theta$ angles of 86.3 and $88.2^{\circ}$. Two pairs of facing phenolic rings exhibit approximately parallel orientations, forming interplanar angles of 3.7 and $7.4^{\circ}$. However, molecule $\mathbf{7 2}$ is asymmetrical with four different $\theta$ angles (Table 2). Two couples of opposite phenolic rings are not parallel, creating interplanar angles of $42.1^{\circ}$ and $44.7^{\circ}$. In 71 (Fig. 67a), two thiourea groups are far away from each other since two $t$-butyl groups fill in the space between them, while two urea units of $\mathbf{7 2}$ locate closely in a parallel way and thus create an intramolecular H-bond between them as two $t$-butyl groups are apart away (Fig. 67b). These differences may be attributed to the varied fashions of $N, N^{\prime}$-disubstituted thiourea 

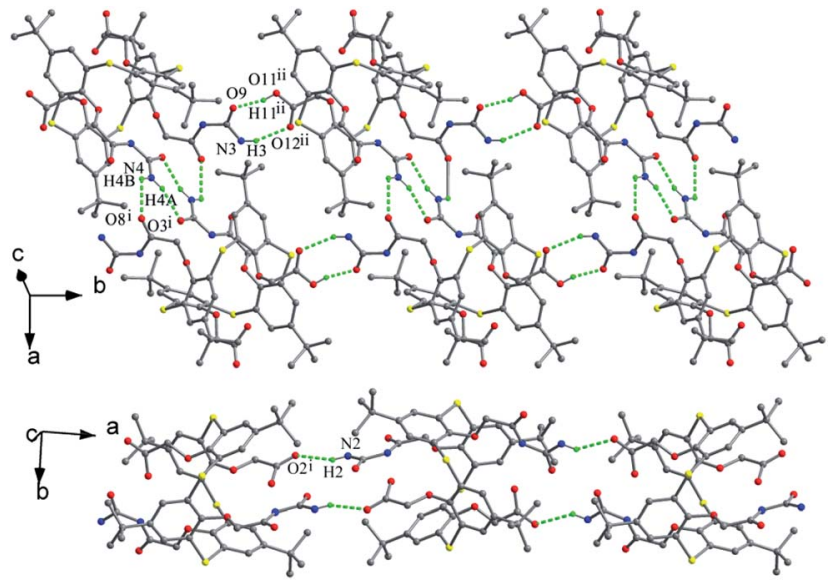

Fig. 65 Partial packing structures of 67 (top) showing a 1-D doublestranded chain and 68 (bottom) displaying a 1-D single-stranded chain.
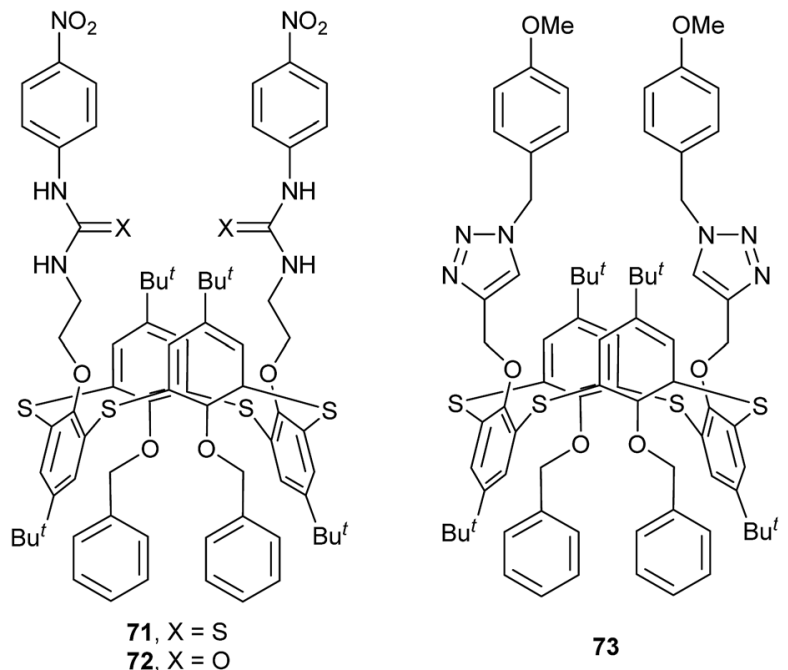

Fig. 66 Structures of compounds 71-73.

$(E, Z)$ and urea $(Z, Z)$, which distort the macrocycle in different manners, thus yielding diverse spatial orientations of these groups. The other important factor is that the thiourea $\mathrm{S}$ atoms have lower $\mathrm{H}$-bond accepting ability than the urea $\mathrm{O}$ atoms. In solution, both compounds could be used as potential receptors for anion recognition, but show poor selectivity.

Thiacalix[4]arene 73 (Fig. 66), ${ }^{70}$ appending two 1,2,3-triazole bridged arms, takes a 1,3-alternate conformation with four $\theta$ values from 92.5 to $107.4^{\circ}$ (Table 2) (Fig. 67c). In addition, two 1,2,3-triazole rings are nearly parallel to each other with a dihedral angle of $3.0^{\circ}$. In the packing, a 1-D chain is produced by $\mathrm{C}-\mathrm{H} \cdots \mathrm{N} \mathrm{H}$-bonds between two 1,2,3-triazole rings of adjacent molecules (Fig. 68).

Thiacalix[4]crown derivatives 74 (ref. 71) and 75 (ref. 72) (Fig. 69) both show a 1,3-alternate conformation with four similar $\theta$ angles (Table 2). In the unit cell of $\mathbf{7 4}$ (Fig. 70), there are two thiacalix[4]arene molecules $\mathbf{A}$ and $\mathbf{B}$, in which it was

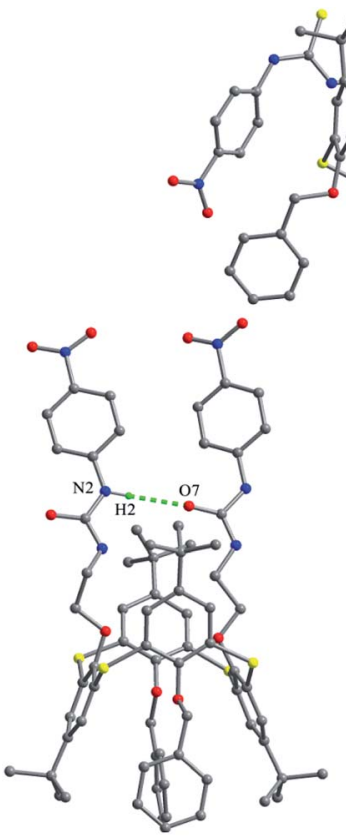

(b)

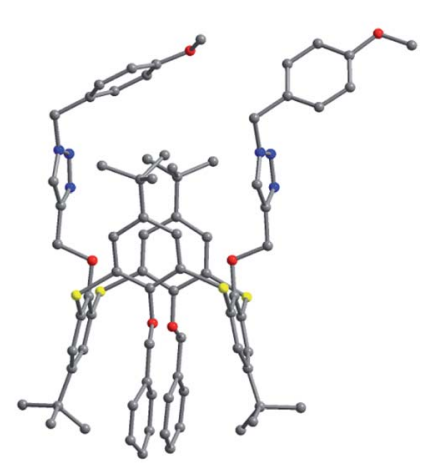

(c)
Fig. 67 Crystal structures of 71 (a), 72 (b) and 73 (c).

found that all three $\mathrm{NH}$ units of one chain act as a donor to form four intermolecular $\mathrm{N}-\mathrm{H} \cdots \mathrm{O}$ H-bonds with one urea carbonyl $\mathrm{O}$ atom of the other chain and two ether $\mathrm{O}$ atoms, and thus the two urea units approach each other in a nearly parallel orientation. In solution, compound $\mathbf{7 4}$ can be employed as a ditopic receptor for molecular recognition based on the positive and negative allosteric effects.

In the structure of 75 (Fig. 70), two phenothiazine rings show a butterfly shape and produce a weak intramolecular $\mathrm{C}-\mathrm{H} \cdots \pi$ contact. In the packing, a molecular dimer is formed by weak $\pi-$ $\pi$ stacking contacts between two face-to-face paralleled phenothiazine rings of adjacent molecules (Fig. 71). Compound 75 exhibits a strong fluorescence emission with a large Stokes shift, which can be quenched selectively by $\mathrm{Fe}^{3+}$ and $\mathrm{Cr}^{3+}$ ions in solution.

Thiacalix[4]arene derivative 76 (Fig. 69) ${ }^{73}$ functionalized with two nitrobenzofurazan (NBD) groups, crystallizes in a 1,3alternate conformation with similar $\theta$ values to $\mathbf{7 4}$ and $\mathbf{7 5}$. Interestingly, the two NBD rings, one of which faces outward yielding an $\mathrm{N}-\mathrm{H} \cdots \mathrm{S}$ H-bond, create a dihedral angle of $135.3^{\circ}$

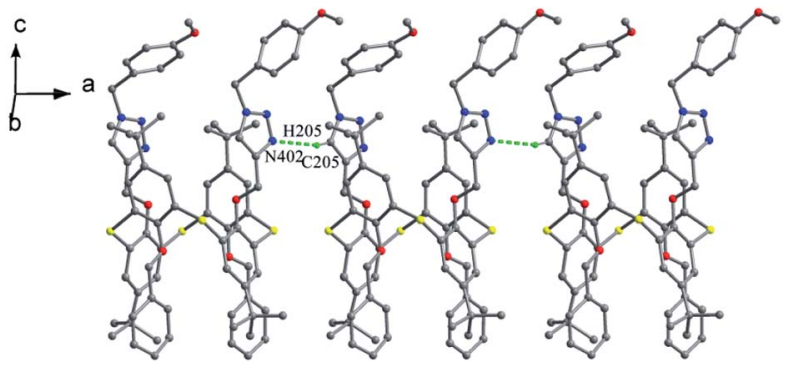

Fig. 68 Partial packing structure of 73, showing a 1-D chain. 


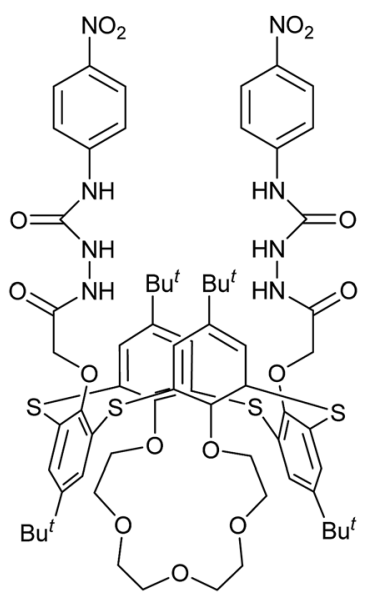

74<smiles>Cc1ccc([N+](=O)[O-])c2nonc12</smiles><smiles>O=[N+]([O-])c1cccc2nonc12</smiles>

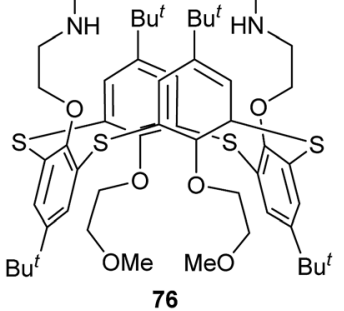

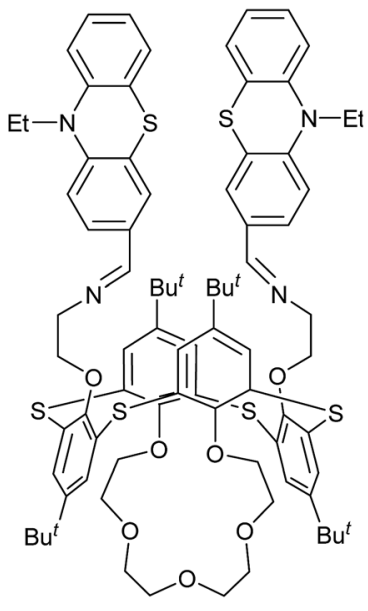

75

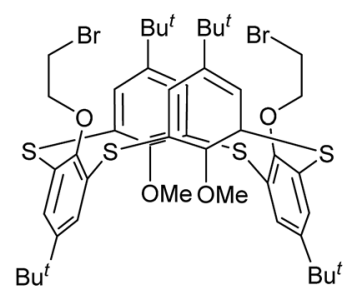

77
Fig. 69 Structures of compounds 74-77.
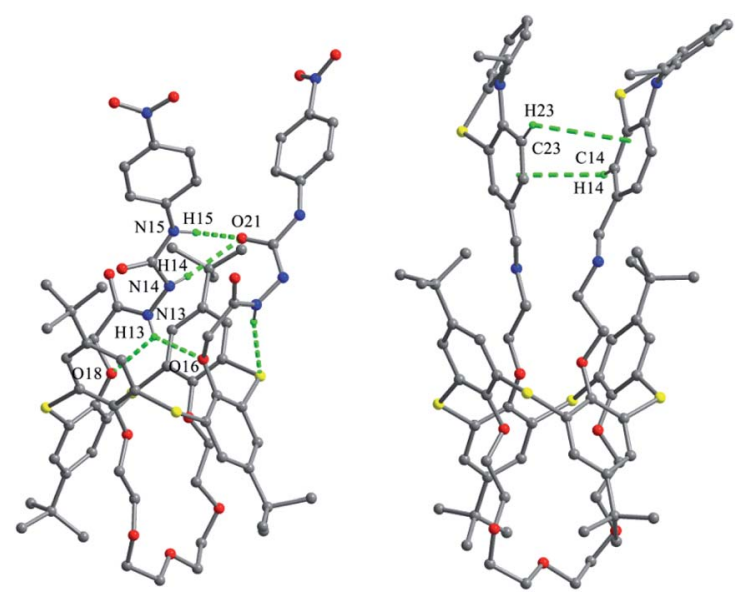

Fig. 70 Crystal structures of 74 (left) showing $\mathrm{H}$-bonds, and 75 (right) showing $\mathrm{C}-\mathrm{H} \cdots \pi$ contacts.

(Fig. 72). Due to the introduction of NBD groups, this compound can be applied as a colorimetric and fluorescence sensor for detection of $\mathrm{Ag}^{+}$and $\mathrm{AcO}^{-}$in solution.

Thiacalix[4] arene derivative 77 (Fig. 69), ${ }^{74}$ with two OMe and two $\mathrm{OCH}_{2} \mathrm{CH}_{2} \mathrm{Br}$ arms, gives a 1,3-alternate conformation with two pairing $\theta$ angles of 100.9 and $102.9^{\circ}$ (Fig. 72). In the packing, a 1-D chain based on intermolecular $\mathrm{Br} \cdots \mathrm{Br}$ contacts is

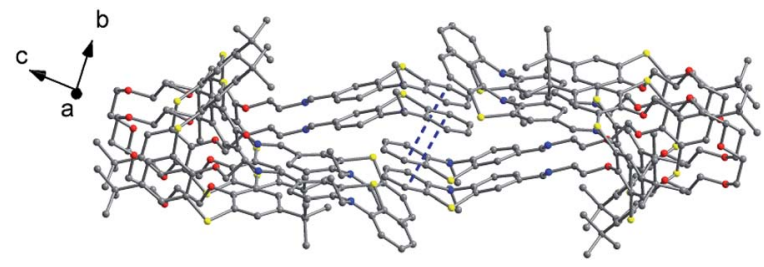

Fig. 71 Partial packing structure of 75 , showing $\pi-\pi$ stackings.

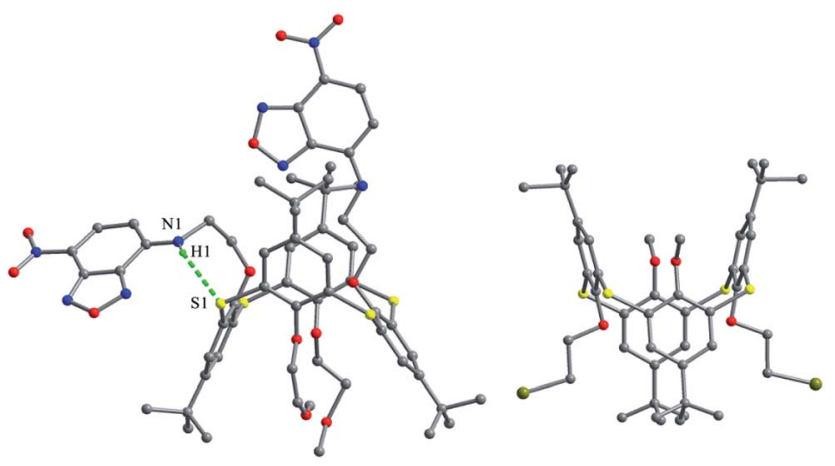

Fig. 72 Crystal structures of 76 (left) and 77 (right).

generated with an inter-halogen distance of $3.81 \AA$ (Fig. 73), which is less than the sum of the van der Waals radii.

\subsection{O/aryl mixed substituted thiacalix[4] arenes}

In some cases, chemical modification of thiacalix[4]arenes can be performed at both the lower rim and the calix aryl rings to create new type of $O$ /aryl substituted thiacalix[4]arenes. Hamada $e t$ al. have synthesized a series of such a type of thiacalix[4] arenes 78-89 (Fig. 74), ${ }^{75-78}$ and studied extensively on their halogen interactions, revealing important insights into the formation of molecular assemblies in the solid state. ${ }^{10}$ These compounds, except for 79 (see 112 in Section 5.2), all take a 1,3alternate conformation with similar $\theta$ values (Table 2), while they exhibit remarkably different assemblies due to the varied length of alkyl chain (methyl to decyl) at the lower rim.

Brominated thiacalix[4]arene 78 (Fig. 75a), with the smallest methyl groups, prefers to yield $\mathrm{Br} \cdots \pi$ contacts between distinct molecules. In its packing, symmetric expansion of molecules assembles into a layer-supramolecular structure with $\mathrm{Br} \cdots \pi$ and $\mathrm{C}-\mathrm{H} \cdots \pi$ interactions (Fig. 76). In the case of molecule 80 (Fig. 75b), bearing $n$-propyl groups, a hexameric ring (Fig. 77), with a cyclohexane molecule enclosed, is formed by combining intermolecular $\mathrm{C}-\mathrm{H} \cdots \mathrm{S} \mathrm{H}$-bonds, $\pi-\pi$ and $\mathrm{S} \cdots \pi$ interactions

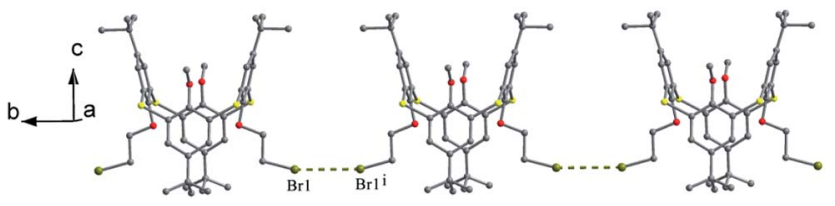

Fig. 73 Partial packing structure of 77, showing a 1-D chain based on $\mathrm{Br} \cdots \mathrm{Br}$ contacts. 


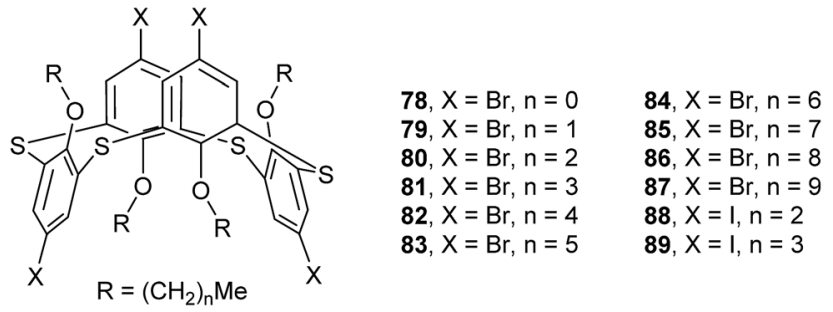

Fig. 74 Structures of compounds 78-89.

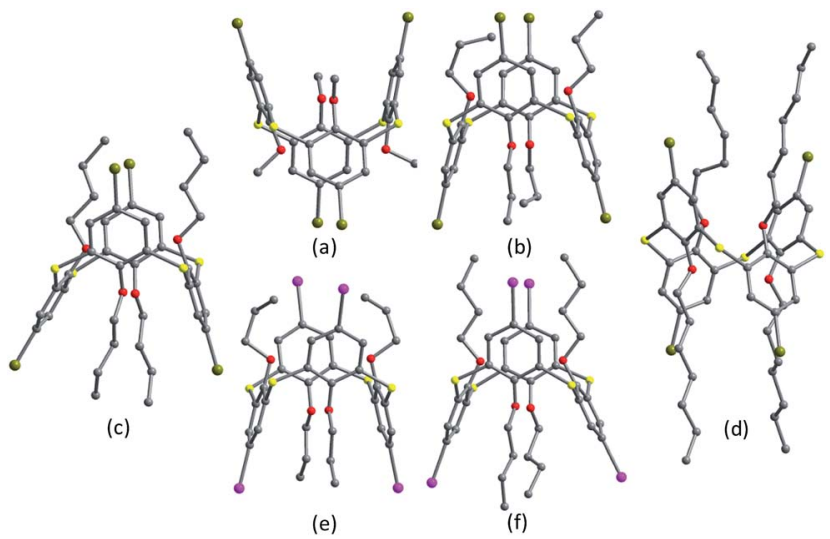

Fig. 75 Crystal structures of 78 (a), 80 (b), 81 (c), 84 (d), 88 (e) and 89 (f).

between vicinal molecules. Molecule 81 (Fig. 75c) possesses moderate $n$-butyl chains and offers a skewed 1,3-alternate conformation with a $\theta$ range of $103.1-123.0^{\circ}$, which is favored to create intermolecular $\mathrm{Br} \cdots \mathrm{Br}$ interactions in the crystalline state. Thus an infinite open-network is generated with six trimeric units through triangular $\mathrm{Br}_{3}$ motif halogen-halogen contacts and $\mathrm{C} 35-\mathrm{H} 35 \cdots \mathrm{Br} 4$ interactions (Fig. 76). However, such halogen interactions were not observed in the crystal structures of brominated thiacalix[4]arenes $\mathbf{8 0 ,} 82$ and $\mathbf{8 3}$.

In comparision, brominated thiacalix[4] arene derivatives 8487 , bearing longer chains, are favored to assemble via $\mathrm{Br} \cdots \mathrm{S}$ halogen bonding. Molecule $\mathbf{8 4}$ with larger $n$-heptyl groups

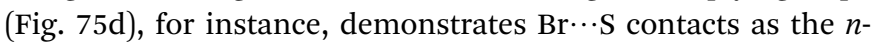
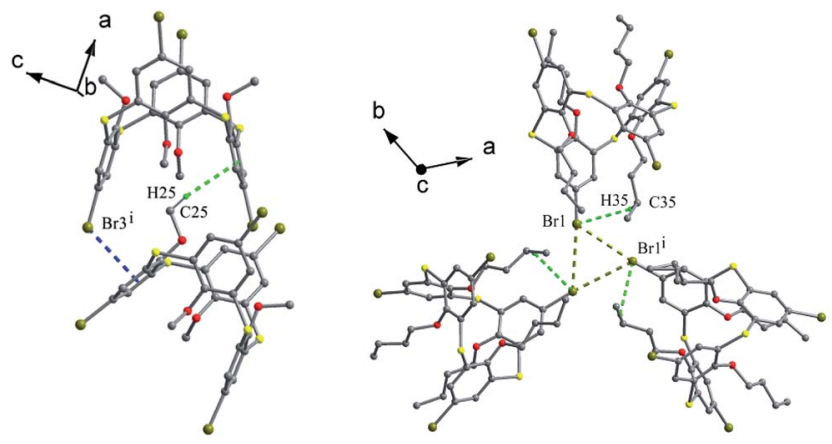

Fig. 76 A dimer of 78 (left) built by $\mathrm{Br} \cdots \pi$ and $\mathrm{C}-\mathrm{H} \cdots \pi$ contacts, and a triangular $\mathrm{Br}_{3}$ motif of 81 (right) formed by $\mathrm{Br} \cdots \mathrm{Br}$ and $\mathrm{C}-\mathrm{H} \cdots \mathrm{Br}$ interactions.

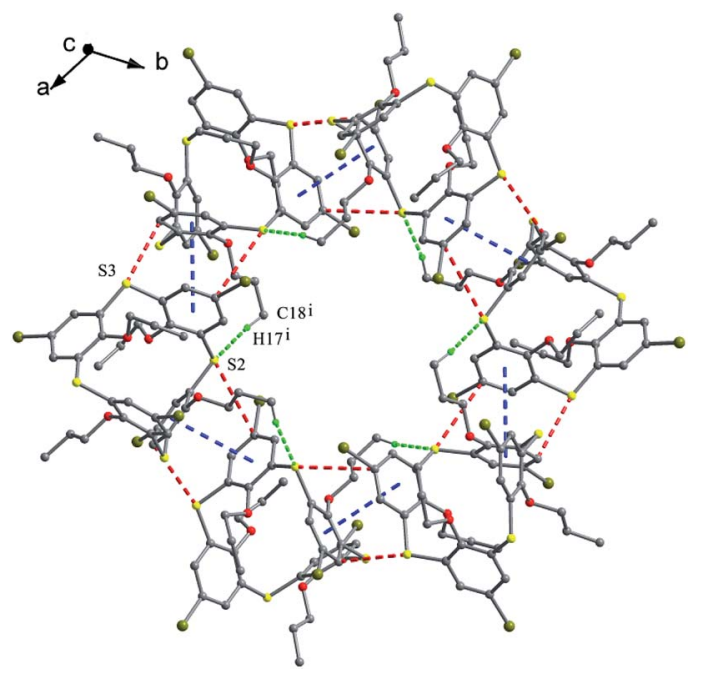

Fig. 77 A hexameric assembly of 80 , showing intermolecular $\pi-\pi$ (blue), $\mathrm{S} \cdots \pi$ (red) and $\mathrm{C}-\mathrm{H} \cdots \mathrm{S}$ (green) interactions.

heptyl chain blocks $\mathrm{Br}$ atom from interacting with other halogens or aromatic rings (Fig. 78).

Thiacalix[4]arenes 88 (Fig. 75e) and 89 (Fig. 75f) have four I atoms at the upper rim. In the packing of $\mathbf{8 8}$, intermolecular $\mathrm{I} \cdots$ $\mathrm{I}, \mathrm{S} \cdots \pi$ and $\mathrm{C}-\mathrm{H} \cdots \mathrm{I}$ interactions were demonstrated in the supramolecular assembly (Fig. 79), which is produced via preferential $\mathrm{I} \cdots \mathrm{I}$ interactions. However, in the case of $\mathbf{8 9}$, a supramolecular assembly is yielded by $\mathrm{S} \cdots \mathrm{I}$ and $\mathrm{C}-\mathrm{H} \cdots \mathrm{S}$ bonding, together with weak $\mathrm{S} \cdots \pi$ and $\mathrm{C}-\mathrm{H} \cdots \mathrm{I}$ interactions (Fig. 79). It should be noted that iodine-containing thiacalix[4] arenes have stronger interactions involving iodine than bromine as the former possesses a stronger polarizing power than the latter.

Tetrapropoxythiacalix[4]arene derivatives 90 (ref. 79) and 91 (ref. 80) (Fig. 80), mono-functionalized at the $m$-position, both exhibit a 1,3-alternate conformation with four similar $\theta$ angles (Table 2). In the packing of 90, a unique dimer is yielded through $\mathrm{Br} \cdots \pi$ interactions between bromine atoms and phenolic rings of the neighboring molecules (Fig. 81). In the case of 91, two NH units of the ureido group at the $m$-position create two asymmetric $\mathrm{H}$-bonds with the $\mathrm{O}$ atom of THF (Fig. 82). In addition, two $p$-nitrophenylureido moieties are

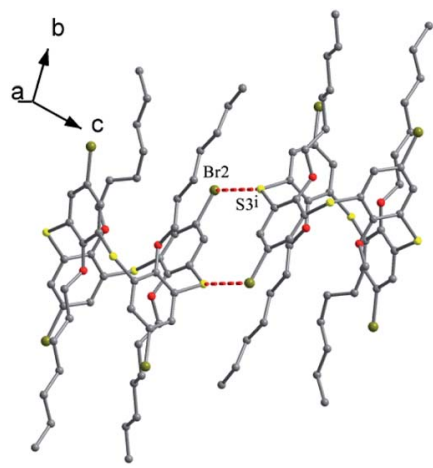

Fig. 78 A dimer of 84 , showing Br $\cdots$ S interactions. 


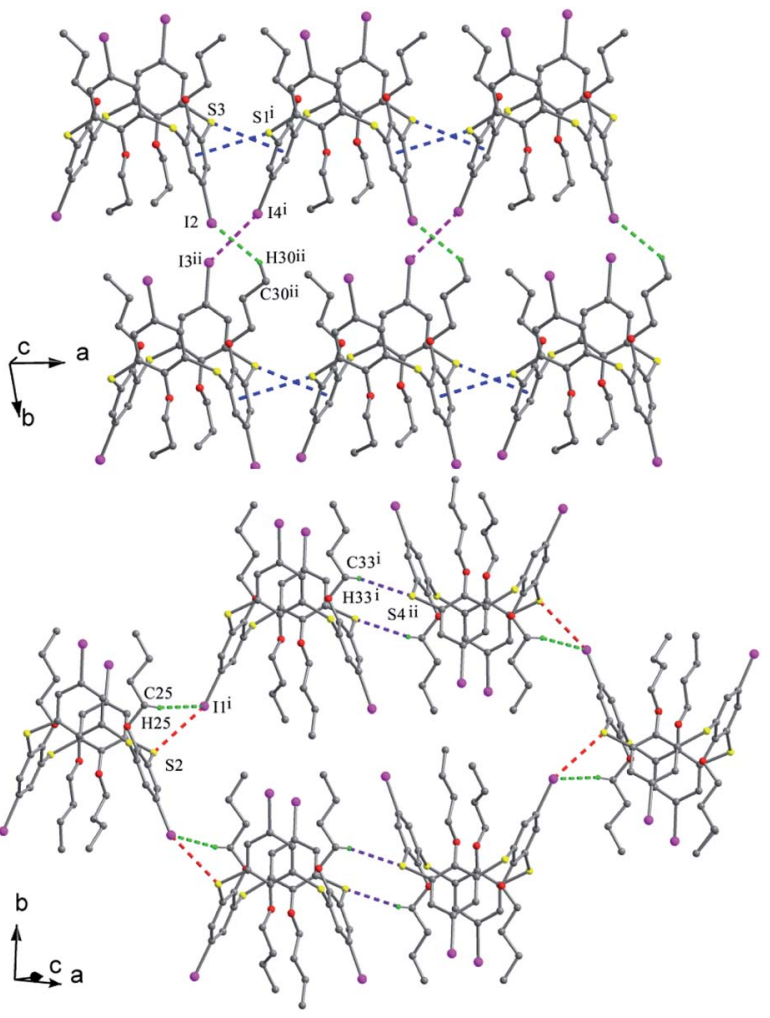

Fig. 79 Supramolecular assemblies of 88 (top) built by $|\cdots|$ (pink), $\mathrm{C}-\mathrm{H} \cdots \mathrm{I}$ (green) and $\mathrm{S} \cdots \pi$ (blue) interactions, and 89 (bottom) built by $\mid \cdots S$ (red), $\mathrm{C}-\mathrm{H} \cdots \mid$ (green) and $\mathrm{C}-\mathrm{H} \cdots \mathrm{S}$ (purple) interactions.

strictly coplanar to each other, producing a dimer by intermolecular $\pi-\pi$ interactions.

Tetrapropoxythiacalix[4]arenes 92 and 93 (Fig. 80), ${ }^{81} \mathrm{~m}$ - and $p$-monomercurated regioisomers, are in a 1,3-alternate or cone conformer. In the asymmetric unit of $\mathbf{9 2}$, there are two pinched cone conformers with $\theta$ ranges of $66.1-154.6^{\circ}$ in $\mathbf{A}(\mathrm{HgCl}$ unit orienting outsides the cavity) and $72.8-155.9^{\circ}$ in $\mathbf{B}$ ( $\mathrm{HgCl}$ unit orienting insides the cavity) (Fig. 83a). In addition, it also gives a 1,3-alternate conformer with a $\theta$ range of $111.0-114.6^{\circ}$ (Fig. 83b). The aromatic rings bearing the $\mathrm{HgCl}$ group at the $\mathrm{m}^{-}$ position are parallel to each other and yield a dimer by cation- $\pi$ interactions (Fig. 84). And the $\mathrm{Hg}$ atoms locate exactly above the centroid of the parallel aromatic ring from the vicinal molecules. But for 93, it is only in a 1,3-alternate conformation with a $\theta$ range from 111.4 to $115.9^{\circ}$ (Fig. 83c). An interesting motif can be found in the crystal packing of 93, where the intermolecular $\mathrm{Hg} \cdots \mathrm{Cl}$ interactions lead to the formation of a dimer

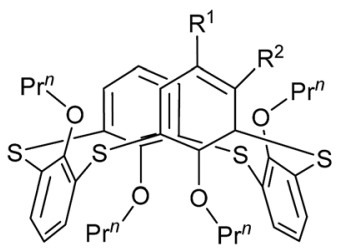

90, $\mathrm{R}_{1}=\mathrm{H}, \mathrm{R}_{2}=\mathrm{Br}$ 91, $\mathrm{R}_{1}=\mathrm{H}, \mathrm{R}_{2}=p-\mathrm{NO}_{2} \mathrm{C}_{6} \mathrm{H}_{4} \mathrm{NHCONH}$ 92, $\mathrm{R}_{1}=\mathrm{H}, \mathrm{R}_{2}=\mathrm{HgCl}$ 93, $\mathrm{R}_{1}=\mathrm{HgCl}, \mathrm{R}_{2}=\mathrm{H}$

Fig. 80 Structures of compounds 90-93.

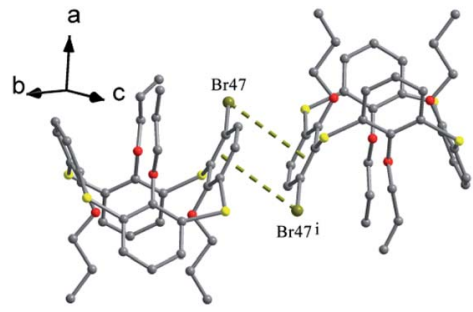

Fig. 81 A dimer of 90 formed with $\mathrm{Br} \cdots \pi$ interactions.
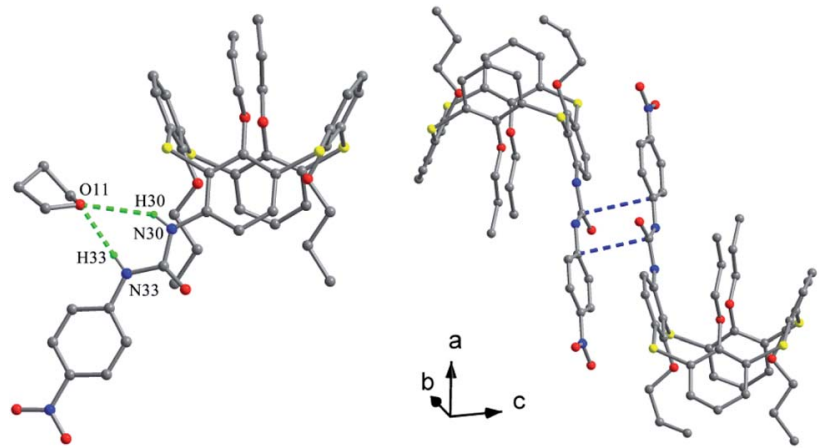

Fig. 82 Crystal structure of 91 (left) showing $\mathrm{H}$-bonds with THF molecule, and a dimer of 91 (right) showing $\pi-\pi$ interactions.

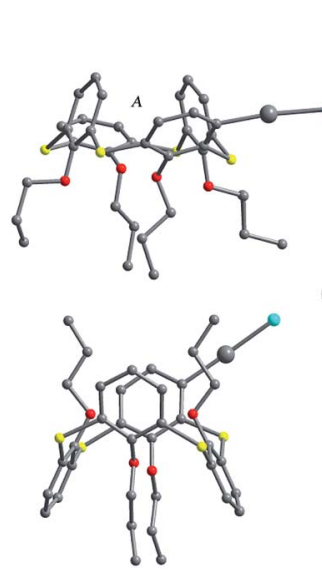

(b)

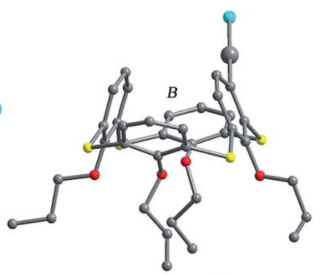

(a)

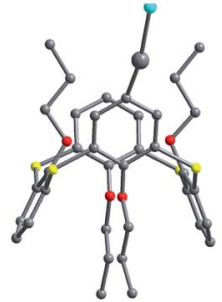

(c)
Fig. 83 Crystal structures of 92 in cone (A and B) (a), in 1,3-alternate (b), and 93 (c)

(Fig. 84), which is further strengthened by additional $\mathrm{C}-\mathrm{H} \cdots \mathrm{Cl}$ $\mathrm{H}$-bonds between the $\mathrm{HgCl}$ unit and the aromatic ring.

In summary, the geometry of thiacalix[4]arenes in a 1,3alternate conformation differs essentially from those in a cone conformer. Most 1,3-alternate thiacalix[4]arenes may be divided into three types based on the $\theta$ variants: (1) with the same four $\theta$ angles, (2) with two pairs of $\theta$ angles, and (3) with four similar $\theta$ angles. The 1,3-alternate conformation is also stabilized by the intramolecular $\mathrm{H}$-bonds and weak contacts similar to the cone conformer. In the packing, the most important feature is that the thiacalix[4]arene core and its pendant groups facilitate the 


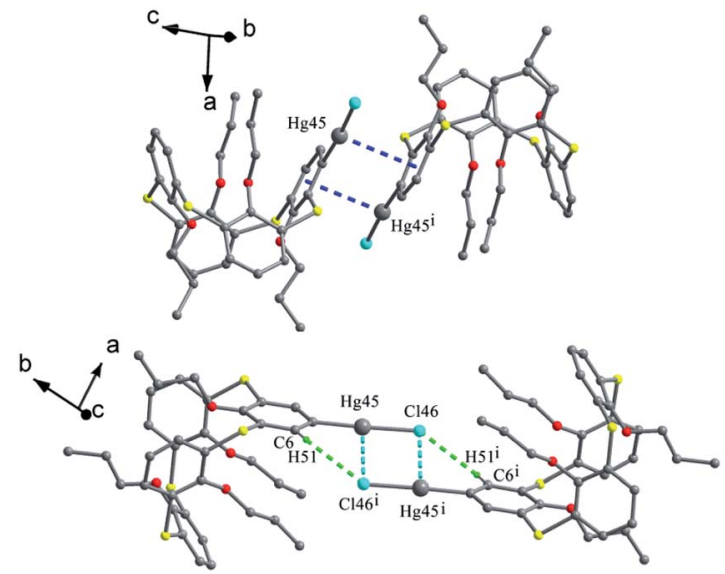

Fig. 84 Dimers of 92 (top) and 93 (bottom)

formation of more complex supramolecular assemblies with branched intermolecular interactions. Especially, various hetero atoms in these compounds can offer more chances in creating diverse kinds of interactions. Therefore various motifs and beautiful channels are constructed by aggregation of the host molecules.

\section{1,2-Alternate structures of thiacalix [4]arenes}

As of now, only few of thiacalix[4] arene derivatives shows a 1,2alternate conformation, usually with a centrosymmetry as their four phenolic rings locate in two opposite sides.

\subsection{O-Substituted thiacalix[4]arenes}

In general, the distally substituted calix[4]arene derivatives prefer a cone conformation in the solid state, while the corresponding thiacalix[4] arene derivatives may adopt either a cone or a 1,2-alternate conformer.

Lhoták et al. have studied the conformational behavior of a series of such thiacalix[4] arenes 94-99 (Fig. 85). ${ }^{\mathbf{4 4 , 8 2}}$ In the solid state, 94-96 and 98 take a 1,2-alternate conformation with approximate (94) or complete centrosymmetry (95, 96, and 98) with similar $\theta$ ranges (Table 3 ). This kind of conformers is governed by two $\mathrm{H}$-bonds between $\mathrm{OH}$ and alkoxy groups of the adjacent aromatic rings. They create a novel type of molecular channels held together by $\pi-\pi$ interactions. For instance, molecule 94 (Fig. 86a), ${ }^{82}$ a dimethoxy derivative of thiacalix[4]arene, shows a 1,2-alternate conformation fixed mainly by two intramolecular $\mathrm{O}-\mathrm{H} \cdots \mathrm{O} \mathrm{H}$-bonds between the $\mathrm{OH}$ and OMe groups. Moreover, two intramolecular $\mathrm{O}-\mathrm{H} \cdots \mathrm{S} \mathrm{H}$-bonds are yielded between the $\mathrm{OH}$ and $\mathrm{S}$ moieties. In the packing, a dimer is built by intermolecular $\pi-\pi$ interactions between the aromatic rings (Fig. 86b). Further expansion of these dimers generates an infinite molecular channel (Fig. 86c). In addition, the 1,2-alternate conformers of 95 (with ethoxy groups) and 96 (with $n$-propoxy groups) are further stabilized by intramolecular $\mathrm{C}-\mathrm{H} \cdots \pi$ interactions between the alkoxy and the neighboring inverted aromatic ring. However, different conformational properties of

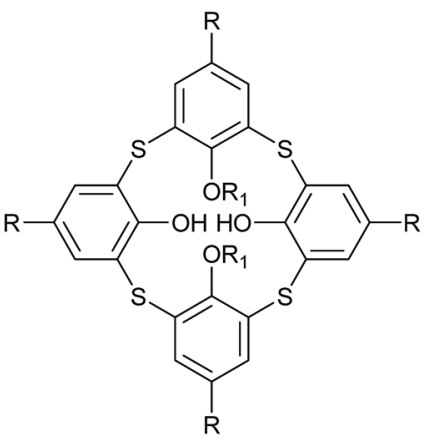

94, $\mathrm{R}=\mathrm{H}, \mathrm{R}_{1}=\mathrm{Me}, 1,2$-alternate 95, $\mathrm{R}=\mathrm{H}, \mathrm{R}_{1}=\mathrm{Et}, 1,2$-alternate 96, $\mathrm{R}=\mathrm{H}, \mathrm{R}_{1}=n$-Pr, 1,2-alternate 97, $\mathrm{R}=t-\mathrm{Bu}, \mathrm{R}_{1}=\mathrm{Me}$, cone 98, $\mathrm{R}=t-\mathrm{Bu}, \mathrm{R}_{1}=\mathrm{Et}, 1,2$-alternate 99, $\mathrm{R}=t-\mathrm{Bu}, \mathrm{R}=n-\mathrm{Pr}$, cone

Fig. 85 Structures of compounds 94-99

Table 3 The $\theta$ angles of compounds $94-105^{a}$

\begin{tabular}{lrrrr}
\hline Compd. & $\theta\left(^{\circ}\right)$ & & & \\
\hline 94 & 113.8 & 129.9 & 114.3 & 131.9 \\
95 & 121.4 & 123.8 & 121.4 & 123.8 \\
$\mathbf{9 6}$ & 115.8 & 126.5 & 115.8 & 126.5 \\
$\mathbf{9 7}$ & 73.2 & 134.9 & 110.8 & 135.8 \\
$\mathbf{9 8}$ & 116.6 & 121.2 & 116.6 & 121.2 \\
$\mathbf{9 9}$ & 72.0 & 155.6 & 107.1 & 141.6 \\
$\mathbf{1 0 0}$ & 105.3 & 114.5 & 105.3 & 114.5 \\
$\mathbf{1 0 1}$ & 118.8 & 130.9 & 118.8 & 130.9 \\
$\mathbf{1 0 2}$ & 102.9 & 167.0 & 102.9 & 167.0 \\
$\mathbf{1 0 3}$ & 106.8 & 123.6 & 106.8 & 123.6 \\
$\mathbf{1 0 4}$ & 111.7 & 114.7 & 111.7 & 114.7 \\
$\mathbf{1 0 5}$ & 116.1 & 132.4 & 116.1 & 132.4
\end{tabular}

${ }^{a}$ Data obtained by calculation with Diamond Version 3.0.

97 and 99, with $t$-butyl at the upper rim, were found in a pinched cone conformation, in which both free $\mathrm{OH}$ groups interact with the same ether $\mathrm{O}$ atom. Interestingly, molecule $\mathbf{9 6}$ also exists in a cone conformer described above (see 29 in Section 2.3), due to the introduction of bulkier $n$-propyl groups than methyl and ethyl groups in 94 and 95, respectively.

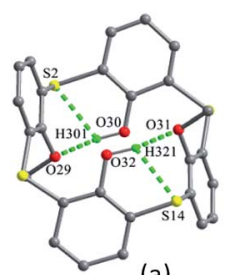

(a)

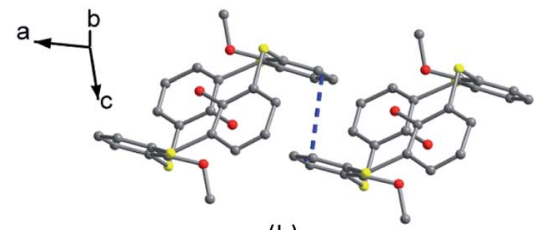

(b)

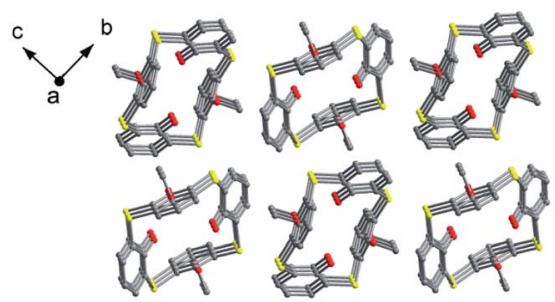

(c)

Fig. 86 Crystal structure of 94 (a) showing $\mathrm{O}-\mathrm{H} \cdots \mathrm{O}$ and $\mathrm{O}-\mathrm{H} \cdots \mathrm{S} \mathrm{H}-$ bonds, a dimer of 94 (b) built via $\pi-\pi$ interactions, and partial packing structure of 94 (c) showing the molecular channels. 
Thiacalix[4]arene derivatives 100-103 (Fig. 87), all adopt a centrosymmetric 1,2-alternate conformation with two pairs of $\theta$ angles (Table 3), and their opposite inverted aromatic rings are nearly parallel. In the crystal structure of 100 (Fig. 88a), ${ }^{83}$ bearing four $n$-propoxy groups at the lower rim, no intramolecular H-bond was observed as in 96 (with two n-propoxy groups), due to the absence of $\mathrm{OH}$ groups. However, an infinite channel is still yielded with molecules being packed parallel to each other (Fig. 89).

Thiacalix[4] arene derivative 101 (Fig. 88b), ${ }^{84}$ with two nitro and two $n$-propoxy groups at the upper and lower rims, repectively, is also stabilized by two intramolecular H-bonds between the $\mathrm{OH}$ and the ether $\mathrm{O}$ atoms, which is similar to 96. Differently, in the packing, a centrosymmetric dimer is formed by two $\mathrm{C}-\mathrm{H} \cdots \mathrm{O}$ H-bonds between the nitro $\mathrm{O}$ atom and the phenolic meta-H atom of the vicinal molecules (Fig. 90).

In addition, some other ancillary forces can also stabilize the 1,2-alternate conformer of thiacalix[4]arenes. Molecule 102 (Fig. 88c), ${ }^{85}$ a phosphorylation derivative of $\mathbf{1}$, is in a flattened 1,2-alternate conformation. Such a flattened structure is fixed by intramolecular weak $\mathrm{P} \cdots \mathrm{S}$ and $\mathrm{P}-\mathrm{Cl} \cdots \pi$ interactions, leading one couple of opposite aromatic rings being nearly parallel to the $R$ plane.

In the crystal structure of 103 (Fig. 88d), ${ }^{86}$ bearing four 2-cyanobenzyloxy units at the lower rim, the two pairs of distal cyanophenyl rings are nearly parallel with the same dihedral angle of $7.3^{\circ}$, owing to the formation of intramolecular $\pi-\pi$ interactions between them.

\subsection{Aryl-functionalized thiacalix[4]arenes}

Thiacalix[4]arene derivatives 104 (ref. 87) and 105 (ref. 88) (Fig. 91), modified with four functions at the upper rim, both show a 1,2-alternate conformation with centrosymmetry, indicating that facing inverted phenolic rings are parallel to each other with two pairs of $\theta$ values (Table 3 ). In the solid state, the typical cyclic intramolecular H-bonds disappear, but other H-bonds were observed in the 1,2-alternate conformer. In

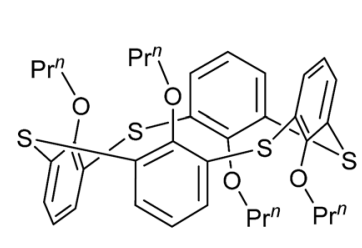

100

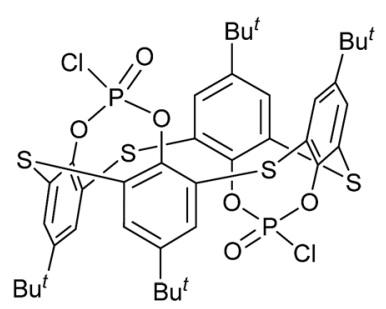

102
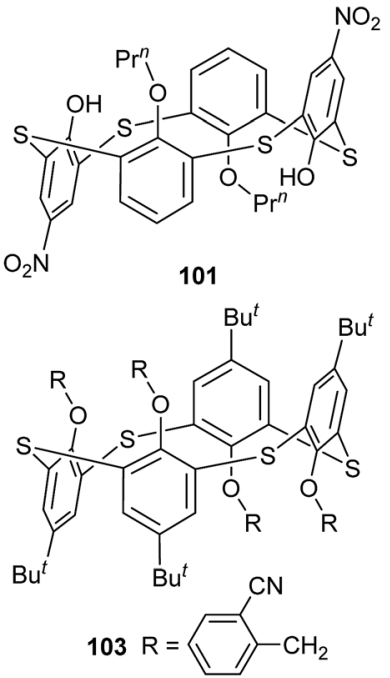

Fig. 87 Structures of compounds 100-103.

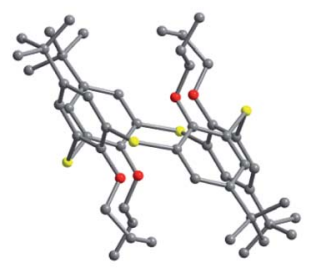

(a)

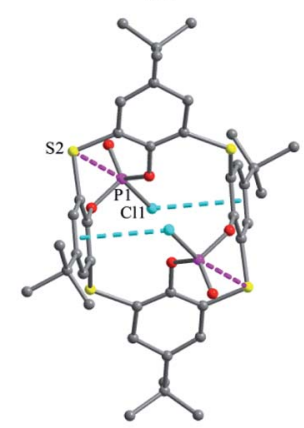

(c)

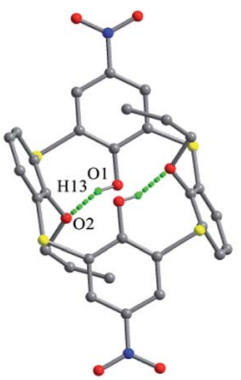

(b)

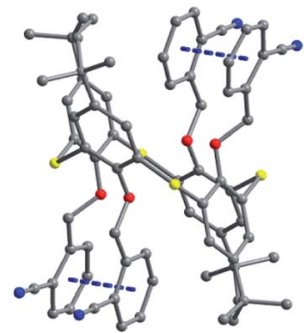

(d)
Fig. 88 Crystal structures of 100 (a), 101 (b), 102 (c) and 103 (d), showing $\mathrm{P} \cdots \mathrm{S}$ (pink), $\mathrm{P}-\mathrm{Cl} \cdots \pi$ (cyan), and $\pi \cdots \pi$ (blue) interactions.

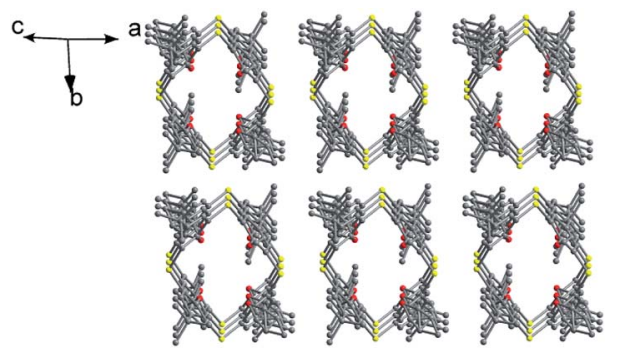

Fig. 89 Partial packing structure of 100 , showing the molecular channels.

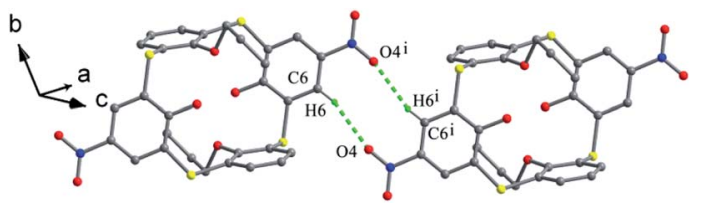

Fig. 90 A dimer of 101 , showing $\mathrm{C}-\mathrm{H} \cdots \mathrm{O} \mathrm{H}$-bonds.

molecule 104 (Fig. 92), four intramolecular $\mathrm{O}-\mathrm{H} \cdots \mathrm{S}$ H-bonds are yielded between the $\mathrm{S}$ bridge and its two vicinal $\mathrm{OH}$ groups at the same side. Moreover, there are strong intermolecular O14-H14 $\cdots$

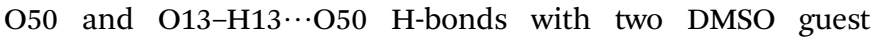
molecules.

In the case of 105 (Fig. 92), with four $p$-nitrophenylazo functions at the upper rim, only two intramolecular $\mathrm{O}-\mathrm{H} \cdots \mathrm{O} \mathrm{H}-$ bonds govern such a conformation rather than the annular $\mathrm{H}$ bond array, while the other two $\mathrm{OH}$ groups create two $\mathrm{O}-\mathrm{H} \cdots \mathrm{N}$ H-bonds with the solvent pyridine molecules crystallized in the crystal structure. Moreover, intramolecular $\mathrm{O}-\mathrm{H} \cdots \mathrm{S}$ $\mathrm{H}$-bonds and $\mathrm{O} \cdots \mathrm{S}$ contacts were also found. 


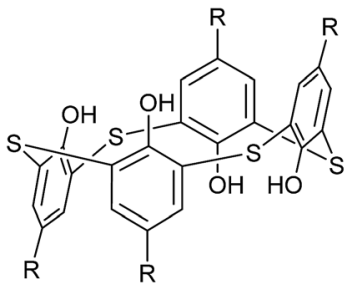

104, $\mathrm{R}=\mathrm{NO}_{2}$

105, $\mathrm{R}=p-\mathrm{NO}_{2} \mathrm{C}_{6} \mathrm{H}_{4} \mathrm{~N}_{2}$

Fig. 91 Structures of compounds 104-105.
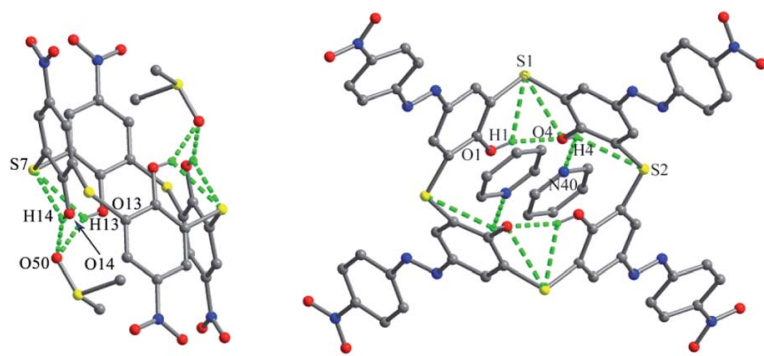

Fig. 92 Crystal structures of 104 (left) and 105 (right), showing intraand intermolecular $\mathrm{H}$-bonds with the solvent molecules.

In brief, identically substituted thiacalix[4]arenes in a 1,2-alternate conformer usually show centrosymmetry with two pairs of $\theta$ values. In such an unusual 1,2-alternate conformer, it is hard to create a cycle of intramolecular $\mathrm{O}-\mathrm{H} \cdots \mathrm{O}$ H-bonds with four free $\mathrm{OH}$ groups, which always exist in the cone conformer. However, the intramolecular $\mathrm{O}-\mathrm{H} \cdots \mathrm{O}$ H-bonds are still a key interaction to control the 1,2-alternate conformation. In the packing, the orientations of four phenolic rings at two opposite sides are usually favored to stack parallel to each other and yield the infinite channels.

\section{Partial cone structures of thiacalix [4]arenes}

In partial cone thiacalix[4]arene derivatives, one of the four phenolic rings is rotated away from the cavity formed by the other three phenolic rings, thus they are all unsymmetrical molecules.

\subsection{O-Substituted thiacalix[4]arenes}

Thiacalix[4] arene derivatives 106-108 possess four ether arms terminated with amide or ester groups at the lower rim (Fig. 93). ${ }^{89}$ In the solid state, they all take a partial cone conformer, in which the inverted aromatic ring is nearly perpendicular to the $R$ plane with $\theta$ angles of 86.6-90.4 (Table 4). In molecule 106 (Fig. 94a), containing two amide and two ester termini, the ester carbonyl group on the inverted aromatic ring is orientated inwards the cavity, while the other one is directed outwards. This conformer is favorable to give an intramolecular $\mathrm{N}-\mathrm{H} \cdots \mathrm{O} \mathrm{H}$-bond between the ester carbonyl group and the vicinal amide unit. In the case of 107 (Fig. 94b), although the ester group on the inverted phenolic ring is replaced by an amide group, it adopts a similar conformation and gives the same intramolecular $\mathrm{N}-\mathrm{H} \cdots \mathrm{O}$ H-bond as in 106. In the packing, similar infinite chains are produced in 106

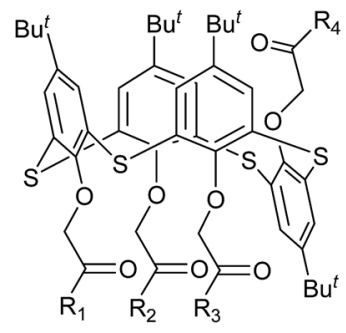

106, $\mathrm{R}_{1}=\mathrm{R}_{4}=\mathrm{OEt}, \mathrm{R}_{2-3}=\mathrm{NHBu}^{\mathrm{n}}$

107, $\mathrm{R}_{1}=\mathrm{OEt}, \mathrm{R}_{2-4}=\mathrm{NHPr}^{n}$

108, $\mathrm{R}_{1-4}=\mathrm{NHBu}^{n}$

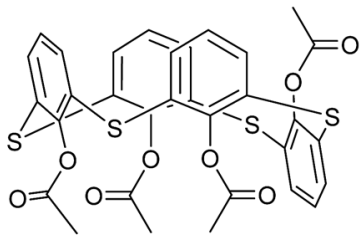

109
Fig. 93 Structures of compounds 106-109.

(Fig. 95a) and 107 (Fig. 95b) by intermolecular $\mathrm{N}-\mathrm{H} \cdots \mathrm{O}$ H-bonds between the amide groups of two vicinal molecules. In addition, such chains in $\mathbf{1 0 7}$ are further linked into supramolecular arrays by inter-chain $\mathrm{N}-\mathrm{H} \cdots \mathrm{O}$ H-bonds with the $\mathrm{NH}$ groups on the inverted phenolic rings as H-bond donors. However, molecule 108, bearing four amide groups (Fig. 94c), displays a partial cone conformation with the $\theta$ range of $80.3-155.0^{\circ}$ larger than those in 106 and 107. In such a conformer, all carbonyls of the amide groups are directed away from the cavity, with two intramolecular $\mathrm{N}-\mathrm{H} \cdots \mathrm{O}$ H-bonds between the three amide groups at the same side. This $\mathrm{H}$-bonding nature is different from that observed in 106 and 107. In the packing, a zigzag 1-D infinite chain is created by intermolecular $\mathrm{N}-\mathrm{H} \cdots \mathrm{O}$ H-bonds (Fig. 95c). In solution, it was observed that only 108 exhibited some affinity towards $\mathrm{Na}^{+}$and $\mathrm{K}^{+}$ions.

In the asymmetric unit of tetraacetylated thiacalix[4]arene 109 (Fig. 93), ${ }^{90}$ there are one thiacalix[4] arene molecule and one $\mathrm{CHCl}_{3}$ solvent molecule. In the packing, a structural motif is formed, in which one thiacalix[4]arene is surrounded by four $\mathrm{CHCl}_{3}$ molecules and vice versa. The $\mathrm{CHCl}_{3}$ molecule is bound by intermolecular $\mathrm{C}-\mathrm{H} \cdots \mathrm{O}, \mathrm{C}-\mathrm{H} \cdots \mathrm{Cl}$ and $\mathrm{Cl} \cdots \mathrm{O}$ interactions with its adjacent thiacalix[4]arene molecules. In addition, strong intermolecular $\pi-\pi$ contacts were found between two parallel phenyl rings, giving rise to a dimer (Fig. 96), which was further fixed by $\mathrm{C}-\mathrm{H} \cdots \mathrm{O}$ H-bonds between the carbonyl group and the $\mathrm{H}$ atom at the $m$-position of the opposite phenyl ring.

\subsection{O/aryl mixed substituted thiacalix[4]arenes}

Thiacalix[4]arene derivative 110 (Fig. 97), ${ }^{45}$ with one $n$-propoxy at the lower rim and three CHO functions at the upper rim,

Table 4 The $\theta$ angles of compounds $106-113^{a}$

\begin{tabular}{lrrrr}
\hline Compd. & $\theta\left(^{\circ}\right)$ & & & \\
\hline $\mathbf{1 0 6}$ & 90.4 & 88.0 & 138.9 & 94.5 \\
$\mathbf{1 0 7}$ & 88.4 & 95.0 & 142.1 & 84.5 \\
$\mathbf{1 0 8}$ & 88.4 & 80.3 & 155.0 & 123.2 \\
$\mathbf{1 0 9}$ & 86.6 & 82.0 & 145.8 & 79.5 \\
$\mathbf{1 1 0}$ & 90.1 & 101.4 & 136.8 & 106.5 \\
$\mathbf{1 1 1}$ & 103.6 & 99.3 & 153.9 & 106.6 \\
$\mathbf{1 1 2}$ & 93.0 & 85.5 & 152.0 & 81.1 \\
$\mathbf{1 1 3}$ & 82.4 & 86.0 & 162.5 & 75.7
\end{tabular}

${ }^{a}$ Data obtained by calculation with Diamond Version 3.0. 


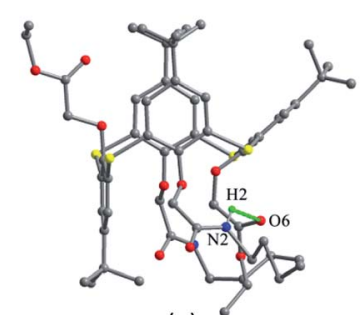

(a)
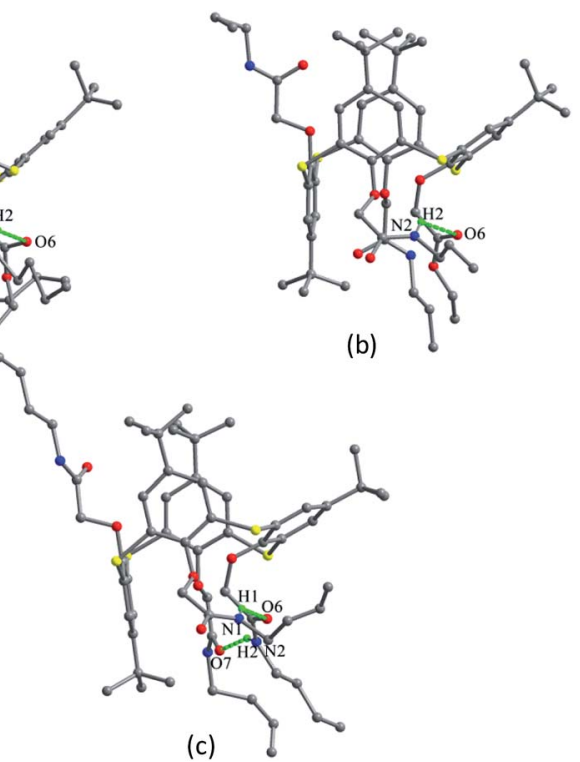

Fig. 94 Crystal structures of 106 (a), 107 (b) and 108 (c), showing Hbonds.

takes a partial cone conformer, in which the inverted aromatic ring is perpendicular to the $R$ plane with $\theta$ value of $90.1^{\circ}$ (Table 4). Such a conformer is fixed by intramolecular $\mathrm{O}-\mathrm{H} \cdots \mathrm{O}$ and $\mathrm{O}-\mathrm{H} \cdots \mathrm{S}$ H-bonds (Fig. 98). In the packing, two molecules of $\mathbf{1 1 0}$
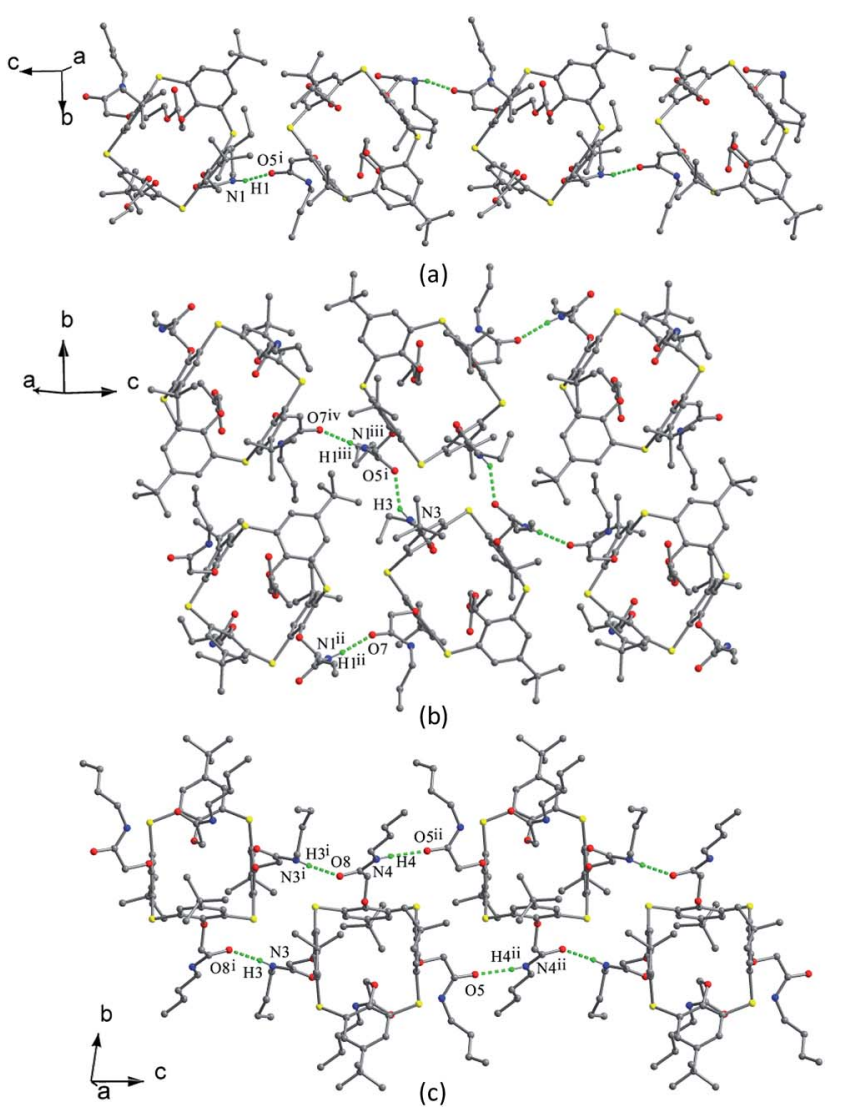

Fig. 95 Partial stacking structures of 106 (a), 107 (b) and 108 (c) built by $\mathrm{H}$-bonds.
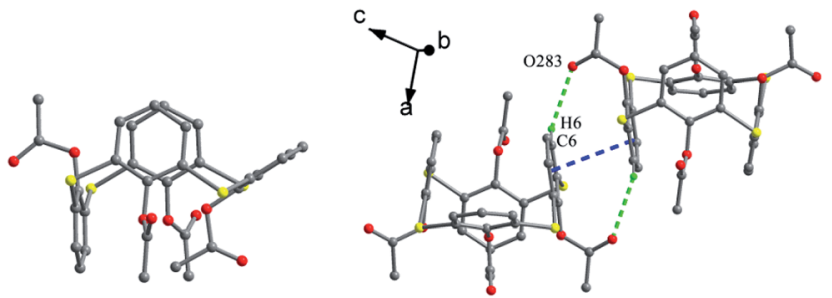

Fig. 96 Crystal structure of 109 (left), and a dimer of 109 (right) built by $\mathrm{C}-\mathrm{H} \cdots \mathrm{O}$ and $\pi-\pi$ interactions.

form a head-to-head dimer by $\pi-\pi$ stacking between the parallel aromatic rings, two weak $\mathrm{C}-\mathrm{H} \cdots \mathrm{O} \mathrm{H}$-bonds and four $\mathrm{C}-\mathrm{H} \cdots \pi$ interactions (Fig. 99). In addition, six molecules of 110 create a hexameric disc in a back-to-back fashion by S3 $\cdots \pi$ and C29H29 $\cdots$ O6 interactions (Fig. 100). These discs are further accumulated into a triply helical tube, which is stabilized by $\mathrm{C}-\mathrm{O} \cdots \pi$ and $\mathrm{C}-\mathrm{H} \cdots \mathrm{O}$ interactions.

Tripropoxythiacalix[4] arene derivative 111 (Fig. 97), ${ }^{91}$ with a $\mathrm{ClCH}_{2}$ group at the $m$-position, shows a partial cone conformer with four different $\theta$ values (Table 4). Two intramolecular $\mathrm{O}-\mathrm{H} \cdots \mathrm{O} \mathrm{H}$-bonds between the $\mathrm{OH}$ and two $n$-propoxy groups at the same side control the strong distortion of the conformer (Fig. 98).

Thiacalix[4]arene derivatives 112 (ref. 78) and 113 (ref. 92) (Fig. 97), functionalized with four $\mathrm{Br}$ atoms at the upper rim, both take a partial cone conformation with inverted aromatic ring nearly perpendicular to the plane $R$ in the solid state (Table 4). For compound 112 (Fig. 101), appending four ethyl groups at the lower rim, two facing rings of the three aromatic rings on the same side are flipped slightly inwards, whereas the middle one is flipped considerably outwards. Such a conformer lets a short $\mathrm{Br} \cdots \pi$ and two $\mathrm{C}-\mathrm{H} \cdots \mathrm{Br}$ interactions contribute to the formation of the self-assembled dimer (Fig. 99). In addition, symmetric expansion of the crystal structure shows $S \cdots \pi$ and $\mathrm{C}-\mathrm{H} \cdots \mathrm{S}$ contacts between the dimers.

In the case of 113 (Fig. 101), bearing four ether chains terminated with ester groups, the ring on the opposite of the

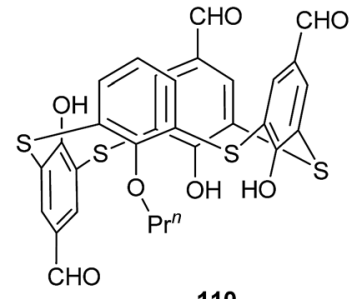

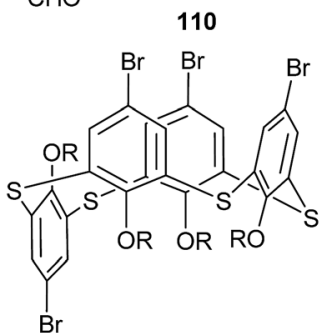

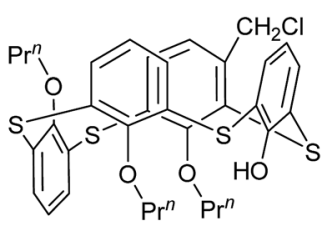

111

112, $\mathrm{R}=\mathrm{Et}$ 113, $\mathrm{R}=\mathrm{CH}_{2} \mathrm{CO}_{2} \mathrm{Me}$
Fig. 97 Structures of compounds 110-113 

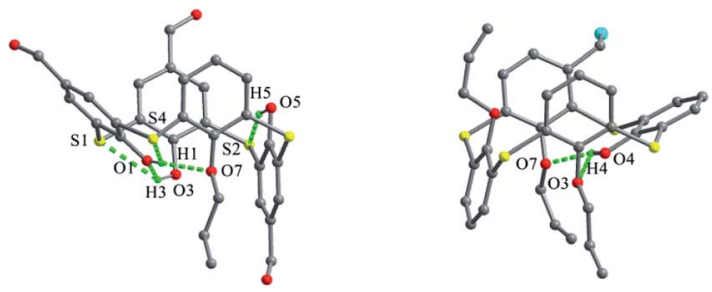

Fig. 98 Crystal structures of 110 (left) and 111 (right), showing $\mathrm{H}$ bonds.
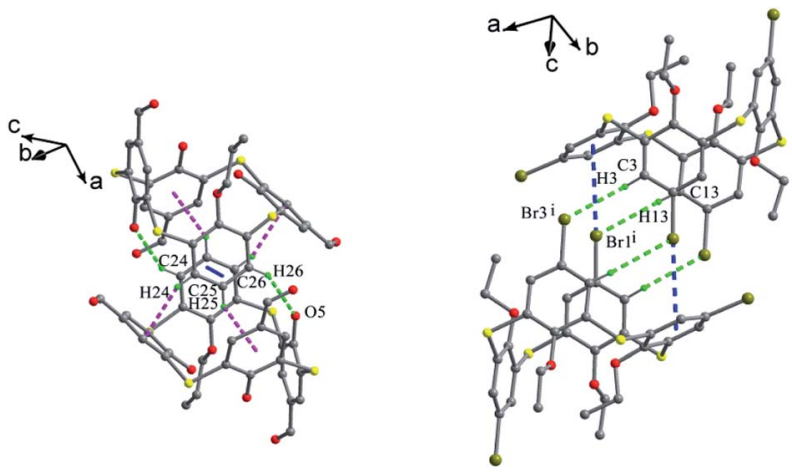

Fig. 99 A dimer of 110 (left) built by $\pi-\pi$ (blue), $\mathrm{C}-\mathrm{H} \cdots \mathrm{O}$ (green) and $\mathrm{C}-\mathrm{H} \cdots \pi$ (pink) interactions; a dimer of 112 (right) built by $\mathrm{Br} \cdots \pi$ (blue) and $\mathrm{C}-\mathrm{H} \cdots \mathrm{Br}$ (green) interactions.

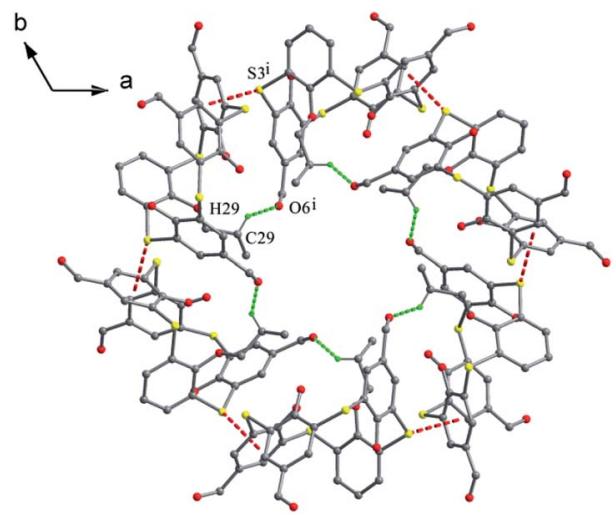

Fig. 100 A disc-like hexamer of 110 built by $\mathrm{C}-\mathrm{H} \cdots \mathrm{O}$ and $\mathrm{S} \cdots \pi$ interactions.

inverted one is tilted away from the cavity and almost coplanar with the $R$ plane. In the crystal structure, $\mathrm{C}-\mathrm{H} \cdots \mathrm{O}, \mathrm{C}-\mathrm{H} \cdots \mathrm{S}$ and $\mathrm{C}-\mathrm{H} \cdots \pi$ interactions fix both the partial cone conformer and the packing. A 1-D chain is created by intermolecular $\mathrm{C}-\mathrm{H} \cdots \mathrm{O}$ $\mathrm{H}$-bonds (Fig. 102). These chains further augmented into a 2-D network via ancillary $\mathrm{C}-\mathrm{Br} \cdots \mathrm{C}$ interactions.

As shown above, for most of thiacalix[4]arenes in a partial cone conformation, the inverted phenolic ring is almost perpendicular to the $R$ plane with the $\theta$ range from 80.3 to $103.6^{\circ}$, while its opposing ring is markedly tilted away from the cavity with the $\theta$ range from 136.8 to $162.5^{\circ}$ (Table 4). These partial cone conformers tailored with different binding sites are

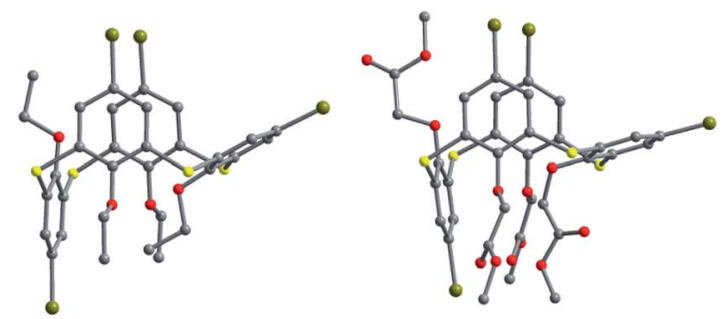

Fig. 101 Crystal structures of 112 (left) and 113 (right).

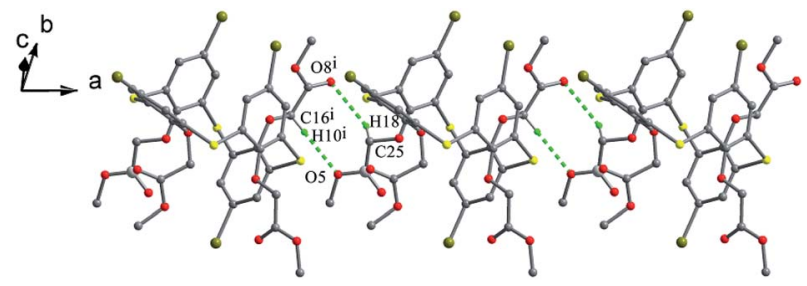

Fig. 102 A 1-D chain of 113 built by $\mathrm{C}-\mathrm{H} \cdots \mathrm{O} \mathrm{H}$-bonds.

available for the formation of intra- and intermolecular interactions, which are able to stabilize both the partial cone conformers and their supramolecular arrays.

\section{Conclusions}

In conclusion, we have briefly summarized the development of thiacalix[4]arene derivatives in crystal structures, including the exact description of various conformers, binding patterns and some supramolecular assemblies.

In the solid state, thiacalix[4]arenes, in cone, 1,3-alternate, 1,2-alternate and partial cone conformations, show diverse conformational preferences with varied substituents at the lower and/or upper rims, as well as the oxidation of the $\mathrm{S}$ bridges. The precise conformations of thiacalix[4]arene cores can be identified with the typical $\theta$ angles. In each type of conformers, the $\theta$ ranges are very different owing to the features of the substituents. The whole molecular structures are mainly governed by the steric and electronic effects of the substituents belonging to the thiacalix[4]arene molecules and the crystallization conditions.

In the crystal structures of thiacalix[4]arenes, various $\mathrm{X}-\mathrm{H} \cdots \mathrm{Y}$ $(\mathrm{X}=\mathrm{O}, \mathrm{N}, \mathrm{C} ; \mathrm{Y}=\mathrm{O}, \mathrm{N}, \mathrm{S}, \mathrm{Cl}, \mathrm{Br}, \mathrm{I}) \mathrm{H}$-bonds, $\mathrm{C}-\mathrm{H} \cdots \pi, \pi-\pi, \mathrm{X} \cdots \pi$ $(\mathrm{X}=\mathrm{S}, \mathrm{Cl}, \mathrm{Br})$ and $\mathrm{X} \cdots \mathrm{X}(\mathrm{X}=\mathrm{S}, \mathrm{Cl}, \mathrm{Br}, \mathrm{I})$ interactions as well as other contacts between different heteroatoms are found to control the whole molecular conformations and stabilize the supramolecular assemblies. In particular, the introduction of $\mathrm{S}$ bridges offers additional binding centres for $\mathrm{H}$-bonds and other non-covalent contacts. Moreover, the solvent molecules play an ancillary role in regulating the conformation and the packing of thiacalix[4]arenes in some cases by two ways: one is guest inclusion occurring in the calix cavity; the other occurs in the holes or channels built by aggregation of the host molecules.

In the supramolecular assemblies, versatile multimeric motifs, chain and channel arrays of thiacalix[4]arenes are 
created via the interactions described above. In particular, those in cone and 1,3-alternate conformers always display square boxshaped cavities and yield very nice infinite channels, which are extensively influenced with the features of substituents at the lower and/or upper rims. These supramolecular arrays are widely favored to allow inclusion or storage of small molecules with complementary size.

In this review, we have highlighted some of the promising advances of thiacalix[4]arenes in crystallographic researches, but it is clear that there is a long path ahead of to develop the perfect thiacalix[4]arene-based supramolecular assemblies. In the future, more attention should be paid to expand the areas involving design of novel molecules, discovery of new interactions and establishment of the rule in molecular recognition and organic supramolecular assemblies based on the thiacalix [4]arene scaffolds. Understanding well the crystal structures of these scaffolds will provide wide applications in biological molecular recognition, functional organic materials and supramolecular chemistry.

\section{Acknowledgements}

We are grateful for the financial support from the National Natural Science Foundation of China (No. 21372147).

\section{References}

1 S. Shinkai, Tetrahedron, 1993, 49, 8933-8968.

2 C. D. Gutsche, in Calixarenes Revisited, Monographs in Supramolecular Chemistry, ed. J. F. Stoddart, The Royal Society of Chemistry, Cam Cambridge, 1989.

3 H. Kumagai, M. Hasegawa, S. Miyanari, Y. Sugawa, Y. Sato, T. Hori, S. Ueda, H. Kamiyama and S. Miyano, Tetrahedron Lett., 1997, 38, 3971-3972.

4 T. Sone, Y. Ohba, K. Moriya, H. Kumada and K. Ito, Tetrahedron, 1997, 53, 10689-10698.

5 E. A. Shokova and V. V. Kovalev, Russ. J. Org. Chem., 2003, 39, 1-28.

6 N. Iki and S. Miyano, J. Inclusion Phenom. Macrocyclic Chem., 2001, 41, 99-105.

7 P. Lhoták, Eur. J. Org. Chem., 2004, 1675-1692.

8 N. Morohashi, F. Narumi, N. Iki, T. Hattori and S. Miyano, Chem. Rev., 2006, 106, 5291-5316.

9 R. Kumar, Y. O. Lee, V. Bhalla, M. Kumar and J. S. Kim, Chem. Soc. Rev., 2014, 43, 4824-4870.

10 M. Yamada, M. R. Gandhi, U. M. R. Kunda and F. Hamada, J. Inclusion Phenom. Macrocyclic Chem., 2016, 85, 1-18.

11 T. Kajiwara, N. Iki and M. Yamashita, Coord. Chem. Rev., 2007, 251, 1734-1746.

12 Y. Bi, S. Du and W. Liao, Coord. Chem. Rev., 2014, 276, 61-72.

13 A. Bilyk, A. K. Hall, J. M. Harrowfield, M. W. Hosseini, B. W. Skelton and A. H. White, Inorg. Chem., 2001, 40, 672686.

14 A. Bilyk, J. W. Dunlop, A. K. Hall, J. M. Harrowfield, M. W. Hosseini, G. A. Koutsantonis, B. W. Skelton and A. H. White, Eur. J. Inorg. Chem., 2010, 14, 2089-2105.
15 Y. Li, W. Yang, Y. Chen and S. Gong, CrystEngComm, 2011, 13, 259-268.

16 H. Akdas, L. Bringel, E. Graf, M. W. Hosseini, G. Mislin, J. Pansanel, A. D. Cian and J. Fischer, Tetrahedron Lett., 1998, 39, 2311-2314.

17 J. Lang, K. Vágnerová, J. Czernek and P. Lhoták, Supramol. Chem., 2006, 18, 371-381.

18 N. Iki, C. Kabuto, T. Fukushima, H. Kumagai, H. Takeya, S. Miyanari, T. Miyashi and S. Miyano, Tetrahedron, 2000, 56, 1437-1443.

19 N. Morohashi, S. Noji, H. Nakayama, Y. Kudo, S. Tanaka, C. Kabuto and T. Hattori, Org. Lett., 2011, 13, 3292-3295.

20 A. Arduini, F. F. Nachtigall, A. Pochini, A. Secchi and F. Ugozzoli, Supramol. Chem., 2000, 12, 273-291.

21 J. Hong, C. Yang, Y. Li, G. Yang, C. Jin, Z. Guo and L. Zhu, J. Mol. Struct., 2003, 655, 435-441.

22 C. Kabuto, Y. Higuchi, T. Niimi, F. Hamada, N. Iki, N. Morohashi and S. Miyano, J. Inclusion Phenom. Macrocyclic Chem., 2002, 42, 89-98.

23 P. Lhoták, T. Šmejkal, I. Stibor, J. Havlíček, M. Tkadlecová and H. Petříčková, Tetrahedron Lett., 2003, 44, 8093-8097.

24 O. Kasyan, V. Kalchenko, M. Bolte and V. Böhmer, Chem. Commun., 2006, 18, 1932-1934.

25 N. Morohashi, M. Kojima, A. Suzuki and Y. Ohba, Heterocycl. Commun., 2005, 11, 249-254.

26 H. Katagiri, S. Tanaka, K. Ohkubo, Y. Akahira, N. Morohashi, N. Iki, T. Hattori and S. Miyano, RSC Adv., 2014, 4, 96089616.

27 H. Katagiri, N. Iki, T. Hattori, C. Kabuto and S. Miyano, J. Am. Chem. Soc., 2001, 123, 779-780.

28 N. Morohashi, H. Katagiri, T. Shimazaki, Y. Kitamoto, S. Tanaka, C. Kabuto, N. Iki, T. Hattori and S. Miyano, Supramol. Chem., 2013, 25, 812-818.

29 S. Kharchenko, A. Drapailo, S. Shishkina, O. Shishkin, M. Karavan, I. Smirnov, A. Ryabitskii and V. I. Kalchenko, Supramol. Chem., 2014, 26, 864-872.

30 M. Lamouchi, E. Jeanneau, R. Chiriac, D. Ceroni, F. Meganem, A. Brioude, A. W. Coleman and C. Desroches, Tetrahedron Lett., 2012, 53, 2088-2090.

31 M. Akkurt, J. P. Jasinski, S. K. Mohamed, O. A. Omran and M. R. Albayati, Acta Crystallogr., Sect. E: Crystallogr. Commun., 2015, 71, o830-0831.

32 I. I. Stoikov, D. S. Ibragimova, N. V. Shestakova, D. B. Krivolapov, I. A. Litvinov, I. S. Antipin, A. I. Konovalov and I. Zharov, Supramol. Chem., 2009, 21, 564-571.

33 J.-L. Zhao, H. Tomiyasu, X.-L. Ni, X. Zeng, M. R. J. Elsegood, C. Redshaw, S. Rahman, P. E. Georghiou and T. Yamato, New J. Chem., 2014, 38, 6041-6049.

34 O. Kasyan, E. R. Healey, A. Drapailo, M. Zaworotko, S. Cecillon, A. W. Coleman and V. Kalchenko, J. Inclusion Phenom. Macrocyclic Chem., 2007, 58, 127-132.

35 O. Kasyan, V. Kalchenko, V. Böhmer and M. Bolte, Acta Crystallogr., Sect. E: Struct. Rep. Online, 2007, 63, o2346o2348.

36 K. Polívková, M. Šimánová, J. Budka, P. Cuřínova, I. Císařová and P. Lhoták, Tetrahedron Lett., 2009, 50, 6347-6350. 
37 M. Dudič, P. Lhoták, H. Petříčková, I. Stibor, K. Lang and J. Sýkora, Tetrahedron, 2003, 59, 2409-2415.

38 O. Kasyan, I. Thondorf, M. Bolte, V. Kalchenko and V. Böhmer, Acta Crystallogr., Sect. C: Cryst. Struct. Commun., 2006, 62, o289-0294.

39 V. Bhalla, M. Kumar, C. Kabuto, T. Hattori and S. Miyano, Chem. Lett., 2004, 33, 184-185.

40 S.-J. Shi, X.-X. Lv, M. Zhao, J.-P. Ma and D.-S. Guo, J. Mol. Struct., 2017, 1127, 81-87.

41 V. Burilov, A. Valiyakhmetova, D. Mironova, R. Safiullin, M. Kadirov, K. Ivshin, O. Kataeva, S. Solovieva and I. Antipin, RSC Adv., 2016, 6, 44873-44877.

42 T. Sreeja, V. B. Ganga, L. Praveen and R. L. Varma, Indian J. Chem., Sect. B: Org. Chem. Incl. Med. Chem., 2011, 50, 704714.

43 V. Bhalla, M. Kumar, H. Katagiri, T. Hattori and S. Miyano, Tetrahedron Lett., 2005, 46, 121-124.

44 H. Dvořáková, J. Lang, J. Vlach, J. Sýkora, M. Čajan, M. Himl, M. Pojarová, I. Stibor and P. Lhoták, J. Org. Chem., 2007, 72, 7157-7166.

45 W. Wang, W. Yang, R. Guo and S. Gong, CrystEngComm, 2015, 17, 7663-7675.

46 A. Habashneh, C. R. Jablonski, J. Collins and P. E. Georghiou, New J. Chem., 2008, 32, 1590-1596.

47 S. Bouhroum, J. S. Kim, S. W. Lee, P. Thuéry, G. Yap, F. Arnaud-Neu and J. Vicens, J. Inclusion Phenom. Macrocyclic Chem., 2008, 62, 239-250.

48 K. U. M. Rao, T. Kimuro, M. Yamada, Y. Kondo and F. Hamada, Heterocycles, 2015, 91, 989-1000.

49 T. Yamato, C. Pérez-Casas, A. Yoshizawa, S. Rahman, M. R. J. Elsegood and C. Redshaw, J. Inclusion Phenom. Macrocyclic Chem., 2009, 63, 301-308.

50 S. N. Podyachev, B. M. Gabidullin, V. V. Syakaev, S. N. Sudakova, A. T. Gubaidullin, W. D. Habicher and A. I. Konovalov, J. Mol. Struct., 2011, 1001, 125-133.

51 V. Št'astný, I. Stibor, H. Petř́ičková, J. Sýkora and P. Lhoták, Tetrahedron, 2005, 61, 9990-9995.

52 P. Lhoták, M. Dudicč, I. Stibor, H. Petříčková, J. Sýkora and J. Hodačová, Chem. Commun., 2001, 8, 731-732.

53 L.-L. Liu, L.-S. Chen, J.-P. Ma and D.-S. Guo, Acta Crystallogr., Sect. E: Struct. Rep. Online, 2011, 67, 01110-01111.

54 L.-J. Zhang, L.-L. Liu, Q.-K. Liu and D.-S. Guo, Acta Crystallogr., Sect. E: Struct. Rep. Online, 2012, 68, o135301354.

55 P. Lhoták, J. Morávek, T. Šmejkal, I. Stibor and J. Sýkora, Tetrahedron Lett., 2003, 44, 7333-7336.

56 G. Mislin, E. Graf, M. W. Hosseini, A. D. Cian and J. Fischer, Tetrahedron Lett., 1999, 40, 1129-1132.

57 N. Morohashi, N. Iki, C. Kabuto and S. Miyano, Tetrahedron Lett., 2000, 41, 2933-2937.

58 G. Mislin, E. Graf, M. W. Hosseini, A. D. Cian and J. Fischer, Chem. Commun., 1998, 13, 1345-1346.

59 L. Hu, Y. Liu, J.-P. Ma and D.-S. Guo, Acta Crystallogr., Sect. E: Struct. Rep. Online, 2009, 65, o385-0386.

60 P. Lhoták, M. Himl, I. Stibor, J. Sýkora, H. Dvořáková, J. Lang and H. Petříčková, Tetrahedron, 2003, 59, 7581-7585.
61 L. Liu, K. Huang and C. G. Yan, J. Inclusion Phenom. Macrocyclic Chem., 2010, 66, 349-355.

62 V. V. Syakaev, S. N. Podyachev, A. T. Gubaidullin, S. N. Sudakova and A. I. Konovalov, J. Mol. Struct., 2008, 885, 111-121.

63 X. Li, S.-L. Gong, W.-P. Yang, Y.-Y. Chen and X.-G. Meng, Tetrahedron, 2008, 64, 6230-6237.

64 X. Li, S.-L. Gong, Y.-F. Liu, Q. Zheng and Y.-Y. Chen, Acta Crystallogr., Sect. E: Struct. Rep. Online, 2007, 63, o2097o2098.

65 B.-T. Zhao, Z. Zhou and Z.-N. Yan, J. Chem. Sci., 2009, 121, 1047-1052.

66 D.-S. Guo, Z.-P. Liu, J.-P. Ma and R.-Q. Huang, Tetrahedron Lett., 2007, 48, 1221-1224.

67 S. N. Podyachev, S. N. Sudakova, B. M. Gabidullin, V. V. Syakaev, A. T. Gubaidullin, W. Dehaen and A. I. Konovalov, Tetrahedron Lett., 2012, 53, 3135-3139.

68 T. Yamato, C. Pérez-Casas, S. Rahman, Z. Xi, M. R. J. Elsegood and C. Redshaw, J. Inclusion Phenom. Macrocyclic Chem., 2007, 58, 193-197.

69 C. Pérez-Casas, H. Höpfl and A. K. Yatsimirsky, J. Inclusion Phenom. Macrocyclic Chem., 2010, 68, 387-398.

70 X.-L. Ni, X. Zeng, D. L. Hughes, C. Redshaw and T. Yamato, Supramol. Chem., 2011, 23, 689-695.

71 H. Tomiyasu, J.-L. Zhao, X.-L. Ni, X. Zeng, M. R. J. Elsegood, B. Jones, C. Redshaw, S. J. Teat and T. Yamato, RSC Adv., 2015, 5, 14747-14755.

72 Q. Sun, L. Mu, X. Zeng, J. Zhao, T. Yamato and J. Zhang, Sci. China: Chem., 2015, 58, 539-544.

73 Y. Fu, X. Zeng, L. Mu, X.-K. Jiang, M. Deng, J.-X. Zhang and T. Yamato, Sens. Actuators, B, 2012, 164, 69-75.

74 B.-T. Zhao, L. Wang and B.-X. Ye, Acta Chim. Sin., 2007, 65, 1663-1669.

75 F. Hamada, M. Yamada, Y. Kondo, S. Ito and U. Akiba, CrystEngComm, 2011, 13, 6920-6922.

76 M. Yamada, Y. Ootashiro, Y. Kondo and F. Hamada, Tetrahedron Lett., 2013, 54, 1510-1514.

77 M. Yamada, R. Kanazawa and F. Hamada, CrystEngComm, 2014, 16, 2605-2614.

78 M. Yamada and F. Hamada, Cryst. Growth Des., 2015, 15, 1889-1897.

79 J. Lukášek, S. Böhm, H. Dvořáková, V. Eigner and P. Lhoták, Org. Lett., 2014, 16, 5100-5103.

80 O. Kundrát, V. Eigner, P. Cuřínová, J. Kroupa and P. Lhoták, Tetrahedron, 2011, 67, 8367-8372.

81 F. Botha, S. Böhm, H. Dvořáková, V. Eigner and P. Lhoták, Org. Biomol. Chem., 2014, 12, 5136-5143.

82 P. Lhoták, L. Kaplánek, I. Stibor, J. Lang, H. Dvoráková, R. Hrabal and J. Sýkora, Tetrahedron Lett., 2000, 41, 93399344.

83 P. Lhoták, M. Himl, I. Stibor and H. Petř́ičková, Tetrahedron Lett., 2002, 43, 9621-9624.

84 J. Kroupa, I. Stibor, M. Pojarová, M. Tkadlecová and P. Lhoták, Tetrahedron, 2008, 64, 10075-10079.

85 I. S. Antipin, I. I. Stoikov, A. T. Gubaidullin, I. A. Litvinov, D. Weber, W. D. Habicher and A. I. Konovalov, Tetrahedron Lett., 1999, 40, 8461-8464. 
86 S. Dong, W. Zhu, D. Yuan and X. Yan, Acta Crystallogr., Sect. C: Cryst. Struct. Commun., 2002, 58, o376-0377.

87 C. Desroches, S. Parola, F. Vocanson, M. Perrin, R. Lamartine, J.-M. Létoffé and J. Bouix, New J. Chem., 2002, 26, 651-655.

88 C. Desroches, S. Parola, F. Vocanson, N. Ehlinger, P. Miele, R. Lamartine, J. Bouix, A. Eriksson, M. Lindgren and C. Lopes, J. Mater. Chem., 2001, 11, 3014-3017.
89 S. P. Singh, A. Chakrabarti, H. M. Chawla and N. Pant, Tetrahedron, 2008, 64, 1983-1997.

90 M. Šimánová, H. Dvořáková, I. Stibor, M. Pojarová and P. Lhoták, Tetrahedron Lett., 2008, 49, 1026-1029.

91 C. Desroches, V. G. Kessler and S. Parola, Tetrahedron Lett., 2004, 45, 6329-6331.

92 W.-N. Xu, J.-M. Yuan, Y. Liu, J.-P. Ma and D.-S. Guo, Acta Crystallogr., Sect. C: Cryst. Struct. Commun., 2008, 64, o349o352. 